\title{
MODELAGEM DA DINÂMICA DA ÁGUA E DO POTÁSSIO NA IRRIGAÇÃO POR GOTEJAMENTO SUPERFICIAL
}

\author{
RENÉ NENE CHIPANA RIVERA
}

\begin{abstract}
Tese apresentada à Escola Superior de Agricultura "Luiz de Queiroz", Universidade de São Paulo, para obtenção do título de Doutor em Agronomia, Área de Concentração: Irrigação e Drenagem.
\end{abstract}

P I R A C I C A B A

Estado de São Paulo - Brasil

Outubro - 2004 


\title{
MODELAGEM DA DINÂMICA DA ÁGUA E DO POTÁSSIO NA IRRIGAÇÃO POR GOTEJAMENTO SUPERFICIAL
}

\author{
RENÉ NENE CHIPANA RIVERA \\ Engenheiro Agrônomo
}

Orientador: Prof. Dr. SERGIO NASCIMENTO DUARTE

\begin{abstract}
Tese apresentada à Escola Superior de Agricultura "Luiz de Queiroz", Universidade de São Paulo, para obtenção do título de Doutor em Agronomia, Área de Concentração: Irrigação e Drenagem.
\end{abstract}

P I R A C I C A B A

Estado de São Paulo - Brasil

Outubro - 2004 


\section{Dados Internacionais de Catalogação na Publicação (CIP) DIVISÃO DE BIBLIOTECA E DOCUMENTAÇÃO - ESALQ/USP}

Rivera, René Nene Chipana

Modelagem da dinâmica da água e do potássio na irrigação por gotejamento superficial / René Nene Chipana Rivera. - - Piracicaba, 2004.

89 p. : il.

Tese (Doutorado) - - Escola Superior de Agricultura Luiz de Queiroz, 2004.

Bibliografia.

1. Água de irrigação 2. Fertilizantes potássicos 3. Fertirrigação 4. Irrigação por gotejamento 5. Modelo matemático I. Título

CDD 631.7

"Permitida a cópia total ou parcial deste documento, desde que citada a fonte - O autor" 
A minha Mãe Eva que me mostrou o caminho certo e me acompanha sempre nele,

\section{IN MEMORIAN}

Aos meus filhinhos Eva Iracema e Camilo Luciano por ser a energía que movimenta minha vida e por tê-los sacrificado injustamente durante a realização do curso.

Ao meu Pai Jorge, pela fortaleza que me transmite

\section{DEDICO}

Às pessoas sofridas que cada vez são mais e mais, mas que agem $e$ acreditam que chegarão a tempos melhores, 


\section{AGRADECIMENTOS}

No final do curso fico feliz e com saudades dos amigos que fiz (professores, estudantes e funcionários) que provavelmente não verei mais, porém os levarei em meu coração .

Quero começar agradecendo ao Curso de Pós Gradauação em Irrigação e Drenagem, nesse momento sob a Coordinação do Prof. José Antonio Frizzone, que me deu a oportunidade de fazer curso, e à CAPES/Programa de Estudantes Convênio, pela bolsa outorgada.

Agradeço aos professores que ajudaram e influenciaram na minha formação, como o Prof. José Antonio Frizzone, pela capacidade em resolver os asuntos que envolvem a irrigação; ao Prof. Tarlei Arriel Botrel, pela orientação inicial; ao Prof. Paulo Leonel Libardi pela iniciação no campo da dinâmica de solutos; ao Prof. Luiz Roberto Angelocci pela dedicação ao ensino; ao Prof Nilson Villa Nova, pelos sábios e simples ensinamentos, ao Prof. Quirijn de Jong van Lier pela capacidade e qualidade humana, ao Prof. e amigo Jarbas Honorio de Miranda pela paciência e colaboração na Tese; a Gilmar Batista Grigolon, pela ajuda no laboratório e demais funcionários e aos alunos da graduação Lelio e Guillerme por terem grande colaboração no experimento.

Ao Prof. Sergio Nascimento Duarte, pela amizade, pelo apoio, pela orientação no decorrer do curso e na realização da Tese, meus maiores agradecimentos. Acho que sem a sua participação não teria chegado ao final do curso.

Aos amigos: Nildo, Luiz Gonzaga, Luiza Duenhas, João Célio, Miguel Ferreira, Tales Miler, Diniz Fronza e demais amigos com os quais compartilhei o curso. 
Aos amigos estrangeiros: Manuel Navarro, Rubén Franco, Pablo Nuñes, Juan Delgado, Everth Ovando, Percy Zeballos, Reynaldo Rocha, e ao meu compatriota e grande amigo Waldo Romero pela força, motivação e acolhida na sua família. À Angela María pelo apoio, mesmo de longe

Aos amigos do futebol, por fazer-me esquecer por uns momentos as preocupações.

OBRIGADO, a todos que, de alguma maneira contribuíram para a realização deste trabalho e do curso de doutorado. 


\section{SUMÁRIO}

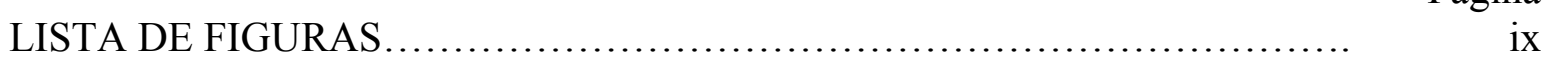

LISTA DE TABELAS .......................................................................... xi

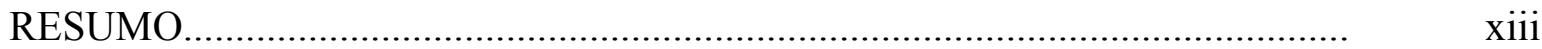

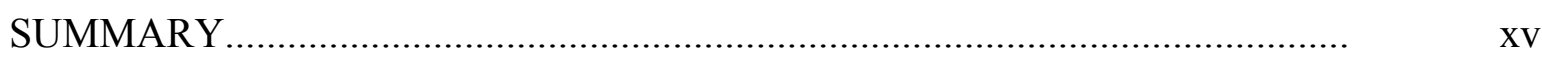

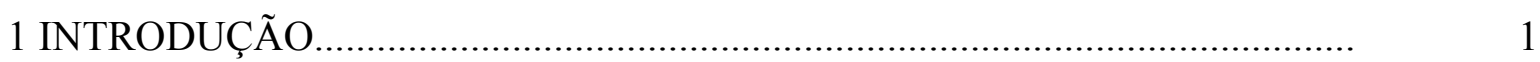

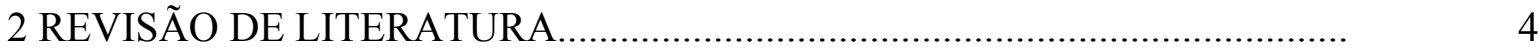

2.1 Fertirrigação e potássio no solo sob irrigação.................................................

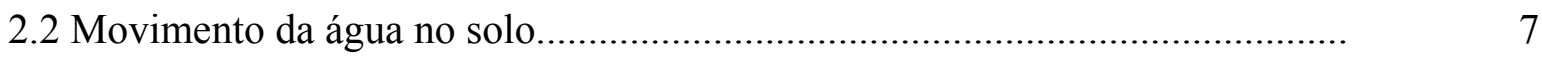

2.2.1 Condutividade hidráulica do meio não saturado........................................

2.2.2 Movimento da água em solo não saturado em regime de fluxo transiente.... $\quad 10$

2.2.3 Fluxo e distribuição de água sob irrigação por gotejamento......................... 11

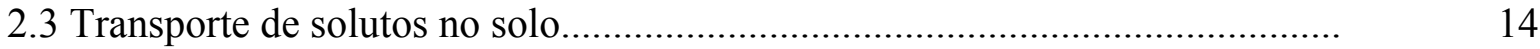

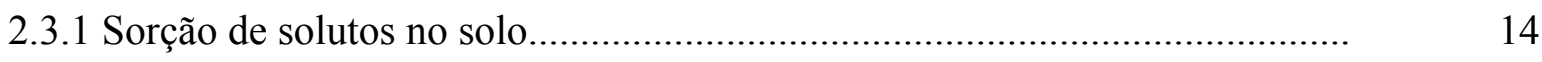

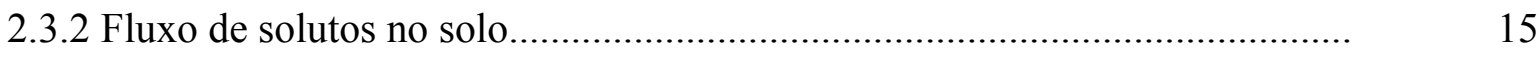

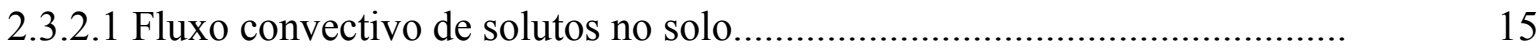

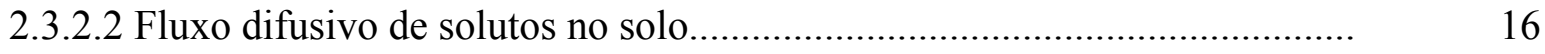

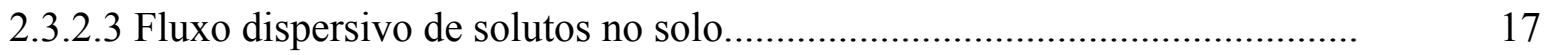

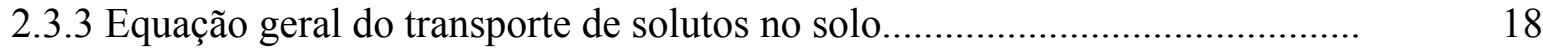

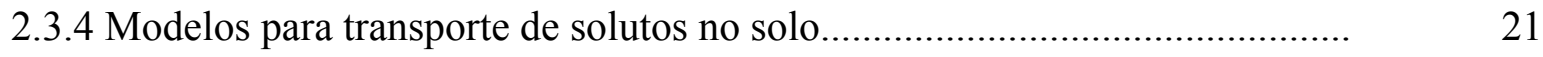

2.3.5 Dinâmica de solutos sob irrigação por gotejamento.....................................

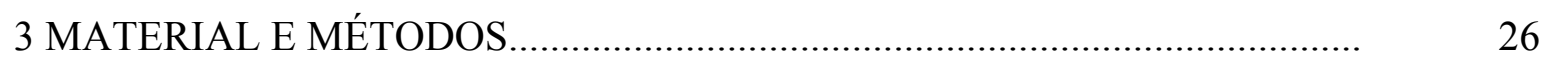

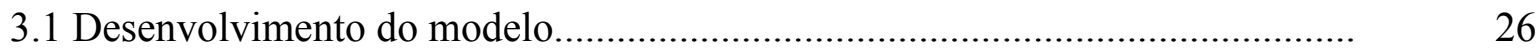




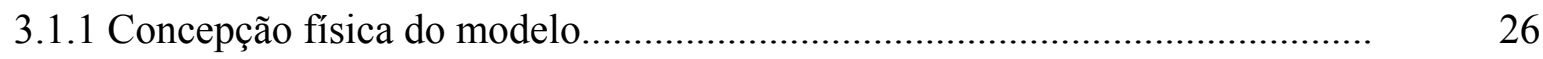

3.1.2 Transporte de água no perfil do solo........................................................... 27

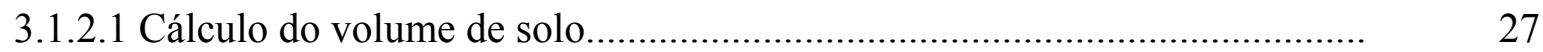

3.1.2.2 Volume de água armazenado em cada anel................................................. 28

3.1.2.3 Condutividade hidráulica e potencial matricial........................................... 28

3.1.2.4 Determinação da densidade do fluxo........................................................... 29

3.1.2.5 Balanço de umidade em cada anel............................................................... 31

3.1.3 Transporte de soluto no bulbo....................................................................

3.1.3.1 Fluxo de massa do soluto.........................................................................

3.1.3.2 Fluxo por dispersão hidrodinâmica...............................................................

3.1.3.3 Balanço do soluto em cada anel............................................................... 36

3.1.4 Desenvolvimento do modelo computacional................................................. 38

3.2 Validação experimental.................................................................................. 39

3.2.1 Caracterização do material de solo utilizado....................................................... 39

3.2.1.1 Parâmetros físico-hídricos do solo................................................................ 39

3.2.1.2 Curva de eluição e parâmetros de transporte do soluto.................................

3.2.2 Aplicação da solução e coleta de dados......................................................... 46

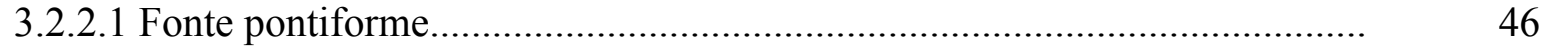

3.2.2.2 Medição da umidade do solo......................................................................

3.2.2.3 Medição da concentração de potássio............................................................

3.2.3 Teste do modelo........................................................................................

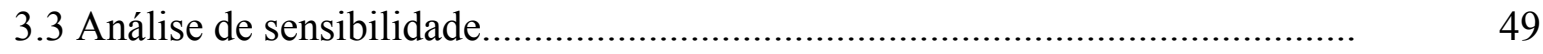

4 RESULTADOS E DISCUSSÃO.................................................................... 50

4.1 Validação experimental do modelo................................................................... 50

4.1.1 Teor de umidade e concetração de potássio no bulbo antes da irrigação........ 50

4.1.2 Umidade do solo após a irrigação................................................................ 51

4.1.3 Concentração do potássio no solo após a irrigação............................................... 59

4.2 Análise de sensibilidade do modelo................................................................. 67

4.2.1 Análise de sensibilidade em relação à distribuição da umidade no 


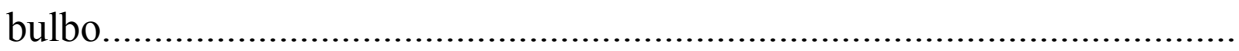

4.2.2 Análise de sensibilidade em relação à distribuição da concentração do potássio no bulbo..

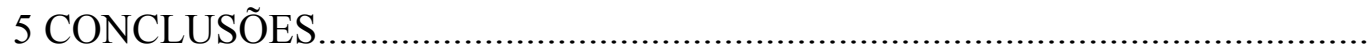

74

REFERÊNCIAS BIBLIOGRÁFICAS......................................................... 76

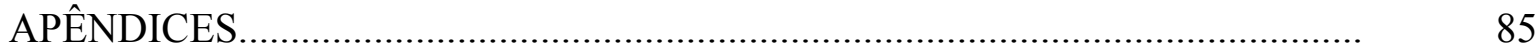




\section{LISTA DE FIGURAS}

Página

1 Esquema dos anéis concêntricos considerandos para a solução numérica

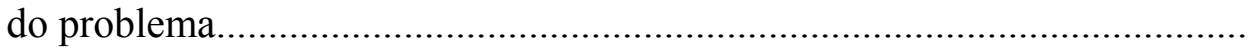

2 Coordenadas de células adjacentes necessárias ao cálculo do movimento da água e dos solutos por convecção (m) e dispersão hidrodinâmica (dh) nas direções radial e vertical................................................................

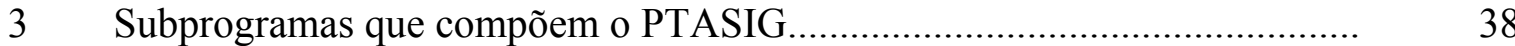

4 Fluxograma do modelo para transporte simultâneo de água e soluto em um bulbo de solo sob fonte pontiforme..................................................... $\quad 40$

$5 \quad$ Vista do solo homogeinizado em caixa de polietileno................................. 41

6 Esquema para a montagem de amostras, para a elaboração das curvas da eluição (extraido de Miranda (2001))...........................................................

7 Relação entre a concentração de potássio e condutividade elétrica da solução.

8 Curva de eluição da solução de potássio na coluna de solo............................ 45

9 Obtenção do extrato por meio de uma bomba a vácuo.................................. 48

10 Umidade volumétrica do solo $\left(\mathrm{cm}^{3} \mathrm{~cm}^{-3}\right)$ simulada pelo modelo e observada após 24 horas do final da irrigação.......................................... 54

11 Umidade volumétrica do solo $\left(\mathrm{cm}^{3} \mathrm{~cm}^{-3}\right)$ simulada pelo modelo e observada após 48 horas do final da irrigação............................................ 56

12 Umidade volumétrica do solo $\left(\mathrm{cm}^{3} \mathrm{~cm}^{-3}\right)$ simulada pelo modelo e observada após 72 horas do final da irrigação 
13 Concentração de potássio na solução do solo simulada e observada

(mg L $\left.{ }^{-1} \mathrm{x} 100\right)$ após 24 horas da irrigação

14 Concentração de potássio na solução do solo simulada e observada (mg L $\left.{ }^{-1} \mathrm{x} 100\right)$ após 48 horas da irrigação

15 Concentração de potássio na solução do solo simulada e observada (mg L $\left.{ }^{-1} \mathrm{x} 100\right)$ após 72 horas da irrigação

16 Representação da analise de sensibilidade do modelo em relação ao perfil de umidade do solo no bulbo, aplicando de $-90 \%$ a $+90 \%$ de variação na umidade volumétrica de saturação $(\theta 0)$ e condutividade hidráulica do solo saturado (Ko)

17 Representação da analise de sensibilidade do modelo em relação ao perfil de umidade do solo no bulbo, aplicando de $-90 \%$ a $+90 \%$ de variação na vazão do gotejador e na umidade volumétrica inicial do solo

18 Representação da analise de sensibilidade do modelo em relação à concentração do potássio no bulbo, aplicando de $-90 \%$ a $+90 \%$ de variação na umidade volumétrica de saturação $(\theta o)$ e na condutividade hidráulica do solo saturado (Ko).

19 Representação da analise de sensibilidade do modelo em relação à concentração do potássio no bulbo, aplicando de $-90 \%$ a $+90 \%$ de variação na vazão do gotejador e na umidade volumétrica inicial do solo ....

20 Representação da analise de sensibilidade do modelo em relação à concentração do potássio no bulbo, aplicando de $-90 \%$ a $+90 \%$ de variação na dispersividade $(\lambda)$ e no fator de retardamento do solo $(\mathrm{Fr})$.......... 


\section{LISTA DE TABELAS}

$1 \quad$ Características físico-hídricas do solo..........................................

Página

42

2 Parâmetros da curva de retenção segundo o modelo de van Genuchten (1980).

3 Parâmetros de transporte do potássio no solo obtidos com o modelo CXTFIT: velocidade da água nos poros (V), coeficiente de difusão-dispersão (D), fator de retardamento (Fr), e

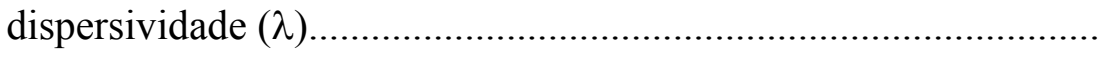

4 Umidade inicial e concentração de potássio médias na solução do solo para várias profundidades.

5 Umidade volumétrica do solo $\left(\mathrm{cm}^{3} \mathrm{~cm}^{-3}\right)$ simulada pelo modelo após 24 horas do final da irrigação.

6 Umidade volumétrica do solo $\left(\mathrm{cm}^{3} \mathrm{~cm}^{-3}\right)$ observada após 24 horas do final da irrigação

7 Umidade volumétrica do solo $\left(\mathrm{cm}^{3} \mathrm{~cm}^{-3}\right)$ simulada pelo modelo após 48 horas do final da irrigação

8 Umidade volumétrica do solo $\left(\mathrm{cm}^{3} \mathrm{~cm}^{-3}\right)$ observada após 48 horas do final da irrigação 
9 Umidade volumétrica do solo $\left(\mathrm{cm}^{3} \mathrm{~cm}^{-3}\right)$ simulada pelo modelo após 72 horas do final da irrigação

10 Umidade volumétrica do solo $\left(\mathrm{cm}^{3} \mathrm{~cm}^{-3}\right)$ observada após 72 horas do final da irrigação

11 Concentração de potássio na solução do solo $\left(\mathrm{mg} \mathrm{L}^{-1}\right)$ simulada pelo modelo 24 horas após a irrigação.

12 Concentração do potássio na solução do solo $\left(\mathrm{mg} \mathrm{L}^{-1}\right)$ observada após 24 horas da irrigação

13 Concentração de potássio na solução do solo $\left(\mathrm{mg} \mathrm{L}^{-1}\right)$ simulada pelo modelo 48 horas após a irrigação.

14 Concentração do potássio na solução do solo $\left(\mathrm{mg} \mathrm{L}^{-1}\right)$ observada após 48 horas da irrigação.

15 Concentração de potássio na solução do solo $\left(\mathrm{mg} \mathrm{L}^{-1}\right)$ simulada pelo modelo, 72 horas após a irrigação.

16 Concentração do potássio na solução do solo $\left(\mathrm{mg} \mathrm{L}^{-1}\right)$ observada após 72 horas da irrigação 


\title{
MODELAGEM DA DINÂMICA DA ÁGUA E DO POTÁSSIO NA IRRIGACAO POR GOTEJAMENTO SUPERFICIAL
}

\author{
Autor: RENÉ NENE CHIPANA RIVERA \\ Orientador: Prof. Dr. SERGIO NASCIMENTO DUARTE
}

\section{RESUMO}

A técnica da aplicação da fertirrigação está ganhando aceitação, principalmente nos sistemas de irrigação por gotejamento, devido às vantagens que apresenta como a possibilidade de controlar a nutrição das plantas, como é o caso do potássio, que é um dos fertilizantes mais empregados. Porém, a descrição do transporte de água e solutos sob condições reais apresenta grande complexidade, além dos altos custos envolvidos nas pesquisas de campo. Portanto, o presente trabalho teve como objetivo desenvolver um modelo matemático para simular o deslocamento simultâneo de água e potássio no solo aplicado sob fonte pontual. O estudo foi executado em três fases: desenvolvimento do modelo, validação experimental e análise de sensibilidade. A modelagem esteve baseada na solução numérica das equações que regem o movimento de água e o transporte de solutos no solo, aplicados a partir de fonte pontiforme, permitindo assim determinar a distribuição de água e dos solutos no solo em função tanto do espaço quanto do tempo. Estas equações foram resolvidas considerando um sistema de volumes de controle, caracterizado pelas dimensões radial e vertical, asumindo que o bulbo úmido está composto por uma série de anéis concêntricos. A validação do modelo foi conduzida no Laboratório de Física de Solo e em uma estufa plástica do Departamento de Engenharia Rural da Escola Superior de Agricultura "Luiz de Queiroz", da 
Universidade de São Paulo, em Piracicaba. A análise de sensibilidade foi feita com respeito às variações individuais da condutividade hidráulica do solo saturado, umidade inicial e saturada do solo, dispersividade, fator de retardamento e vazão do emissor. Foi obtido um bom ajuste entre os valores simulados pelo modelo e os observados, indicando que o movimento e distribuição de água e potássio aplicados via irrigação por gotejamento podem ser modelados matematicamente a partir da solução das equações de fluxo transiente mediante o uso do método dos volumes de controle. $\mathrm{O}$ resultado da análise de sensibilidade revelou que o modelo, com relação à distribuição de água, é bastante sensivel à umidade de saturação e inicial do solo. A respeito da distribuição de potássio, é bastante sensível a variações negativas da condutividade hidráulica do solo saturado, vazão do gotejador e fator de retardamento do solo, e pouco sensível às variações da dispersividade do solo. 


\title{
DYNAMICS OF WATER AND POTASSIUM MODELING UNDER SUPERFICIAL TRICKLE IRRIGATION
}

\author{
Author: RENÉ NENE CHIPANA RIVERA \\ Adviser: Prof. Dr. SERGIO NASCIMENTO DUARTE
}

\section{SUMMARY}

The technique of fertigation application is winning acceptance, mainly in trickle irrigation, due to the advantages that it presents as the possibility of controlling the nutrition of the plants, as the case of the potassium, that is one of the most used fertilizers. However, the description of the transport of water and solute under real conditions presents great complexity, besides the high costs involved in the field researches. Therefore, the present work had as objective develop a mathematical model to simulate the simultaneous displacement of water and potassium applied in the soil under a punctual source. The study was executed in three phases: model development, experimental validation and sensibility analysis. The modeling was based on the numeric solution of the equations that govern the movement of water and the solute transport in the soil, applied from a punctual source, allowing to determine the distribution of water and of the solute in the soil in function of the space and time. These equations were resolved considering a system of control volumes, characterized by the radial and vertical dimensions, considering that the humid bulb is composed for a series of concentric rings. The validation of the model was driven at Soil Physics Laboratory and in a plastic greenhouse of the Department of Rural Engineering of the Escola 
Superior de Agricultura "Luiz of Queiroz", of the São Paulo University, in Piracicaba Brazil. The sensibility analysis was made with regard to the individual variations of the saturated soil hydraulic conductivity, initial and saturated soil humidity, dispersivity, retardation factor and emitter flow. It was obtained a good adjustment among the model simulated values and the observed ones, indicating that the movement and distribution of water and potassium applied in trickle irrigation can be modeled mathematically by the solution of the transient flow equations by using the control volumes method. The result of the sensibility analysis revealed that the model is quite sensitive to the soil saturation and initial humidity, regarding the distribution of water. Regarding the potassium distribution, it is quite sensitive to negative variations of soil saturated hydraulic conductivity, emitter flow and retardation factor of the soil, and little sensitive to the variations of the soil dispersivity.. 


\section{INTRODUÇÃO}

O declínio na disponibilidade de água de boa qualidade para irrigação é um problema crescente para a agricultura irrigada moderna, devido principalmente ao incremento da competição com o uso em áreas urbanas e industrias (Mmolawa \& Or, 2000a). Assim, a irrigação por gotejamento é uma das tecnologias que estão se expandindo mais rapidamente na agricultura irrigada moderna, tendo em vista seu grande potencial para melhorar a economia do uso da água.

Neste método de irrigação a água é disponibilizada no solo pontualmente em alta freqüência, e assim os parâmetros de dimensionamento como a porcentagem da zona radicular umedecida, o espaçamento e a localização dos emissores, as taxas de aplicação, a freqüência e a lâmina de irrigação, são governadas pelo padrão de distribuição de umidade no perfil do solo. Lubana e Narda (2001) afirmam que não são bem conhecidas as relações entre os fatores que afetam o movimento da água no solo em resposta a fontes pontuais superficiais, fato este que se deve à complexa natureza das condições de contorno superficiais, o que pode resultar em problemas de manejo da irrigação.

Devido a estes fatos, modelos matemáticos foram desenvolvidos para analisar o movimento tridimensional da água no solo sob irrigação por gotejamento, usando métodos de análise numérica (Brandt et al . 1971), elementos finitos (Taghavi et al. 1984), fluxos em duas e três dimensões sob equilíbrio dinâmico (Parlange, 1972), volumes de controle (Botrel, 1988; Cruz, 2000), teoría dos tubos capilares (Tung Chu, 1993), entre outros. Na mesma linha, considerando o solo isotrópico e homogêneo, Angelakis et al. (1993) resolveram a equação combinada de Richards e Darcy, assumindo um fluxo bidimensional, enquanto que Kerkides et al. (1997) estudaram 
soluções analíticas linearizadas e não linearizadas para fontes de água em pequenas faixas.

Por outro lado, nos últimos anos, a técnica de aplicação de produtos químicos via água de irrigação (quimigação) está ganhando aceitação, principalmente em sistemas de irrigação por gotejamento, devido às vantagens que apresenta como a possibilidade de manipular e controlar a nutrição das plantas irrigadas (Keng et al., 1979). Porém, esta técnica requer que a irrigação seja realizada sob elevadas eficiências, caso contrário pode acarretar problemas econômicos e danos ao meio ambiente.

Os produtos químicos aplicados através da água de irrigação sofrem processos de alteração espacial e temporal no solo, variando a distribuição dos solutos no perfil, resultando em diferentes padrões de distribuição. Alguns solutos reagem com a matriz do solo, outros se movimentam através dele, podendo resultar em dissolução e precipitação, dentro ou fora da solução do solo (Mmolawa \& Or, 2000b).

Clothier (1984) indica que a compreensão do transporte simultâneo de água e solutos em duas ou três dimensões, a partir de uma fonte pontual, permite desenvolver eficientes estratégias na aplicação conjunta de água e fertilizantes minerais (fertirrigação); assim, o conhecimento da forma do volume molhado e da distribuição de solutos dentro deste volume é importante para o dimensionamento, operação e manejo de sistemas agrícolas sob irrigação. Apesar da fertirrigação possuir um uso bastante difundido, escassa informação relacionada ao movimento simultâneo de água e de produtos químicos a partir de fontes pontuais está disponível.

Segundo Jury \& Flühler (1992), uma quantidade significativa de pesquisas foram conduzidas estudando o transporte e a transformação de produtos químicos no solo; porém, a maioria desses estudos foram feitos em laboratório, geralmente em colunas de solo. Desta forma, existe pouca informação que possa ajudar a decifrar os mecanismos dominantes a nível do campo.

Modelos matemáticos estão sendo usados também para descrever o transporte de água e solutos em meios porosos visando dar subsídios à irrigação por gotejamento. Modelos de infiltração e redistribuição para fontes pontiformes foram apresentados por Brandt et al. (1971), Warrick (1974), Ben-Asher et al. (1978) e Warrick (1986), entre 
outros. Mmolawa (2000b) relatou que a dinâmica de água e solutos no solo, em ausência de culturas, pode ser representada adequadamente por soluções analíticas do fluxo transitório a partir de fontes puntiformes. Entretanto, a maioria dos estudos não tem incluído fontes pontiformes para estimar a distribuição da água e produtos químicos no solo (Biggar \& Nielsen, 1976; Jury et al. 1986).

Os altos custos envolvidos nas pesquisas de campo e os avanços computacionais dos últimos anos estão fazendo com que os modelos matemáticos, aliados às técnicas numéricas, se constituam numa ferramenta bastante viável, possibilitando uma predição e avaliação do destino e do comportamento da água e dos solutos na irrigação localizada. Entretanto, o desenvolvimento de modelos matemáticos para descrever com precisão o transporte de água e solutos sob condições reais de campo apresenta grande complexidade devido ao grande número de fatores intervinientes.

Dentre as substâncias químicas utilizadas na fertirrigação, o potássio é um dos fertilizantes mais empregados, devido ao fato de que os efeitos da deficiência deste elemento no crescimento das plantas são bastante pronunciados. Quando aplicado via água de irrigação, em pequenas doses, movimenta-se consideravelmente na zona radicular, tornando mais fácil a absorção pelas raízes.

Diante do exposto, o presente trabalho teve como objetivo geral desenvolver um modelo matemático para simular o deslocamento simultâneo de água e potássio no solo aplicado sob fonte pontual, tendo como objetivos específicos os seguintes:

1) Desenvolver um programa computacional para resolver numericamente as equações que governam o fluxo de água e solutos no solo a partir de uma fonte pontiforme;

2) Testar o modelo por meio da comparação dos resultados simulados com os observados experimentalmente;

3) Realizar uma análise de sensibilidade do modelo aos principais parâmetros de entrada. 


\section{REVISÃO DE LITERATURA}

\subsection{Fertirrigação e potássio no solo sob irrigação}

De acordo com Hernandez (1994) a fertirrigação é o termo usado para descrever a introdução e a aplicação simultânea de água e fertilizantes no solo através de um sistema de irrigação. Frizzone \& Botrel (1994) indicam que um termo mais abrangente, que englobaria também a fertirrigação, seria a quimigação, que nada mais é que a aplicação de produtos químicos via água de irrigação, como por exemplo, fertilizantes, fungicidas (fungigação), herbicidas (herbigação), inseticidas (insetigação), nematicidas (nematigação), condicionadores do solo, reguladores de crescimento, agentes biológicos e dejetos de animais. A irrigação e a fertilização são as práticas de manejo cultural mais importantes por meio dos quais se pode controlar o desenvolvimento de uma cultura, a produção de frutos e a qualidade dos mesmos. A introdução simultânea da microirrigação e da fertilização (fertirrigação) abre uma nova possibilidade de controlar o fornecimento de água e nutrientes às culturas, mantendo em níveis ótimos a concentração e a distribuição de água e íons no solo. O conceito moderno do manejo da fertirrigação propõe a maximização do lucro e a minimização da poluição do meio ambiente, que depende de fatores econômicos e do desenvolvimento da cultura, da produção e da qualidade dos frutos (Bar-Yosef, 2000).

Segundo este último autor, avanços significativos em fertirrigação tem sido feitos nas últimas três décadas no que se refere aos equipamentos de fertirrigação, à automação e à compreensão dos processos básicos envolvidos nesta técnica; mas é necessário dados adicionais no que diz respeito à concentração e absorção de nutrientes, aos parâmetros 
básicos do solo pertinentes e ao transporte de íons. As plantas tem uma absorção preferencial de elementos, o que pode levar a elevadas concentrações de determinados sais em detrimento de um ótimo crescimento. Assim, a fertirrigação é necessária para incrementar a disponibilidade de certos nutrientes. Consequentemente, uma precisa predição de quando e quanto de fertilizante deve-se aplicar é um fator critico para o bom manejo da fertirrigação. A quantidade de fertilizante a ser aplicada depende, entre outros fatores, do tipo de solo, das restrições no dimensionamento do sistema e da duração da estação de crescimento (Hochmuth, 1992).

Por outro lado, o potássio é o segundo macronutriente em teor contido nas plantas. Ele desempenha várias funções na planta, como o controle de turgidez dos tecidos, a ativação de muitas enzimas envolvidas na respiração e fotossíntese, a abertura e o fechamento de estômatos, o transporte de carbohidratos, a resistência à geada, à seca e à salinidade, e a manutenção da qualidade dos frutos. Távora (1982) indica que o potássio está presente na maioria das rochas em combinação com outros elementos, principalmente com o alumínio e a sílica, sob a forma de silicatos de alumínio e potássio, em minerais tais como o ortoclásio, a muscovita e a biotita. Cerca de $95 \%$ da produção mundial de potássio é consumida sob a forma de fertilizantes. Segundo Lopes (1982), o potássio representa $1,4 \%$ da composição do solo, sendo encontrado sob quatro formas básicas: como componente estrutural de minerais tais como micas e feldespatos, temporariamente "fixado" entre lâminas de argilas expansivas tais como ilita e montmorillonita, facilmente trocável por um sal neutro não tamponado e na solução do solo, em pequenas quantidades.

Sparks e Huang (1985) indicam que o potássio do solo pode ser lixiviado, adsorvido pelo solo ou absorvido pela planta. Os fatores que influenciam no movimento do potássio no solo são a condutividade hidráulica, o pH do solo, o método e a taxa de aplicação deste elemento, a umidade do solo e a absorção pela planta. A habilidade do solo em reter o potássio aplicado é muito dependente da capacidade de troca de cátions do solo; assim, a quantidade de argila e matéria orgânica no solo influenciam fortemente no grau de lixiviação. Solos com alta capacidade de troca tem grande habilidade em reter 
o potássio aplicado; entretanto, a lavagem deste elemento é freqüentemente um problema em solos arenosos.

Segundo Uriu et al. (1997), as formas de potássio presentes no sistema soloágua-planta mantêm-se em equilíbrio com o complexo de troca no solo. Assim, quando as plantas absorvem potássio, decresce o nível de potássio solúvel e o potássio trocável se movimenta em direção à solução do solo, restabelecendo-se o equilíbrio. Da mesma maneira, quando são aplicados grandes quantidades de fertilizantes, o potássio solúvel pode converter-se em potássio trocável para manter o equilíbrio. Em muitos solos o potássio não pode ser disponibilizado com a rapidez requerida nos períodos de forte absorção pelas culturas; daí a vantagem de ser aplicado via sistemas de fertirrigação, em doses que podem ser fracionadas segundo a demanda da cultura.

Existem investigações que demonstram que o potássio aplicado em doses altas em fertirrigação, como por exemplo na concetração de $190 \mathrm{ppm}$, se move até $57 \mathrm{~cm}$ por debaixo e até $85 \mathrm{~cm}$ aos lados dos emissores num solo franco-argiloso (Uriu et al., 1997). Este tipo de movimento do potássio no solo é possível somente com sistemas de irrigação por gotejamento.

Os mecanismos que controlam o transporte do potássio no solo são baseados na rápida troca com outros cátions no solo. Quando a quantidade de potássio no solo é relativamente pequena com relação a capacidade de troca de cations, a adsorsão é controlada principalmente pelas variações da concentração de potássio na solução do solo. Quando a concentração de potássio na solução do solo aumenta, a capacidade tampão do potássio decresce e a velocidade de transporte do potássio se incrementa. No período de máxima taxa de absorção de potássio pela planta, com alta demanda de potássio, este elemento deve ser suprido pela água de irrigação até que a concentração no solo seja suficiente (Bar-Yosef, 2000). Por outro lado, a fertilização com potássio quando adicionado via água de irrigação, geralmente não causa qualquer reação química adversa nas tubulações e emissores, mas pode causar precipitação de sais insolúveis se são misturados com outros fertilizantes. Por exemplo, se o nitrato de cálcio é misturado com sulfato de potássio, pode resultar em um sulfato de cálcio insolúvel (Rolston et al., 1986). 


\subsection{Movimento da água no solo}

Como descrito por Libardi (2000), a água no estado líquido move-se quando ocorrem diferenças de potencial entre os pontos de um sistema, sendo o movimento no sentido do decréscimo do potencial. No ano 1856 o engenheiro hidráulico Henry Darcy propôs a famosa fórmula ou equação de Darcy, também conhecida como Lei de Darcy, sendo o primeiro a estabelecer uma equação que permite quantificar o movimento da água em materiais porosos saturados. Esta equação só é valida quando se trabalha sob condições de saturação, sendo aplicável portanto a fluidos incompreensíveis, sob condições isotérmicas, para fluxo laminar e para situações em que as interações soloágua não resultem em variações na fluidez e na condutividade hidráulica, sendo esta última uma constante que representa a propriedade do meio em transmitir água.

$$
q=-\mathrm{Ko} \frac{\mathrm{dH}}{\mathrm{ds}}
$$

em que

$\mathrm{q}=$ densidade de fluxo, ou seja, volume de água por unidade de área e de tempo, $\mathrm{LT}^{-1}$;

$\mathrm{Ko}=$ condutividade hidráulica do meio saturado, $\mathrm{LT}^{-1}$;

$\mathrm{dH} / \mathrm{ds}=$ gradiente de potencial hidráulico, $\mathrm{LL}^{-1}$;

$\mathrm{H}=$ potencial hidráulico, $\mathrm{L} ; \mathrm{e}$

$\mathrm{s}=$ coordenada de posição, $\mathrm{L}$.

O sinal negativo na equação serve para indicar que o sentido de movimento é contrário ao do crescimento do potencial hidráulico.

Sob condições de não saturação, os poros ocupados por ar reduzem a área efetiva ao fluxo, aumentando a tortuosidade do fluxo remanescente, o que acarreta a diminuição da condutividade hidráulica, pois a mesma depende do conteúdo de água nos poros (Prevedello, 1996). De acordo com Libardi (2000), o primeiro trabalho de que se tem notícia que apresenta uma equação sob estas condições, é o de Buckingham em 1907, de 
forma que posteriormente a equação (2) passou a se chamar de equação de DarcyBuckingham:

$$
q=-K(\theta) \frac{d H}{d s}
$$

em que

$$
\begin{aligned}
\mathrm{K}(\theta) & =\text { condutividade hidráulica em função umidade }(\theta), \mathrm{LT}^{-1} \\
\mathrm{H} & =\text { potencial hidráulico total da água no solo, } \mathrm{L} ; \mathrm{e} \\
\mathrm{s} & =\text { coordenada de posição qualquer, } \mathrm{x}, \mathrm{y} \text { ou } \mathrm{z}, \mathrm{L} .
\end{aligned}
$$

O movimento de água no solo em condições de não saturação é controlado pelos potenciais gravitacional e matricial, sendo o potencial hidráulico total $(\mathrm{H})$ igual à soma do potencial matricial com o potencial gravitacional $(\mathrm{H}=\mathrm{h}+\mathrm{z})$ (Libardi, 2000).

\subsubsection{Condutividade hidráulica do meio não saturado}

A condutividade hidráulica expressa a "facilidade" com que determinado fluido escoa em um meio, sendo dependente do meio e do fluido. De acordo com Libardi (2000), as principais características da matriz do solo que interferem na condutividade hidráulica são a distribuição dos diâmetros dos poros, a tortuosidade, a superfície específica e a porosidade. Já no fluido, as principais caraterísticas são a massa específica e a viscosidade dinâmica.

van Genuchten (1980) indica que as estimativas da condutividade hidráulica do solo não saturado são difíceis de ser obtidas, fundamentalmente devido à grande variabilidade do solo. Os métodos para a determinação de K podem ser classificados em permanente, variável e computacional. A mensuração direta da condutividade hidráulica é teoricamente simples, mas difícil experimentalmente, pela sua alta variabilidade no campo (Stankovich \& Lockington ,1995; Libardi, 2000).

Mualem (1976) e van Genuchten (1980) desenvolveram equações e metodologias para determinar a condutividade hidráulica para solos não saturados, a partir da 
condutividade hidráulica relativa $(\mathrm{Kr})$, por meio de parâmetros da curva de retenção de água no solo, como apresentado nas equações de 3 a 6 .

$$
\Theta=\frac{\theta-\theta \mathrm{r}}{\theta \mathrm{s}-\theta \mathrm{r}}
$$

em que

$\Theta=$ saturação efetiva, refletindo de forma relativa o conteúdo de água no solo, adimensional;

$\theta=$ umidade volumétrica do solo na condição atual, $\mathrm{L}^{3} \mathrm{~L}^{-3}$;

$\theta \mathrm{r}=$ umidade volumétrica residual do solo, $\mathrm{L}^{3} \mathrm{~L}^{-3} ; \mathrm{e}$

$\theta s=$ umidade volumétrica do solo no ponto de saturação, $L^{3} L^{-3}$.

$\Theta$ também pode ser expresso segundo a equação 4:

$$
\Theta=\left[\frac{1}{1+(\alpha \psi)^{\mathrm{n}}}\right]^{\mathrm{m}}
$$

em que:

$\mathrm{m}$ e $\mathrm{n}=$ parâmetros de regressão da equação (adimensional);

$\alpha=$ parâmetro com dimensão igual ao inversão do potencial, $\mathrm{L}^{-1}$; e

$\psi=$ potencial matricial da água no solo, $\mathrm{L}$.

A equação 5 expressa o valor da condutividade hidráulica relativa:

$\mathrm{Kr}=\Theta^{1 / 2}\left[\frac{\int_{0}^{\Theta} \frac{1}{\psi(\mathrm{x})} \mathrm{dx}}{\int_{0}^{1} \frac{1}{\psi(\mathrm{x})} \mathrm{dx}}\right]^{2}$ 
em que

$\mathrm{Kr}=$ condutividade hidráulica relativa do solo, $\mathrm{LT}^{-1}$.

De posse do valor de $\mathrm{Kr}$ pode-se então determinar o valor da condutividade hidráulica do solo não saturado $(\mathrm{K}(\theta))$ como produto da condutividade hidráulica relativa pela condutividade do solo saturado:

$$
\mathrm{K}(\theta)=\mathrm{KrKo}
$$

\subsubsection{Movimento da água em solo não saturado em regime de fluxo transiente}

Lubana e Narda (2001) indicam que sob irrigação por gotejamento há uma variação temporal e espacial do teor de água no solo e, portanto, sob essas condições, o regime de fluxo é transitório. A equação básica que governa o movimento da água em solo não saturado em regime de fluxo transitório é deduzida por meio do principio da conservação da massa, e pode ser expressa por:

$$
\frac{\partial \theta}{\partial t}=-\left[\frac{\partial q x}{\partial x}+\frac{\partial q y}{\partial y}+\frac{\partial q z}{\partial z}\right]
$$

que expressa a taxa de acumulação de água por unidade de tempo t no elemento dé volume $\Delta \mathrm{V}$, nas coordenadas $\mathrm{x}, \mathrm{y}$ e $\mathrm{z}$ (fluxo tridimensional), denominada também de equação da continuidade (Libardi, 2000). O sinal negativo expressa que a variação da umidade com o tempo se dá no sentido contrario à variação da densidade de fluxo no espaço. Se na equação (7) as densidades de fluxo qx, qy, qz forem substituídas pela equação de Darcy-Buckingham para as respectivas direções, obtém-se a equação (8).

$$
\frac{\partial \theta}{\partial \mathrm{t}}=\frac{\partial}{\partial \mathrm{x}}\left[\operatorname{Kx}(\theta) \frac{\partial \mathrm{H}}{\partial \mathrm{x}}\right]+\frac{\partial}{\partial \mathrm{y}}\left[\operatorname{Ky}(\theta) \frac{\partial \mathrm{H}}{\partial \mathrm{y}}\right]+\frac{\partial}{\partial \mathrm{z}}\left[\operatorname{Kz}(\theta) \frac{\partial \mathrm{H}}{\partial \mathrm{z}}\right]
$$


que é a equação diferencial que governa o movimento de água em solos não saturados, em regime transiente, também conhecida como equação de Richards (Prevedello, 1996; Libardi, 2000).

Se assumirmos as considerações feitas por Botrel (1988) e Cruz (2000) para o caso de fontes pontiformes, supondo o solo homogêneo no eixo "y" e conformado por anéis concêntricos, a equação (8) pode ser expressa para fluxo bidimensional (radial e vertical) da seguinte maneira:

$$
\frac{\partial \theta}{\partial \mathrm{t}}=\frac{\partial}{\partial \mathrm{x}}\left[\mathrm{Kx}(\theta) \frac{\partial \mathrm{H}}{\partial \mathrm{x}}\right]+\frac{\partial}{\partial \mathrm{z}}\left[\mathrm{Kz}(\theta) \frac{\partial \mathrm{H}}{\partial \mathrm{z}}\right]
$$

\subsubsection{Fluxo e distribuição de água sob irrigação por gotejamento}

Mmolawa e Or (2000a) afirmam que os sistemas de irrigação por gotejamento são usualmente operados na forma intermitente e consistem de fontes pontiformes ou lineares sob as quais a água aplicada movimenta-se no solo. A importância do processo de redistribuição deve ser patente na determinação da quantidade de água retida em função do tempo e da profundidade, o que pode afetar a economia de água das plantas. A taxa e a duração do fluxo descendente durante a redistribuição determina o volume efetivo de água armazenada. Finalmente o processo de redistribuição é importante devido ao fato de se poder determinar a quantidade de água que flui através da zona radicular e que pode perder-se por percolação, havendo a possibilidade de lixiviar solutos.

Modelos matemáticos e experimentos de laboratório tem sido efetuados para estudar o transporte de água sob irrigação por gotejamento. Brandt, et al. (1971) e Bresler et al. (1971) desenvolveram soluções matemáticas para analisar o movimento multidimensional transitório a partir de uma fonte pontual. Os primeiros autores basearam-se em num modelo de fluxo em 2 dimensões envolvendo as coordenadas cartesianas x e z. Já Bresler et al. (1971) basearam-se num modelo de fluxo vertical e radial descrito pelas coordenadas cilíndricas z e $r$, sendo que somente para o caso onde a taxa de infiltração foi grande é que foram encontradas significativas discrepâncias entre 
os dados teóricos e os medidos no laboratório. Tanto a teoria, assim como os dados experimentais, indicam que para as condições estudadas, um incremento na taxa de descarga resulta num incremento do molhamento horizontal em detrimento do molhamento vertical.

Parlange (1972) derivou expressões analíticas para a absorção de água a partir de cavidades cilíndricas e esféricas e Warrick (1974) analisou a infiltração em função do tempo utilizando uma equação de fluxo linearizada. Levin et al. (1979) compararam a distribuição de umidade sob fontes pontuais a partir de dados obtidos experimentalmente e dados simulados empregando o modelo de Bresler (1975), encontrando uma boa concordância entres os dados simulados e os observados. Para o caso de solos estratificados, Armstrong et al. (1983) desenvolveram um modelo computadorizado para simular a distribuição da água aplicada a partir de uma fonte pontual, denominado CSMP, sendo os dados de entrada do programa as tensões e as umidades iniciais e os valores de condutividade hidráulica em cada perfil.

Tentando estudar o fluxo multidimensional, Clothier (1984) e Clothier et al. (1985) testaram sob condições de campo as teorias existentes referentes à movimentação tridimensional da água na irrigação por gotejamento, e verificaram que a distribuição de umidade no perfil do solo é dominada pelas propriedades físicas deste e que podem variar no tempo e no espaço. Por sua vez, Lafolie et al. (1989a) e LaFolie et al. (1989b) apresentaram uma solução numérica (diferenças finitas) das equações diferenciais parciais que governam o movimento de água a partir de fontes pontuais em solos estratificados e anisotrópicos, tentando predizer a distribuição da água e o tamanho da área saturada na superfície do solo. Observaram uma boa concordância entre os dados simulados de distribuição da água e os dados medidos no perfil do solo.

Ben-Asher et al. (1978) estudaram a infiltração e a absorção de água em solos irrigados com fontes pontuais, considerando o volume de solo molhado como um hemisfério, sendo o raio molhado do bulbo calculado em função da vazão do gotejador e da distribuição do teor de água existente antes da irrigação. Os resultados alcançados demostraram ser consistentes com os dados experimentais. Seguindo o mesmo raciocínio Botrel (1988) desenvolveu um modelo matemático visando estimar a 
distribuição de água no solo sob fontes pontiformes. O modelo utilizou a equação de Darcy-Buckingham para descrever o fluxo de água em solos não saturados e o principio da conservação da massa, além de ter se baseado nas considerações feitas por van Der Ploeg \& Benecke (1974) e van Genuchten (1980). O solo foi imaginariamente dividido em anéis concêntricos, onde a linha vertical sob o gotejador é o eixo de simetria. Foi verificado que os perfis observados de distribuição de água no solo apresentaram-se semelhantes aos simulados pelo modelo.

Em uma região semi-árida, Nogueira et al. (2000) fizeram comparações entre os bulbos molhados originados da ação de gotejadores localizados na superfície do solo e enterrados, num solo Podzolico Vermeho-Amarelo, sob uma vazão de 2,6 $\mathrm{Lh}^{-1}$. Observaram que a disponibilidade de água (entre 29 a 44\%), foi maior no caso do emissor enterrado. A este respeito, Assouline (2002) indica que sob irrigação por gotejamento a zona de encharcamento que se desenvolve em torno ao emissor é fortemente afetada pela taxa de aplicação e pelas propriedades do solo. O padrão de molhamento durante a aplicação de água geralmente consiste de duas regiões: (i) região saturada perto do emissor e (ii) região onde o conteúdo de água diminui em direção à frente de molhamento.

Or (1996) avaliou o desempenho de modelos analíticos de predição do movimento de água em solos heterogêneos sob irrigação por gotejamento com dados experimentais. Os resultados revelaram uma grande discrepância entre os dados medidos e os simulados. Muitos desses modelos tem sido validados no campo e em laboratório, em solos uniformes. As dificuldades no uso desses modelos no dimensionamento de sistemas de irrigação é que esses não são prontamente adaptáveis a solos estratificados, requerendo extensa habilidade matemática para sua resolução.

Segundo Lubana e Narda (2001), considerando a complexidade dos fenômenos físicos envolvidos no movimento de água na irrigação por gotejamento, a atenção deve estar voltada à elaboração de modelos de simulação que combinam processos simultâneos de entrada de água, extração de água pelas raízes, evaporação da superfície do solo e redistribuição multidimensional da umidade do solo. Esses modelos devem ser modificados para incluírem os efeitos da gravidade e de condições de solo não 
isotropicos, considerando-os como solos estratificados. As análises multidimensionais da dinâmica da água no solo sob fontes pontiformes devem ser convertidas em algoritmos computacionais.

\subsection{Transporte de solutos no solo}

\subsubsection{Sorção de solutos no solo}

Os solos podem reter solutos segundo sua capacidade de aprisionar um elemento químico, retardando ou evitando o seu movimento (Koskinen \& Harper, 1990). Porém, também pode ocorrer solubilização, precipitação da substância química e sua absorção pelas plantas e organismos do solo; mas como esses termos são difíceis de separar, chama-se ao conjunto dos processos de sorção, que engloba a adsorsão, absorção e precipitação (Prevedello, 1996).

$\mathrm{Na}$ simulação do movimento de solutos, a partição dos solutos entre as fases líquida e sólida do solo deve ser precisamente definida mediante equações denominadas isotermas de adsorsão, tais como as isotermas de Langmuir, de Freundlich, etc. Segundo Cleary (1991) a isoterma de Freundlich é a expressão mais comumente utilizada em estudos sobre contaminação do solo e da água subterrânea, e é descrita por:

$$
\mathrm{S}=\mathrm{Kd} \mathrm{C}^{\mathrm{n}}
$$

em que

$\mathrm{S}=$ concentração de soluto adsorvido pelo solo, $\mathrm{MM}^{-1}$;

$\mathrm{C}=$ concentração do soluto na solução do solo, $\mathrm{ML}^{-3}$;

$\mathrm{Kd}=$ coeficiente de distribuição ou de partição, $\mathrm{L}^{3} \mathrm{M}^{-1}$; e

$\mathrm{n}=$ constante empírica.

No caso específico da isoterma de Freundlich, representa-se um equilíbrio linear de adsorsão, sendo n igual a um. A isoterma linear é valida para baixas concentrações de 
equilíbrio; se a concentração de equilíbrio dos solutos for menor que a metade do seu limite de solubilidade, a isoterma de adsorsão linear é possivelmente válida (van Genuchten \& Wierenga, 1986).

\subsubsection{Fluxo de solutos no solo}

Quando a água se movimenta no solo, arrasta consigo os solutos. Prevedello (1996) indica que o movimento de solutos no solo não acontece apenas em decorrência do deslocamento de água; eles também podem dispersar-se na água em resposta a gradientes de concentração. Ao mesmo tempo os solutos reagem entre si e interagem com a matriz do solo. Essas interações podem ser influenciadas por uma serie de fatores como a acidez, temperatura, potencial de óxido-redução, composição e concentração da solução do solo. Smith et al. (1985) indicam que o movimento e o destino dos produtos químicos aplicados ao solo são influenciados por cinco processos: transporte, adsorsão, transformação/degradação, volatilização e extração pelas plantas, sendo que as interações desses processos no tempo e no espaço determinam o destino dos solutos no ambiente solo-água-planta.

Segundo van Genuchten \& Wierenga (1986), devido ao fato do solo ser um meio poroso com extensa heterogeneidade química e física, a troca de solutos entre os poros de diferentes categorias pode ser dada por três vias: transporte de massa ou fluxo convectivo; transporte difusivo e transporte dispersivo.

\subsubsection{Fluxo convectivo de solutos no solo}

O transporte convectivo, também denominado fluxo de massa, refere-se ao movimento passivo do soluto com água, onde o transporte de solutos ocorre de forma proporcional à sua concentração e segundo à densidade do fluxo da água (equação 11). $\mathrm{Na}$ ausência de difusão, a água e o íon dissolvido movem-se na mesma taxa.

$$
J c=q C=-C\left[K(\theta) \frac{d H}{d s}\right]
$$


em que

$\mathrm{Jc}=$ fluxo convectivo de solutos em termos de massa de soluto que passa por unidade de área de solo e de tempo, $\mathrm{ML}^{-2} \mathrm{~T}^{-1}$;

$\mathrm{q}=$ volume do líquido (solução) que passa por unidade de área de solo, na unidade de tempo, $\mathrm{LT}^{-1}$;

$\mathrm{C}=$ massa do soluto por unidade de volume de solução, $\mathrm{ML}^{-3}$;

$\mathrm{s}=$ coordenadas de posição qualquer, $\mathrm{L}$.

\subsubsection{Fluxo difusivo de solutos no solo}

O movimento de solutos se dá ao acaso para íons individuais ou moléculas nos sistemas isotérmicos. Portanto, quando a concentração de solutos numa zona é maior que na adjacente, pode ocorrer um fluxo líquido ou difusão no sentido de decréscimo da concentração. A difusão é um processo espontâneo, resultante do movimento térmico natural de moléculas e íons em solução, proporcionado por gradientes de concentração, isto é, no sentido do decréscimo dos valores de concentração do soluto no solo. Torna-se importante quando o líquido está em repouso ou movendo-se lentamente; em analogia com a lei de Fick, pode ser descrita como :

$$
\mathrm{Jd}=-\theta \mathrm{Dm} \frac{\partial \mathrm{C}}{\partial \mathrm{s}}
$$

em que

$$
\begin{aligned}
\mathrm{Jd} & =\text { fluxo difusivo, } \mathrm{ML}^{-2} \mathrm{~T}^{-1} ; \mathrm{e} \\
\mathrm{Dm} & =\text { coeficiente de difusão molecular ou iônico, } \mathrm{L}^{2} \mathrm{~T}^{-1} .
\end{aligned}
$$

O coeficiente de difusão molecular, pode ser representado por:

$$
\mathrm{Dm}=\operatorname{Do} \tau
$$

em que

$$
\text { Do }=\text { coeficiente de difusão do soluto em água pura, } \mathrm{L}^{2} \mathrm{~T}^{-1} ; \mathrm{e}
$$


$\tau=$ fator de tortuosidade, adimensional.

O coeficiente Dm é menor que o equivalente coeficiente de difusão em água pura. Segundo Wagenet \& Rao (1990), essa diferença se deve à tortuosidade do meio poroso, que tem seu valor dependente do conteúdo de umidade do solo e independente da velocidade da água nos poros.

Várias relações foram desenvolvidas para estimar o coeficiente $\tau$. Miranda (2001) no estudo da dinâmica do nitrato em colunas verticais de solo não saturado, utilizou com sucesso a equação de Millington e Quirk (1961):

$$
\tau=\frac{\theta^{10 / 3}}{\theta \mathrm{s}^{2}}
$$

em que

$\theta=$ umidade atual do solo, $\mathrm{L}^{3} \mathrm{~L}^{-3} ; \mathrm{e}$

$\theta \mathrm{s}=$ umidade do solo saturado, $\mathrm{L}^{3} \mathrm{~L}^{-3}$.

\subsubsection{Fluxo dispersivo de solutos no solo}

De acordo com van Genuchten e Wierenga (1986), o transporte dispersivo resulta do fato de que as velocidades locais do fluido variam dentro dos poros individuais e entre poros de diferentes formas e tamanhos; portanto as variações de velocidade causam o transporte de soluto no sentido do decréscimo do gradiente a diferentes taxas. Assim, a dispersão é um processo passivo, e de forma diferente da difusão, ocorre somente durante o movimento de água, podendo ser representada pela seguinte equação:

$$
\mathrm{Jh}=-\theta \mathrm{Dh} \frac{\partial \mathrm{C}}{\partial \mathrm{s}}
$$

em que

$\mathrm{Jh}=$ fluxo dispersivo, $\mathrm{ML}^{-2} \mathrm{~T}^{-1} ; \mathrm{e}$

$\mathrm{Dh}=$ coeficiente de dispersão, $\mathrm{L}^{2} \cdot \mathrm{T}^{-1}$. 
O sinal negativo indica que o sentido do fluxo é inverso ao gradiente de concentração, ou seja, o fluxo ocorre no sentido do decréscimo da concentração.

O coeficiente de dispersão aumenta com o incremento da velocidade da solução nos poros, podendo ser descrito pela seguinte relação:

$$
\mathrm{Dh}=\lambda \vartheta^{\eta}
$$

em que

$\lambda=$ dispersividade do solo, $\mathrm{L}$;

$\vartheta=$ velocidade da solução no poro, L.T $^{-1}$; e

$\eta=$ parâmetro de ajuste do modelo.

\subsubsection{Equação geral do transporte de solutos no solo}

Devido à dificuldade de separar os efeitos de dispersão e difusão, os coeficientes Dh e Dm são geralmente considerados aditivos, sendo que ao resultado dá-se o nome de coeficiente de dispersão-difusão, também conhecido como coeficiente de dispersão hidrodinâmica (D) (van Genuchten e Wierenga, 1986).

$$
\mathrm{D}=\mathrm{Dm}+\mathrm{Dh}
$$

Combinando as equações (12) e (15) se obtém a equação do fluxo de dispersão hidrodinâmica de solutos no solo:

$$
\mathrm{Jdh}=-\theta \mathrm{D} \frac{\partial \mathrm{C}}{\partial \mathrm{s}}
$$

Se considerarmos que a água do solo pode ser operacionalmente dividida em água potencialmente móvel e água imóvel, o transporte de solutos na fase móvel é descrita pela equação de convecção-dispersão (Tillman et al. 1991). Combinando as equações (11) e (18) se obtém a equação de transporte de solutos no solo: 


$$
J=-C\left[K(\theta) \frac{d H}{d s}\right]-\theta D \frac{\partial C}{\partial s}
$$

em que

$\mathrm{J}=$ massa total de soluto transportado por unidade de área de solo e de tempo, $\mathrm{ML}^{-2} \mathrm{~T}^{-1}$.

A equação (19) limita-se a solutos inertes, isto é, solutos não sujeitos à adsorsão pelos sólidos e nem reações químicas e/ou biológicas (Prevedello, 1996). A equação da conservação da massa preconiza que a variação da massa de um soluto com o tempo num elemento de volume do solo, é igual à variação na densidade de fluxo de entrada e saída desse soluto nesse elemento, assumindo-se que não há processos de ganho ou perda por qualquer mecanismo operante dentro do próprio elemento de volume, ou seja:

$$
\frac{\partial(\theta \mathrm{C})}{\partial \mathrm{t}}=-\frac{\partial \mathrm{J}}{\partial \mathrm{s}}
$$

Substituindo-se a equação 19 na equação 20, e considerando o movimento apenas na vertical obtém-se:

$$
\frac{\partial(\theta \mathrm{C})}{\partial \mathrm{t}}=-\frac{\partial(\mathrm{qC})}{\partial \mathrm{z}}+\frac{\partial}{\partial \mathrm{z}}\left[\mathrm{D} \theta \frac{\partial \mathrm{C}}{\partial \mathrm{z}}\right]
$$

que é a equação diferencial geral do fluxo de solutos na direção vertical, em regime de fluxo transiente.

Quando o soluto interage com a matriz do solo, o balanço de solutos sob fluxo tridimensional no solo apresenta-se da seguinte forma:

$$
\frac{\partial}{\partial t}(\theta C+\rho S)=-\frac{\partial(q C)}{\partial z}+\frac{\partial}{\partial z}\left[D \theta \frac{\partial C}{\partial z}\right]-\frac{\partial(q C)}{\partial x}+\frac{\partial}{\partial x}\left[D \theta \frac{\partial C}{\partial x}\right]-\frac{\partial(q C)}{\partial y}+\frac{\partial}{\partial y}\left[D \theta \frac{\partial C}{\partial y}\right]
$$


em que

$\rho=$ massa específica do solo, $\mathrm{ML}^{-3}$.

$\mathrm{S}=$ concentração do soluto adsorvido pelo solo, $\mathrm{M} \mathrm{M}^{-3}$.

Considerando a existência de equilíbrio linear de sorção e substituindo na equação (10) n=1, obtém-se:

$$
\frac{\partial \theta \mathrm{C}}{\partial \mathrm{t}}\left(1+\frac{\rho \mathrm{Kd}}{\theta}\right)=-\frac{\partial(\mathrm{qC})}{\partial \mathrm{z}}+\frac{\partial}{\partial \mathrm{z}}\left[\mathrm{D} \theta \frac{\partial \mathrm{C}}{\partial \mathrm{z}}\right]-\frac{\partial(\mathrm{qC})}{\partial \mathrm{x}}+\frac{\partial}{\partial \mathrm{x}}\left[\mathrm{D} \theta \frac{\partial \mathrm{C}}{\partial \mathrm{x}}\right]-\frac{\partial(\mathrm{qC})}{\partial \mathrm{y}}+\frac{\partial}{\partial \mathrm{y}}\left[\mathrm{D} \theta \frac{\partial \mathrm{C}}{\partial \mathrm{y}}\right]
$$

ou

$$
\operatorname{Fr} \frac{\partial \theta C}{\partial t}=-\frac{\partial(\mathrm{qC})}{\partial \mathrm{z}}+\frac{\partial}{\partial \mathrm{z}}\left[\mathrm{D} \theta \frac{\partial \mathrm{C}}{\partial \mathrm{z}}\right]-\frac{\partial(\mathrm{qC})}{\partial \mathrm{x}}+\frac{\partial}{\partial \mathrm{x}}\left[\mathrm{D} \theta \frac{\partial \mathrm{C}}{\partial \mathrm{x}}\right]-\frac{\partial(\mathrm{qC})}{\partial \mathrm{y}}+\frac{\partial}{\partial \mathrm{y}}\left[\mathrm{D} \theta \frac{\partial \mathrm{C}}{\partial \mathrm{y}}\right]
$$

em que

$\mathrm{Fr}=$ fator de retardamento, adimensional, ou seja:

$$
\operatorname{Fr}=1+\frac{\rho K d}{\theta}
$$

O fator de retardamento, pode ser definido como a capacidade de retenção ou o efeito "buffer" de um determinado elemento, ou como a velocidade do soluto em relação à velocidade da solução no poro (Matos et al., 1999). Se não existirem interações entre o soluto e o solo, o valor de Kd é zero e o fator de retardamento torna-se unitário. Se Fr for menor que um, significa que apenas uma fração da fase líquida participa no processo de transporte, como ocorre por exemplo em agregados muito densos contendo poros de diâmetro muito pequeno (Van Genuchten \& Wierenga, 1986). Segundo Toride et al. (1999) existe uma correlação negativa entre a velocidade da solução no poro $(\vartheta)$ e o coeficiente de distribuição ou de partição $(\mathrm{Kd})$, o que implica que Fr e $\vartheta$ também estão inversamente correlacionados. 
Assim, os parâmetros $\lambda$ e Fr, determinam a forma com que um soluto avança ou é retido no solo (Alvarez, 1995). A forma mais direta de se determinar os parâmetros $\lambda$ e Fr é a partir de experimentos utilizando colunas de solo, em que uma solução é aplicada no topo da coluna e os valores de concentração do soluto são coletados na saída. Nielsen \& Biggar (1962) indicam que a forma padrão de apresentação dos dados de concentração coletados na saída constitui a chamada de curva de eluição ("breakthrough curve"), devendo-se ter cuidado no uso correto das condições de contorno pois, caso contrário, sua utilização pode levar a sérios erros quando os dados experimentais são extrapolados ao campo.

Quando se assume um fluxo bidimensional para a irrigação por gotejamento a equação geral de fluxo de solutos sob regime transiente apresenta-se da seguinte forma:

$$
\frac{\partial(\theta \mathrm{C}+\rho \mathrm{s})}{\partial \mathrm{t}}=-\frac{\partial(\mathrm{qC})}{\partial \mathrm{z}}+\frac{\partial}{\partial \mathrm{z}}\left[\mathrm{D} \theta \frac{\partial \mathrm{C}}{\partial \mathrm{z}}\right]-\frac{\partial(\mathrm{qC})}{\partial \mathrm{x}}+\frac{\partial}{\partial \mathrm{x}}\left[\mathrm{D} \theta \frac{\partial \mathrm{C}}{\partial \mathrm{x}}\right]
$$

ou

$$
\operatorname{Fr} \frac{\partial \theta C}{\partial t}=-\frac{\partial(\mathrm{qC})}{\partial \mathrm{z}}+\frac{\partial}{\partial \mathrm{z}}\left[\mathrm{D} \theta \frac{\partial \mathrm{C}}{\partial \mathrm{z}}\right]-\frac{\partial(\mathrm{qC})}{\partial \mathrm{x}}+\frac{\partial}{\partial \mathrm{x}}\left[\mathrm{D} \theta \frac{\partial \mathrm{C}}{\partial \mathrm{x}}\right]
$$

\subsubsection{Modelos para transporte de solutos no solo}

As primeiras representações simplificadas do transporte de água e solutos no solo foram feitas para prover estimativas grosseiras da lixiviação de materiais solúveis. Num segundo momento, modelos mais complexos tem sido desenvolvidos, tentando integrar os mecanismos físicos e químicos que influenciam no movimento de solutos. Esses modelos são baseados, geralmente, em soluções que utilizam métodos numéricos e usam a predição do fluxo de água como partida para a simulação do fluxo de solutos (Wagenet, 1986).

O desenvolvimento de modelos matemáticos para descrever com precisão o transporte de água e solutos é bastante difícil, quando usados para condições reais de 
campo, pois apresentam grande complexidade. Segundo van Genuchten e Wierenga (1986), vários modelos teóricos têm sido desenvolvidos ao longo dos anos para descrever o transporte de solutos no solo. O sucesso desses modelos, porém, depende em grande parte da capacidade de se quantificar os parâmetros de transporte, que são as variáveis de entrada para esses modelos. Os parâmetros mais importantes são o fluxo do fluido, o coeficiente de dispersão e o fator de retardamento. A modelagem do transporte de solutos fica simplificada quando se assume a linearidade da isoterma de adsorção, singularidade nos processos de adsorção-desorção e equilíbrio instantâneo durante o transporte.

Jury \& Flühler (1992) indicam que nos modelos de transporte de solutos devem ser considerados os seguintes aspectos: a lei da conservação da massa, as distintas fases da massa no solo, a lei do fluxo para cada fase, as leis que descrevem o movimento entre fases e as reações do soluto no sistema. As abordagens dos modelos de transporte de solutos variam em suas suposições, complexidade, e também na necessidade de aquisição de dados de entrada. Segundo Jury (1984), os modelos de transporte de solutos a nível de campo geralmente podem ser divididos em duas categorias: modelos determinísticos e modelos estocásticos. Os modelos determinísticos usam equações continuas com parâmetros que variam em cada ponto no espaço e tem uma relação lógica fixa entre um ponto e o outro. Por outro lado, os modelos estocásticos usam parâmetros que podem variar fortuitamente e podem ser caracterizados em termos de uma distribuição de probabilidade.

Biggar e Nielsen (1967) verificaram experimentalmente que o formato e a posição das curvas de eluição dependem, para um mesmo tipo de solo, do tamanho dos agregados e da magnitude da velocidade convectiva; se não houvesse processo de difusão e se o meio poroso possuísse uma faixa estreita de variação das velocidades convectivas, a inflexão da curva passaria pelo ponto $\mathrm{C} / \mathrm{Co}=0,5$ (em que $\mathrm{C}$ é a concentração instantânea do efluente e Co é a concentração do fluido deslocador), quando o volume de efluente coletado fosse igual ao volume de poros da amostra. Tillman et al. (1991) estudaram a movimentação de brometo e observaram que a distribuição final deste elemento é altamente dependente do conteúdo inicial de água no 
solo. O brometo aplicado inicialmente a solos secos é muito resistente ao transporte nas subsequentes lixiviações com água.

Oliveira e Carvalho (1997) desenvolveram um programa computacional para resolver numericamente a equação diferencial do transporte de solutos no solo, utilizando diferenças finitas e o método de Crank-Nicholson para resolver as equações. Foi utilizado como solução deslocadora $\mathrm{CaCl}_{2}$, considerou-se um valor unitário para o fator de retardamento, o termo que incorpora a velocidade convectiva foi omitido e o soluto foi considerado não reativo. Verificou-se que a solução numérica superestimou os valores de concentração para o incremento de tempo de 10 dias em distâncias inferiores a $4 \mathrm{~m}$. Para os incrementos de tempo de 1, 5 e 10 dias e distâncias superiores a 5 m, obteve-se uma subestimativa das concentrações obtidas pela resolução numérica, em relação à solução analítica.

Com o intuito de simular o transporte de água e solutos no solo, Costa (1998) gerou um modelo computacional sob condições de escoamento não permanente, denominado SIMASS. Este modelo apresentou bom desempenho quando comparado com os resultados experimentais e com os simulados pelo modelo CXTFIT, desenvolvido por Parker e van Genuchten em 1984; mostrou sensibilidade aos incrementos de profundidade e tempo, evidenciando a necessidade de escolha adequada entre parâmetros utilizados como dados de entrada no modelo. Foi também observada uma tendência do SIMASS em subestimar a concentração de solutos para grandes tempos de aplicação da solução.

Por sua vez, Oliveira (1999) desenvolveu um modelo matemático para simular o transporte de água e soluto no solo e o transporte de solutos e sedimentos no escoamento superficial, por meio do método de diferenças finitas. Foi observado que o movimento de água no solo e o escoamento superficial foram os processos simulados que apresentaram os menores desvios em relação aos dados experimentais. Já a concentração de solutos no perfil do solo e no escoamento superficial, bem como a quantidade de sedimentos, apresentaram altos valores de erro relativo médio. Na mesma linha, Miranda (2001) elaborou um modelo computacional para estudar a dinâmica de solutos no solo por meio da técnica dos volumes de controle, encontrando um bom ajuste das 
concentrações de nitrato, assim como dos perfis de umidade simulados com relação aos medidos em condições de laboratório, em uma coluna de solo não saturado.

Segundo Wang et al. (1997), o desenvolvimento de modelos de simulação tem sido grandemente realçado com descrições quantitativas e predição do transporte de solutos em solos não saturados. Esses modelos, com vários níveis de sofisticação, incluem o LEACHM (Modelo de diferenças finitas para simular movimento de água e sal na zona radicular) o GLEAMS , o PRZM (Modelo para transporte de pesticidas na zona radicular), o RZWQM (Modelo da qualidade da água na zona radicular), e mais recentemente o CSUID (Modelo de manejo e dimensionamento da irrigação e drenagem). Na maioria desses modelos não é fácil fazer modificações para incluir as variações espaciais e temporais dos parâmetros físico-hídricos do solo.

\subsubsection{Dinâmica de solutos sob irrigação por gotejamento.}

$\mathrm{O}$ transporte de soluto no bulbo molhado é freqüentemente descrito pela equação de convecção-dispersão e leva em conta os três principais mecanismos do transporte de solutos, isto é, a convecção, a difusão e a dispersão (Mmolawa \& Or, 2000b).

Apesar da fertirrigação por meio da irrigação por gotejamento estar sendo muito difundida, os dados disponíveis relacionados ao movimento da água e solutos dissolvidos a partir de fontes pontuais são escassos (Clothier \& Sauer, 1988). Devido ao padrão de distribuição de água em torno do emissor, obtém-se uma distribuição de sais no bulbo úmido seguindo uma tendência de dentro para fora.

A dinâmica de solutos sob irrigação por gotejamento foi estudada por Bresler (1977) que calculou e comparou a concentração volumétrica de sal para dois tipos de textura e descarga de emissores, concluindo que o tipo de solo e a taxa de descarga dos emissores influenciavam na distribuição das sais no solo. Na mesma linha, Bresler (1975) desenvolveu um modelo para analisar o transporte multidimensional simultâneo e interativo de água e solutos sob irrigação por gotejamento. Empregou equações que descrevem o fluxo transitório do soluto em duas dimensões por convecção e difusão. Estudos posteriores, realizados por Warrick (1986), acrescentaram informações para 
resolver a equação bidimensional de convecção-dispersão, com ênfase em aplicações agronômicas.

A influência da quantidade de água aplicada na distribuição de solutos foi explicada por Nightingale et al. (1986). Eles investigaram o efeito da quantidade de água aplicada no préplantío e a subsequente distribuição dos sais no solo para uma cultura de algodão; foi observado que a irrigação no préplantío levava a uma considerável redução da salinidade do solo. Khan et al. (1996) fizeram avaliações de campo para determinar a distribuição de água e solutos sob fontes pontiformes, utilizando vazões de 1,5; 2,0 e 2,5 $\mathrm{Lh}^{-1}$, aplicando volumes de água de 15, 20 e $25 \mathrm{~L}$, e concentrações de sais de 100, 300 e $500 \mathrm{mgL}^{-1}$. Uma clara relação entre a taxa de aplicação e a forma do volume de solo molhado foi observada. Um incremento na vazão resultou num incremento do volume molhado na horizontal e diminuição na profundidade, para um mesmo volume de água aplicado. A concentração de solutos incrementou-se segundo a elevação da concentração de sais na fonte pontiforme, do volume de água aplicado e da taxa de aplicação.

Por sua vez, Mmolawa \& Or (2000b) conduziram experimentos sob estufas para investigar e elucidar a dinâmica espacial e temporal dos solutos. A técnica da Refletometria no Domínio no Tempo (TDR) foi utilizada para monitorar simultaneamente a variação espacial e temporal do conteúdo de água no solo e condutividade elétrica global da solução do solo. O monitoramento foi feito utilizando plantas crescendo ativamente. Foi observado quase imediatamente após o final da irrigação a ocorrência de um alto teor de umidade em torno do gotejador, diminuindo posteriormente por efeito da redistribuição da água. A concentração de sais aumentou conforme se avançou na direção da periferia do bulbo úmido e alcançou um valor baixo próximo da fonte do emissor. Portanto, o volume máximo de acumulação do sal é afetado principalmente pelas propriedades físico-hídricas do solo.

Uma abordagem teórica para transporte em três dimensões de água e brometo e água e nitrogênio, a partir de uma fonte pontual, foi feita por Clothier (1984) e Clothier e Sauer (1988), respectivamente. Khan et al. (1996) efetuaram avaliações de campo para estudar a distribuição da água e do brometo de potássio sob fonte pontiforme. 


\section{MATERIAL E MÉTODOS}

O presente estudo foi executado em três fases:

- Desenvolvimento do modelo;

- Validação experimental.; e

- Análise de sensibilidade.

\subsection{Desenvolvimento do Modelo}

O desenvolvimento do modelo computacional foi realizado no Departamento de Engenharia Rural da ESALQ/USP, empregando a linguagem de programação Delphi 5.0. A modelagem esteve baseada na solução numérica de duas equações diferenciais parciais de segunda ordem aplicadas a fontes pontiformes sob fluxo transiente, isto é, a equação do movimento de água no solo e a equação de transporte de solutos, permitindo assim determinar a distribuição de água e dos solutos no solo em função tanto do espaço quanto do tempo.

Estas equações foram resolvidas numericamente considerando um sistema de volumes de controle, caracterizado bidimensionalmente pelas dimensões radial e vertical ( $\Delta \mathrm{r}$ e $\Delta \mathrm{z}$, respectivamente) e efetuando incrementos sucessivos de tempo $(\Delta \mathrm{t})$.

\subsubsection{Concepção física do modelo}

No desenvolvimento do modelo, levou-se em consideração as hipóteses básicas descritas por Botrel (1988) e Cruz (2000), segundo os quais a região de estudo (bulbo úmido) pode ser descrita em um espaço de forma cilíndrica e composto imaginariamente 
de anéis concêntricos, cada um com largura $(\Delta \mathrm{r})$ e profundidade $(\Delta \mathrm{z})$. Os anéis têm como centro uma linha vertical que parte da fonte pontual na superfície do solo e variam de tamanho, de acordo com sua posição (i) e (j), em que (i) representa o eixo radial e (j) o eixo vertical, conforme é ilustrado na Figura 1.

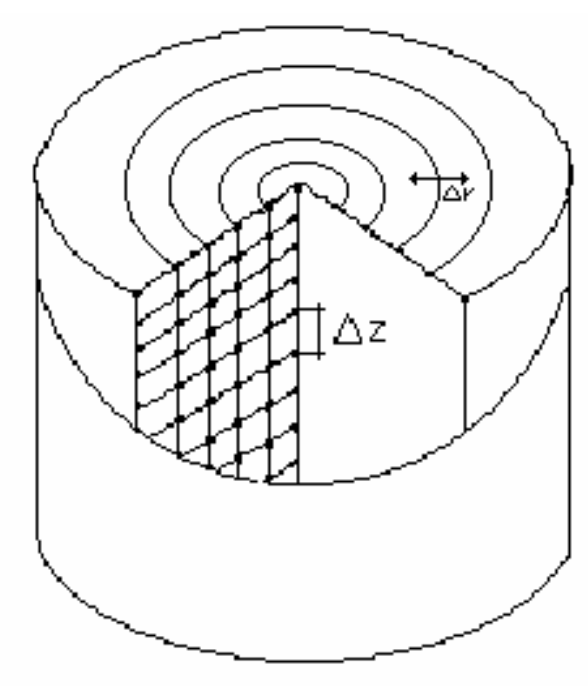

Figura 1 - Esquema dos anéis concêntricos considerados para a solução numérica do problema

\subsubsection{Transporte de água no perfil do solo}

\subsubsection{Cálculo do volume de solo}

Ao considerar o solo dividido em anéis concêntricos, o eixo de simetria é constituído pela linha vertical que passa pelo emissor. Nesse caso, o primeiro anel tem um raio igual à metade do incremento no eixo horizontal $(\Delta \mathrm{r} / 2)$.

O cálculo do volume do solo foi feito considerando-se os volumes dos anéis nos eixos radial e vertical. Por exemplo, o volume do anel $(\mathrm{i}, \mathrm{j})$ será o volume do cilindro definido pelo raio maior do anel $\left(\mathrm{R}_{\mathrm{ij}}\right)$, menos o volume do cilindro definido pelo raio menor do anel $\left(\mathrm{R}_{\mathrm{i}, \mathrm{j}-1}\right)$, considerando uma altura $\Delta \mathrm{z}$, conforme apresentado na equação 28 . 
$\mathrm{Vs}_{(\mathrm{i}, \mathrm{j})}=\pi\left(\mathrm{R}_{\mathrm{i}, \mathrm{j}}{ }^{2}-\mathrm{R}_{\mathrm{i}, \mathrm{j}-1}{ }^{2}\right) \Delta \mathrm{z}$

em que

$$
\begin{aligned}
\mathrm{Vs} & =\text { volume de solo em cada anel, } \mathrm{L}^{3} ; \\
\mathrm{R} & =\text { raio do anel, } \mathrm{L} ; \mathrm{e} \\
\Delta \mathrm{z} & =\text { profundidade do anel, } \mathrm{L} .
\end{aligned}
$$

Na direção vertical os volumes dos anéis variam em função da sua distância ao eixo, mas são constantes para cada posição (j), qualquer que seja a profundidade.

\subsubsection{Volume de água armazenado em cada anel}

$\mathrm{O}$ volume de água estocado em cada anel (Va) é determinado multiplicando-se o volume do solo pelo valor de umidade volumétrica do solo $(\theta)$ :

$$
\mathrm{Va}=\mathrm{Vs} \theta
$$

este cálculo foi realizado para cada incremento de tempo $(\Delta t)$ tanto na direção radial como na vertical

\subsubsection{Condutividade hidráulica e potencial matricial}

Os valores de condutividade hidráulica relativa para condições de não saturação foram calculados em função do tempo e do espaço. Como primeiro passo, foi determinada a saturação efetiva a partir da equação (3) e na seqüência foi determinada a condutividade hidráulica relativa, conforme a equação (30):

$$
\mathrm{Kr}=\Theta^{0,5}\left[1-\left(1-\Theta^{1 / \mathrm{m}}\right)^{\mathrm{m}}\right]^{2}
$$


Com base em $\mathrm{Kr}$ calculou-se a condutividade hidráulica para solo não saturado $\mathrm{K}(\theta)$, multiplicando-se $\mathrm{Kr}$ por Ko. Posteriormente foi determinado o potencial matricial da água do solo $(\psi)$, transformando a equação (4), tal como é apresentado na equação (31):

$$
\psi=\frac{\left[\frac{1}{\Theta^{1 / \mathrm{m}}}-1\right]^{2}}{\alpha}
$$

\subsubsection{Determinação da densidade do fluxo}

O cálculo da densidade de fluxo de uma célula para outra foi realizado seguindo as considerações preconizadas por van Der Ploeg e Benecke (1974) e van Genuchten (1980), por meio das quais se assume que o fluxo dentro os anéis ou células ocorre em duas direções, tanto para a entrada como para a saída de água e solutos (Figura 2).

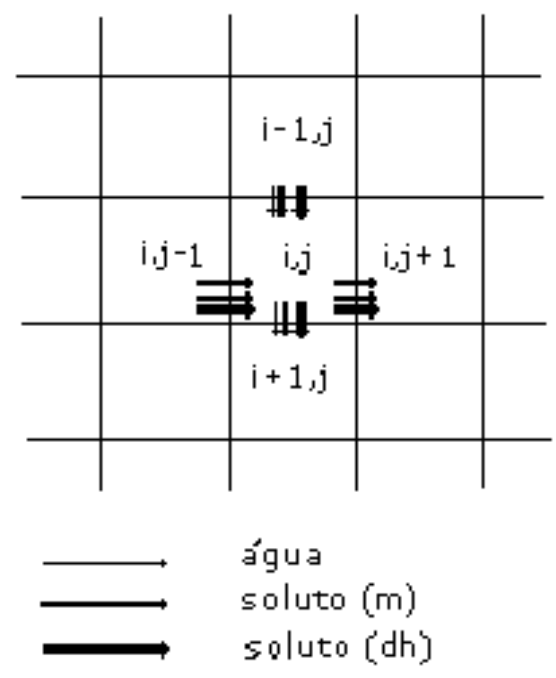

Figura 2 - Coordenadas de células adjacentes necessárias ao cálculo do movimento da água e dos solutos por convecção (m) e dispersão hidrodinâmica (dh) nas direções radial e vertical

\section{Densidade de fluxo radial}

O movimento de água de um anel a outro seguindo o eixo radial é calculado conforme a equação (2). Tendo em vista que o fluxo ocorre entre dois anéis adjacentes, 
foi assumido que a condutividade hidráulica não saturada da região onde acontece o fluxo, pode ser representada pela condutividade hidráulica não saturada média dos anéis adjacentes.

$$
\mathrm{K}_{(\mathrm{i}, \mathrm{j}-1 ; i, \mathrm{i})}=\frac{\mathrm{K}_{(\mathrm{i}, \mathrm{j}-1)}+\mathrm{K}_{(\mathrm{i}, \mathrm{j})}}{2}
$$

em que

$$
\begin{aligned}
\mathrm{K}_{(\mathrm{i}, \mathrm{j}-1 ; \mathrm{i}, \mathrm{j})} & =\text { condutividade hidráulica não saturada média das células }(\mathrm{i}, \mathrm{j}-1) \text { e }(\mathrm{i}, \mathrm{j}) ; \\
\mathrm{K}_{(\mathrm{i}, \mathrm{j}-1)} & =\text { condutividade não saturada da célula }(\mathrm{i}, \mathrm{j}-1) ; \mathrm{e} \\
\mathrm{K}_{(\mathrm{i}, \mathrm{j})} & =\text { condutividade hidráulica não saturada da célula }(\mathrm{i}, \mathrm{j}) .
\end{aligned}
$$

Por tanto a equação (2) para a determinação do fluxo de água pode ser reescrita da seguinte forma:

$$
q_{(i, j-1 ; i, j)}=-K_{(i, j-1 ; i, j)} \frac{H_{(i, j)}-H_{(i, j-1)}}{\Delta r}
$$

em que

$\mathrm{q}_{(\mathrm{i}, \mathrm{j}-1 ; \mathrm{i}, \mathrm{j})}=$ densidade de fluxo entre a célula $(\mathrm{i}, \mathrm{j}-1)$ e a célula $(\mathrm{i}, \mathrm{j})$;

$\mathrm{H}_{\mathrm{i}, \mathrm{j}}=$ potencial hidráulico total da água na célula $(\mathrm{i}, \mathrm{j})$;

$\mathrm{H}_{\mathrm{i}, \mathrm{j}-1}=$ potencial hidráulico total da água na célula $(\mathrm{i}, \mathrm{j}-1) ; \mathrm{e}$

$\Delta r=$ incremento no raio, ou seja, a diferença entre o raio médio das duas células.

Da mesma maneira, a densidade de fluxo radial entre a célula $(\mathrm{i}, \mathrm{j})$ e a célula $(\mathrm{i}, \mathrm{j}+1)$ é calculada tomando por base as equações (34) e (35):

$$
\begin{aligned}
\mathrm{K}_{(\mathrm{i}, \mathrm{j} ; \mathrm{i}, \mathrm{j}+1)} & =\frac{\mathrm{K}_{(\mathrm{i}, \mathrm{j})}+\mathrm{K}_{(\mathrm{i}, \mathrm{j}+1)}}{2} \\
\mathrm{q}_{(\mathrm{i}, \mathrm{j} ; \mathrm{i}, \mathrm{j}+1)} & =-\mathrm{K}_{(\mathrm{i}, \mathrm{j} ; \mathrm{i}, \mathrm{j}+1)} \frac{\mathrm{H}_{(\mathrm{i}, \mathrm{j}+1)}-\mathrm{H}_{(\mathrm{i}, \mathrm{j})}}{\Delta \mathrm{r}}
\end{aligned}
$$




\section{Densidade de fluxo vertical}

De maneira análoga ao caso do transporte radial, a densidade de fluxo vertical das células $(i-1, j)$ a $(i, j)$ e $(i, j)$ a $(i+1, j)$, foi determinada mediante as seguintes equações:

$$
\begin{aligned}
& \mathrm{K}_{(\mathrm{i}-1, \mathrm{j} ; \mathrm{j}, \mathrm{j})}=\frac{\mathrm{K}_{(\mathrm{i}-1, \mathrm{j})}+\mathrm{K}_{(\mathrm{i}, \mathrm{j})}}{2} \\
& \mathrm{q}_{(\mathrm{i}-1, \mathrm{j} ; \mathrm{i}, \mathrm{j})}=-\mathrm{K}_{(\mathrm{i}-1, \mathrm{j} ; \mathrm{i}, \mathrm{j})} \frac{\mathrm{H}_{(\mathrm{i}, \mathrm{j})}-\mathrm{H}_{(\mathrm{i}-1, \mathrm{j})}}{\Delta \mathrm{z}} \\
& \mathrm{K}_{(\mathrm{i}, \mathrm{j} ; \mathrm{i}+1, \mathrm{j})}=\frac{\mathrm{K}_{(\mathrm{i}, \mathrm{j})}+\mathrm{K}_{(\mathrm{i}+1, \mathrm{j})}}{2} \\
& \mathrm{q}_{(\mathrm{i}, \mathrm{j} ; \mathrm{i}+1, \mathrm{j})}=-\mathrm{K}_{(\mathrm{i}, \mathrm{j} ; \mathrm{i}+1, \mathrm{j})} \frac{\mathrm{H}_{(\mathrm{i}+1, \mathrm{j})}-\mathrm{H}_{(\mathrm{i}, \mathrm{j})}}{\Delta \mathrm{z}}
\end{aligned}
$$

\subsubsection{Balanço de umidade em cada anel}

Antes e após a aplicação de água pela fonte pontiforme calculou-se a umidade na profundidade (i) e na posição radial (j), para cada incremento do tempo $(\Delta t)$. O volume de água que passa horizontalmente da célula $(\mathrm{i}, \mathrm{j}-1)$ a $(\mathrm{i}, \mathrm{j})$ é determinado a partir da área lateral de cada anel e da densidade de fluxo:

$$
\mathrm{Va}_{(\mathrm{i}, \mathrm{j}-1 ; \mathrm{i}, \mathrm{j})}=\mathrm{q}_{(\mathrm{i}, \mathrm{j}-1 ; \mathrm{i}, \mathrm{j})} 2 \pi\left(\mathrm{R}_{(\mathrm{i}, \mathrm{j}-1)}\right) \Delta \mathrm{z} \Delta \mathrm{t}
$$

entretanto o volume que passa da célula $(\mathrm{i}, \mathrm{j}) \mathrm{a}(\mathrm{i}, \mathrm{j}+1)$ é representada por:

$$
\mathrm{Va}_{(\mathrm{i}, \mathrm{j} ; \mathrm{i}, \mathrm{j}+1)}=\mathrm{q}_{(\mathrm{i}, \mathrm{j} ; \mathrm{i}, \mathrm{j}+1)} 2 \pi\left(\mathrm{R}_{(\mathrm{i}, \mathrm{j})}\right) \Delta \mathrm{z} \Delta \mathrm{t}
$$

De forma análoga, a quantidade o volume de água que passa verticalmente dos anéis $(i-1, j)$ a $(i, j)$ e $(i, j)$ a $(i+1, j)$ é calculado por:

$$
\begin{aligned}
& \mathrm{Va}_{(\mathrm{i}-1, \mathrm{j} ; \mathrm{i}, \mathrm{j})}=\mathrm{q}_{(\mathrm{i}-1, \mathrm{j} ; \mathrm{i}, \mathrm{j})} \pi\left(\mathrm{R}_{(\mathrm{i}, \mathrm{j})}{ }^{2}-\mathrm{R}_{(\mathrm{i}, \mathrm{j}-1)}{ }^{2}\right) \Delta \mathrm{t} \\
& \mathrm{Va}_{(\mathrm{i}, \mathrm{j} ; \mathrm{i}+1, \mathrm{j})}=\mathrm{q}_{(\mathrm{i}, \mathrm{j} ; \mathrm{i}+1, \mathrm{j})} \pi\left(\mathrm{R}_{(\mathrm{i}, \mathrm{j})}{ }^{2}-\mathrm{R}_{(\mathrm{i}, \mathrm{j}-1)}{ }^{2}\right) \Delta \mathrm{t}
\end{aligned}
$$


A quantidade de água que permaneceu em um determinado anel após o incremento $\Delta \mathrm{t}$ é representada pela variação no volume de água no anel $\left(\Delta \mathrm{Va}_{(\mathrm{i}, \mathrm{j})}\right)$ devido

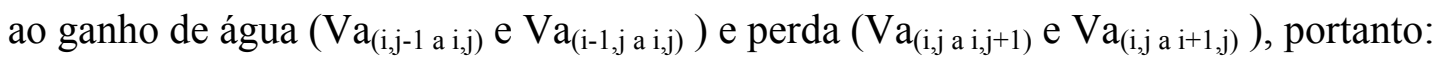

$$
\Delta V a_{(i, j)}=V a_{(i, j-1 ; i, j)}+V a_{(i-1, j ; i, j)}-V a_{(i, j ; i, j+1)}-V a_{(i, j ; i+1, j)}
$$

Sendo assim, a nova umidade do anel ao final de $\Delta$ t é calculada pela equação 45:

$$
\theta_{(\mathrm{i}, \mathrm{j})}=\theta_{(\mathrm{i}, \mathrm{j}, \mathrm{ini})}+\frac{\Delta \mathrm{Va}_{(\mathrm{i}, \mathrm{j})}}{\mathrm{Vs}_{(\mathrm{i}, \mathrm{j})}}
$$

em que

$\theta_{(\mathrm{i}, \mathrm{j}, \text { ini })}=$ umidade do solo no inicio do intervalo $\Delta \mathrm{t}, \mathrm{L}^{3} \mathrm{~L}^{-3}$.

Portanto, ao considerarmos a discretização em volumes de controle, a equação (9) fica transformada em:

$$
\frac{\Delta \theta}{\Delta \mathrm{t}}=\frac{\Delta \mathrm{qx}}{\Delta \mathrm{x}}+\frac{\Delta \mathrm{qz}}{\Delta \mathrm{z}}
$$

ou

$$
\frac{\Delta \theta}{\Delta \mathrm{t}}=-\overline{\mathrm{K}} \mathrm{x}(\theta) \frac{\Delta \mathrm{Hx}}{\Delta \mathrm{x}}-\overline{\mathrm{K}} \mathrm{z}(\theta) \frac{\Delta \mathrm{Hz}}{\Delta \mathrm{z}}
$$

Uma hipótese importante foi considerada para resolver os casos em que a umidade dentro do anel tornava-se superior ao conteúdo de umidade sob saturação $\left(\theta_{(\mathrm{i}, \mathrm{j})}\right.$ $\left.>\theta_{(\mathrm{i}, \mathrm{j})}\right)$. Neste caso os anéis da superfície passam o volume de água não infiltrado para os anéis mais externos (formação de um circulo saturado superficial) e nos anéis não situados na superfície, o volume de água que não é possível ser transportado é deixado nos anéis superiores. 


\subsubsection{Transporte de soluto no bulbo}

Uma vez calculados os valores do fluxo do volume de água e da variação de umidade dos anéis, inicia-se a determinação da concentração do soluto em cada anel. Novamente é empregada a técnica de volumes de controle para calcular o fluxo de massa, o fluxo por dispersão hidrodinâmica e a variação de concentração do soluto no solo $(\Delta \mathrm{C})$.

\subsubsection{Fluxo de massa do soluto}

O fluxo em massa do soluto é determinado tanto para a direção radial quanto para a direção vertical.

\section{Fluxo de massa radial}

$\mathrm{Jc}_{(\mathrm{i}, \mathrm{j}-1 ; \mathrm{i}, \mathrm{j})}=\mathrm{q}_{(\mathrm{i}, \mathrm{j}-1 ; \mathrm{i}, \mathrm{j})} \mathrm{C}_{(\mathrm{i}, \mathrm{j}-\mathrm{-1})}$

em que

$\mathrm{Jc}_{(\mathrm{i}, \mathrm{j}-1 ; \mathrm{i}, \mathrm{j})}=$ fluxo de massa do soluto da célula $(\mathrm{i}, \mathrm{j}-1)$ à célula $(\mathrm{i}, \mathrm{j}), \mathrm{ML}^{-2} \mathrm{~T}^{-1}$.

$\mathrm{Jc}_{(\mathrm{i}, \mathrm{j} ; \mathrm{i}, \mathrm{j}+1)}=\mathrm{q}_{(\mathrm{i}, \mathrm{j} ; \mathrm{i}, \mathrm{j}+1)} \mathrm{C}_{(\mathrm{i}, \mathrm{j})}$

em que

$\mathrm{Jc}_{(\mathrm{i}, \mathrm{j}-1 ; i, \mathrm{i}, \mathrm{j}}=$ fluxo de massa do soluto da célula $(\mathrm{i}, \mathrm{j})$ à célula $(\mathrm{i}, \mathrm{j}+1)$.

\section{Fluxo de massa vertical}

O fluxo de massa do soluto da célula (i-1,j) à célula (ij) e da célula $(i, j)$ à célula $(\mathrm{i}+1, \mathrm{j})$ é determinado por:

$$
\begin{aligned}
& J_{c_{(i-1, j ; i, j)}}=q_{(i-1, j ; i, j)} C_{(i-1, j)} \\
& J_{(i, j ; i+1, j)}=q_{(i, j ; j i+1, j)} C_{(i, j)}
\end{aligned}
$$




\section{Transporte de massa do soluto entre anéis adjacentes}

A massa (M) do soluto que passa de um anel a outro (E) tanto na direção horizontal como na vertical, é calculada mediante as seguintes relações matemáticas:

- Direção radial

$\mathrm{Ec}_{(\mathrm{i}, \mathrm{j}-1 ; \mathrm{i}, \mathrm{j})}=\mathrm{Jc}_{(\mathrm{i}, \mathrm{j}-1 ; \mathrm{i}, \mathrm{j})} 2 \pi \mathrm{R}_{(\mathrm{i}, \mathrm{j}-1)} \Delta \mathrm{z} \Delta \mathrm{t}$

em que

$\operatorname{Ec}_{(\mathrm{i}, \mathrm{j}-1 ; \mathrm{i}, \mathrm{j})}=$ massa do soluto que passa da célula $(\mathrm{i}, \mathrm{j}-1)$ à célula $(\mathrm{i}, \mathrm{j}), \mathrm{M}$.

$\mathrm{Ec}_{(\mathrm{i}, \mathrm{j} ; \mathrm{i}, \mathrm{j}+1)}=\mathrm{Jc}_{(\mathrm{i}, \mathrm{j} ; \mathrm{i}, \mathrm{j}+1)} 2 \pi \mathrm{R}_{(\mathrm{i}, \mathrm{j})} \Delta \mathrm{z} \Delta \mathrm{t}$

em que

$\operatorname{Ec}_{(i, j ; i, j+1)}=$ massa de soluto que passa da célula $(i, j)$ à célula $(i, j+1)$.

- Direção vertical

$\mathrm{Ec}_{(\mathrm{i}-1, \mathrm{j} ; \mathrm{i}, \mathrm{j})}=\mathrm{Jc}_{(\mathrm{i}-1, \mathrm{j} ; \mathrm{i}, \mathrm{j})} \pi\left(\mathrm{R}_{(\mathrm{i}, \mathrm{j})}{ }^{2}-\mathrm{R}_{(\mathrm{i}, \mathrm{j}-1)}{ }^{2}\right) \Delta \mathrm{t}$

$\mathrm{Ec}_{(\mathrm{i}, \mathrm{j} ; \mathrm{i}+1, \mathrm{j})}=\mathrm{Jc}_{(\mathrm{i}, \mathrm{j} ; \mathrm{i}+1, \mathrm{j})} \pi\left(\mathrm{R}_{(\mathrm{i}, \mathrm{j})}{ }^{2}-\mathrm{R}_{(\mathrm{i}, \mathrm{j}-1)}{ }^{2}\right) \Delta \mathrm{t}$

\subsubsection{Fluxo por dispersão hidrodinâmica}

Antes do cálculo do fluxo por dispersão hidrodinâmica, foram determinados os parâmetros Dm e D para cada incremento de $\Delta \mathrm{t}$, entre as células consecutivas:

$$
\operatorname{Dm}=\operatorname{Do} \frac{(\bar{\theta})^{10 / 3}}{\theta \mathrm{s}^{2}}
$$


$\mathrm{D}=\mathrm{Dm}+\left(\frac{\lambda \mathrm{q}}{\bar{\theta}}\right)$

em que

$\bar{\theta}=$ umidade média entre anéis ou células consecutivas.

Então a equação (18) pode ser rescrita como:

$$
\mathrm{Jdh}=-\bar{\theta} \mathrm{D} \frac{\Delta \mathrm{C}}{\Delta \mathrm{s}}
$$

A partir da equação (58) calcula-se o fluxo por dispersão hidrodinâmica, tanto horizontal como vertical, com as equações de número 59 à 62 :

- Fluxo por dispersão hidrodinâmica radial

$$
\begin{aligned}
& \operatorname{Jdh}_{(\mathrm{i}, \mathrm{j}-1 ; \mathrm{i}, \mathrm{j})}=-\left(\frac{\theta_{(\mathrm{i}, \mathrm{j}-1)}+\theta_{(\mathrm{i}, \mathrm{j})}}{2}\right) \mathrm{D}_{(\mathrm{i}, \mathrm{j}-\mathrm{l} ; \mathrm{i}, \mathrm{j})}\left[\frac{\mathrm{C}_{(\mathrm{i}, \mathrm{j})}-\mathrm{C}_{(\mathrm{i}, \mathrm{j}-1)}}{\Delta \mathrm{r}}\right] \\
& \mathrm{Jdh}_{(\mathrm{i}, \mathrm{j} ; \mathrm{i}, \mathrm{j}+1)}=-\left(\frac{\theta_{(\mathrm{i}, \mathrm{j})}+\theta_{(\mathrm{i}, \mathrm{j}+1)}}{2}\right) \mathrm{D}_{(\mathrm{i}, \mathrm{j} ; \mathrm{i}, \mathrm{j}+1)}\left[\frac{\mathrm{C}_{(\mathrm{i}, \mathrm{j}+1)}-\mathrm{C}_{(\mathrm{i}, \mathrm{j})}}{\Delta \mathrm{r}}\right]
\end{aligned}
$$

- Fluxo por dispersão hidrodinâmica vertical

$$
\begin{aligned}
& \operatorname{Jdh}_{(i-1, j, i, j)}=-\left(\frac{\theta_{(i-1, j)}+\theta_{(i, j)}}{2}\right) D_{(i-1, j ; i, j)}\left[\frac{C_{(i, j)}-C_{(i-1, j)}}{\Delta z}\right] \\
& \operatorname{Jdh}_{(i, j ; i+1, j)}=-\left(\frac{\theta_{(i, j)}+\theta_{(i+1, j)}}{2}\right) D_{(i, j ; i+1, j)}\left[\frac{C_{(i+1, j)}-C_{(i, j)}}{\Delta z}\right]
\end{aligned}
$$




\section{Transporte de solutos entre anéis por dispersão hidrodinâmica}

De forma análoga ao movimento convectivo de solutos, foi calculada a massa de solutos (E) que passa de um anel a outro nas direções radial e vertical.

- Direção radial

$$
\begin{aligned}
& \operatorname{Edh}_{(\mathrm{i}, \mathrm{j}-1 ; \mathrm{i}, \mathrm{j})}=\mathrm{Jh}_{(\mathrm{i}, \mathrm{j}-1 ; \mathrm{i}, \mathrm{j})} 2 \pi \mathrm{R}_{(\mathrm{i}, \mathrm{j}-1)} \Delta \mathrm{z} \Delta \mathrm{t} \\
& \mathrm{Edh}_{(\mathrm{i}, \mathrm{j} ; \mathrm{i}, \mathrm{j}+1)}=\mathrm{Jh}_{(\mathrm{i}, \mathrm{j} ; \mathrm{i}, \mathrm{j}+1)} 2 \pi \mathrm{R}_{(\mathrm{i}, \mathrm{j})} \Delta \mathrm{z} \Delta \mathrm{t}
\end{aligned}
$$

- Direção vertical

$$
\begin{aligned}
& \operatorname{Edh}_{(\mathrm{i}-1, \mathrm{j} ; \mathrm{i}, \mathrm{j})}=\mathrm{Jh}_{(\mathrm{i}-1, \mathrm{j} ; \mathrm{i}, \mathrm{j})} \pi\left(\mathrm{R}_{(\mathrm{i}, \mathrm{j})}{ }^{2}-\mathrm{R}_{(\mathrm{i}, \mathrm{j}-1)}{ }^{2}\right) \Delta \mathrm{t} \\
& \operatorname{Edh}_{(\mathrm{i}, \mathrm{j} ; \mathrm{i}+1, \mathrm{j})}=\mathrm{Jh}_{(\mathrm{i}, \mathrm{j} ; \mathrm{i}+1, \mathrm{j})} \pi\left(\mathrm{R}_{(\mathrm{i}, \mathrm{j})}{ }^{2}-\mathrm{R}_{(\mathrm{i}, \mathrm{j}-1)}{ }^{2}\right) \Delta \mathrm{t}
\end{aligned}
$$

\subsubsection{Balanço do soluto em cada anel}

De forma similar para o caso de transporte de água, após a aplicação da solução pela fonte pontiforme calculou-se a concentração de soluto no anel localizado à profundidade (i) e posição horizontal $(\mathrm{j})$, para cada incremento do tempo $(\Delta \mathrm{t})$. A quantidade de soluto que ficou em um determinado anel após o incremento $\Delta$ t é representada pela variação na massa de soluto no anel $\left(\Delta \mathrm{E}_{(\mathrm{i}, \mathrm{j})}\right)$ devido ao ganho de massa por:

- Convecção (Ecg):

$$
\operatorname{Ecg}_{(\mathrm{i}, \mathrm{j})}=\mathrm{Ec}_{(\mathrm{i}, \mathrm{j}-1 ; \mathrm{i}, \mathrm{j})}+\mathrm{Ec}_{(\mathrm{i}-1, \mathrm{j} ; \mathrm{i}, \mathrm{j})}
$$


- Dispersão hidrodinâmica (Ehg)

$$
\operatorname{Ehg}_{(i, j)}=E_{(i, j-1 ; i, j)}+E_{(i-1, j ; i, j)}
$$

e perda de massa por:

- Convecção (Ecp):

$$
\operatorname{Ecp}_{(\mathrm{i}, \mathrm{j})}=\operatorname{Ecp}_{(\mathrm{i}, \mathrm{j} ; \mathrm{i}, \mathrm{j}+1)}+\operatorname{Ecp}_{(\mathrm{i}, \mathrm{j} ; \mathrm{i}+1, \mathrm{j})}
$$

- Dispersão hidrodinâmica (Ehg)

$$
\operatorname{Ehp}_{(\mathrm{i}, \mathrm{j})}=\operatorname{Ehp}_{(\mathrm{i}, \mathrm{j} ; \mathrm{i}, \mathrm{j}+1)}+\operatorname{Ehp}_{(\mathrm{i}, \mathrm{j} ; \mathrm{i}+1, \mathrm{j})}
$$

obtendo-se finalmente:

$$
\Delta E_{(i, j)}=\frac{\operatorname{Ecg}_{(i, j)}+\operatorname{Ehg}_{(i, j)}-\operatorname{Ecp}_{(i, j)}-\operatorname{Ehp}_{(i, j)}}{F r}
$$

Consequentemente, a nova concentração do soluto no anel ao final de $\Delta t$ é determinada pela seguinte equação:

$$
\mathrm{C}_{(\mathrm{i}, \mathrm{j})}=\left[\frac{\frac{\mathrm{C}_{(\mathrm{i}, \mathrm{jini})}}{\theta_{(\mathrm{i}, \mathrm{jini})} \mathrm{Vs}_{(\mathrm{i}, \mathrm{j})}}+\Delta \mathrm{E}_{(\mathrm{i}, \mathrm{j})}}{\theta_{(\mathrm{i}, \mathrm{j})} \mathrm{Vs}_{(\mathrm{i}, \mathrm{j})}}\right]
$$

em que

$\mathrm{C}_{(\mathrm{i}, \mathrm{jini})}=$ concentração do soluto no inicio do intervalo $\Delta \mathrm{t}, \mathrm{ML}^{-3}$. 
Quando se aplica a técnica de discretização em volumes de controle, a equação (27) pode ser rescrita como:

$$
\operatorname{Fr} \frac{\Delta \theta \mathrm{C}}{\Delta \mathrm{t}}=-\frac{\Delta(\mathrm{qC})}{\Delta \mathrm{z}}+\frac{\Delta}{\Delta \mathrm{z}}\left[\mathrm{D} \bar{\theta} \frac{\Delta \mathrm{C}}{\Delta \mathrm{z}}\right]-\frac{\Delta(\mathrm{qC})}{\Delta \mathrm{x}}+\frac{\Delta}{\Delta \mathrm{x}}\left[\mathrm{D} \bar{\theta} \frac{\Delta \mathrm{C}}{\Delta \mathrm{x}}\right]
$$

\subsubsection{Desenvolvimento do modelo computacional}

O modelo computacional desenvolvido, denominado "Programa para o Transporte de Água e Solutos sob Irrigação por Gotejamento" (PTASIG), tem a característica de ser estruturado e apresentar varias opções, como a entrada de dados, criação de base de dados, recuperação de dados do disco e saída de dados tanto na tela como na impressora. A estrutura do PTASIG é mostrada na Figura 3:

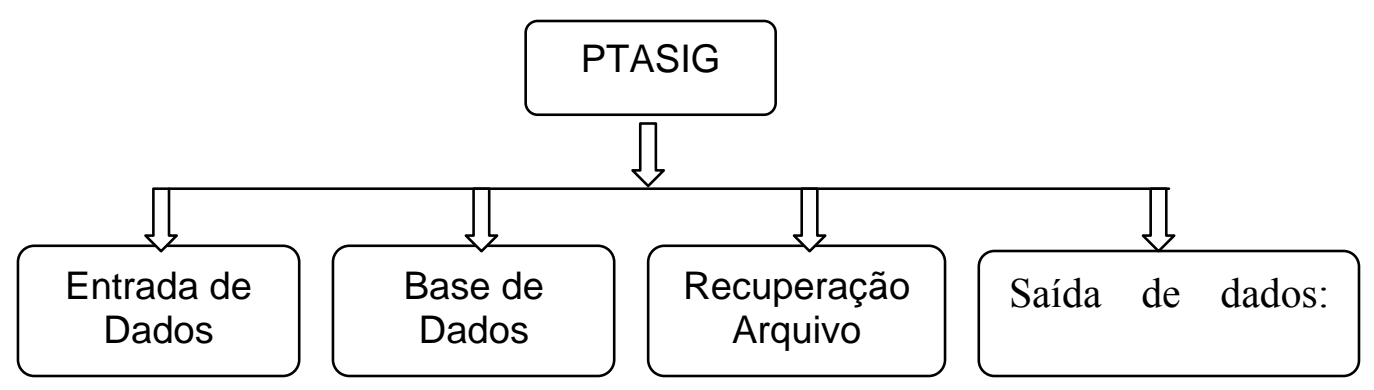

Figura 3 - Subprogramas que compõem o PTASIG

No desenvolvimento do modelo computacional, inicialmente foi realizada a construção do algoritmo para posteriormente se passar à linguagem fonte do programa.

Os valores de entrada do programa são vazão, tempo de irrigação, tempo de aplicação do soluto, tempo de redistribuição, incremento do tempo, dados do solo para cada camada (umidade inicial, umidade residual, umidade a saturação, profundidade do solo, raio de influência do emissor e parâmetros da equação de van Genuchten), e dados do soluto (concentração inicial no solo, concentração na água de irrigação, coeficiente 
de difusão em água pura, fator de retardamento e a dispersividade do solo). Inicialmente o programa calcula para cada $\Delta \mathrm{t}$ (num volume do solo com limites $\Delta \mathrm{z}$ e $\Delta \mathrm{r}$ ) a saturação efetiva, o potencial da água no solo e a condutividade hidráulica (K). Com base nesses dados determina para cada uma das células a densidade de fluxo, a variação do volume de água, a umidade posterior do solo, o fluxo em massa de solutos e fluxo por dispersão hidrodinâmica para finalmente, por meio de um balanço de massa, determina a nova concentração do soluto no final de $\Delta$ t.

A seqüência dos passos apresentados anteriormente para a resolução do problema do transporte de água e solutos em um bulbo úmido de solo estão resumidos no fluxograma apresentado na Figura 4.

\subsection{Validação experimental}

Esta etapa do trabalho foi conduzida no Laboratório de Física de Solo e em uma estufa plástica do Departamento de Engenharia Rural da Escola Superior de Agricultura “Luiz de Queiroz”, da Universidade de São Paulo, em Piracicaba.

\subsubsection{Caracterização do material de solo utilizado}

\subsubsection{Parâmetros físico-hídricos do solo}

O material de solo utilizado neste experimento foi originado de um perfil classificado como Latossolo Vermelho, fase arenosa, denominado Série "Sertaozinho" coletado dentro do campus da ESALQ/USP. A coleta foi realizada de uma camada que se extendia da superfície até uma profundidade de 30 centímetros.

Este solo foi seco ao ar e posteriormente peneirado através de uma peneira com malha de $5 \mathrm{~mm}$. Logo após encheu-se com o solo uma caixa feita de polietileno, com a forma de tronco de cone de 2,0 $\mathrm{m}^{3}$ de capacidade, com $166 \mathrm{~cm}$ diâmetro na parte superior e $142 \mathrm{~cm}$ de diâmetro na parte inferior, e com uma altura de $110 \mathrm{~cm}$. Em volta da caixa foram colocados arames galvanizados e réguas de madeira para que esta pudesse ter uma melhor sustentação, facilitando assim a posterior coleta de amostras. 
O solo homogeneizado foi colocado na caixa em camadas de $10 \mathrm{~cm}$, as quais foram compactadas levemente (Figura 5). Coletaram-se amostras de solo de cada camada para determinação da umidade e da concentração de potássio inicial do solo.

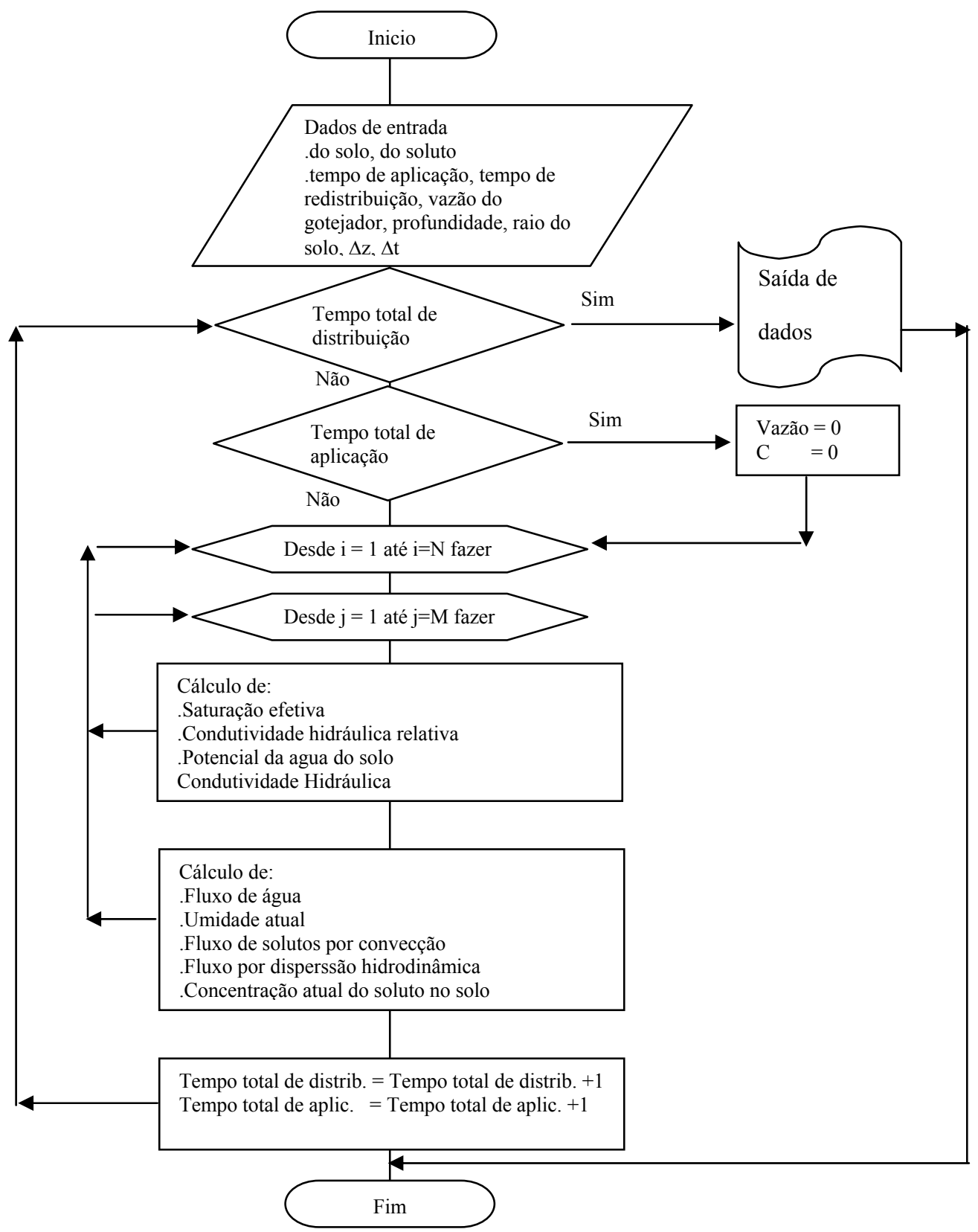

Figura 4 - Fluxograma do modelo para transporte simultâneo de água e soluto em um bulbo úmido de solo sob fonte pontiforme 


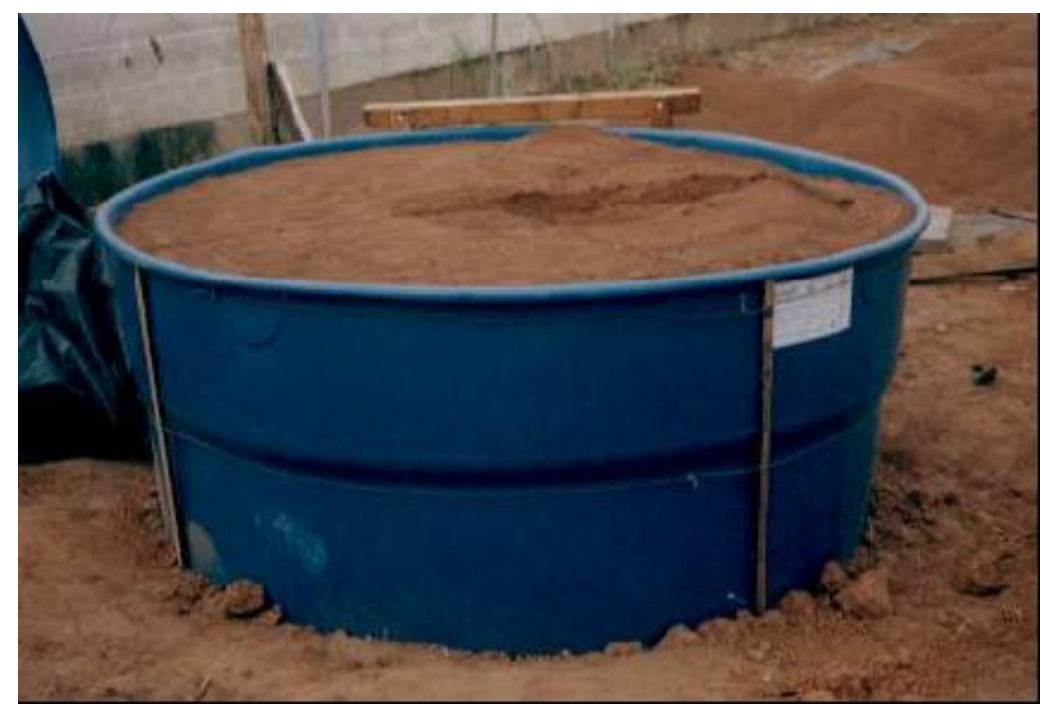

Figura 5 - Vista do solo homogeneizado em caixa de polietileno

Para a determinação da densidade global e da condutividade hidráulica do solo saturado foram coletadas amostras utilizando-se cilindros amostradores de 4,89 $\mathrm{cm}$ de diâmetro por $3 \mathrm{~cm}$ de altura. A condutividade hidráulica do solo saturado (Ko) foi calculada utilizando-se um permeâmetro de carga constante, onde foi mantida uma carga de $2 \mathrm{~cm}$, com um fluxo continuo de água, sendo o excesso drenado. Após a saturação foi medido o volume de água que atravessou a área da amostra num determinado o intervalo de tempo.

Para a determinação das curvas características também foram coletadas amostras indeformadas do solo da caixa, utilizando-se anéis amostradores de 4,89 cm de diâmetro por $3 \mathrm{~cm}$ de altura. As tensões aplicadas foram: $0 ; 2 ; 3 ; 4 ; 10 ; 30 ; 50 ; 100 ; 500$ e 1500 $\mathrm{kPa}$. Para tensões de até $4 \mathrm{kPa}$ foi utilizada uma mesa de tensão, e acima deste valor uma câmara de Richards com placas porosas de cerâmica. Posteriormente determinaram-se os parâmetros da curva de retenção $(\alpha, n, m)$, ajustando-se os pontos obtidos ao modelo de van Genuchten (1980).

$\mathrm{Na}$ Tabela 1 são apresentadas as características físico-hídricas do solo e na Tabela 2 os parâmetros da curva de retenção. 
Tabela 1. Características físico-hídricas do solo

\begin{tabular}{|c|c|c|c|c|c|c|}
\hline \multicolumn{3}{|c|}{ Textura } & \multicolumn{2}{|c|}{ Densidade } & Porosidade & Ko \\
\hline $\begin{array}{l}\text { Areia } \\
(\%)\end{array}$ & $\begin{array}{l}\text { Silte } \\
(\%)\end{array}$ & $\begin{array}{c}\text { Argila } \\
(\%)\end{array}$ & Global & Partículas & $(\%)$ & $\left(\mathrm{cmh}^{-1}\right)$ \\
\hline 67 & 6 & 27 & 1,369 & 2,575 & 46,835 & 10,221 \\
\hline
\end{tabular}

Tabela 2. Parâmetros da curva de retenção, segundo o modelo de van Genuchten (1980)

\begin{tabular}{ccccc}
\hline \multicolumn{5}{c}{ Parâmetros da Curva de Retenção } \\
\hline $\begin{array}{c}\theta \mathrm{r} \\
\text { Os }\end{array}$ & $\begin{array}{c}\alpha \\
\left(\mathrm{cm}^{3} \mathrm{~cm}^{-3}\right)\end{array}$ & $\begin{array}{c}\left.\mathrm{cm}^{3} \mathrm{~cm}^{-3}\right) \\
\left(\mathrm{cm}^{-1}\right)\end{array}$ & & $\mathrm{n}$ \\
0,113 & 0,482 & 0,029428 & 1,828069 & 0,452975 \\
\hline
\end{tabular}

\subsubsection{Curva de eluição e parâmetros de transporte do soluto}

Com o objetivo de se obter os parâmetros de transporte do potássio no bulbo úmido do solo a partir do ajuste de uma da curva de eluição ("breakthrough curve"), foi montado um esquema segundo a Figura 6, composto pelos seguintes componentes: coluna de PVC com $5 \mathrm{~cm}$ de diâmetro e $20 \mathrm{~cm}$ de altura (preenchido com um volume de solo de $392,7 \mathrm{~cm}^{3}$ ), dosador de soro, solução de cloreto de potássio, frasco coletor, manta geotextil (Bidim OP-30) e balança eletrônica com precisão de 0,01 g. 


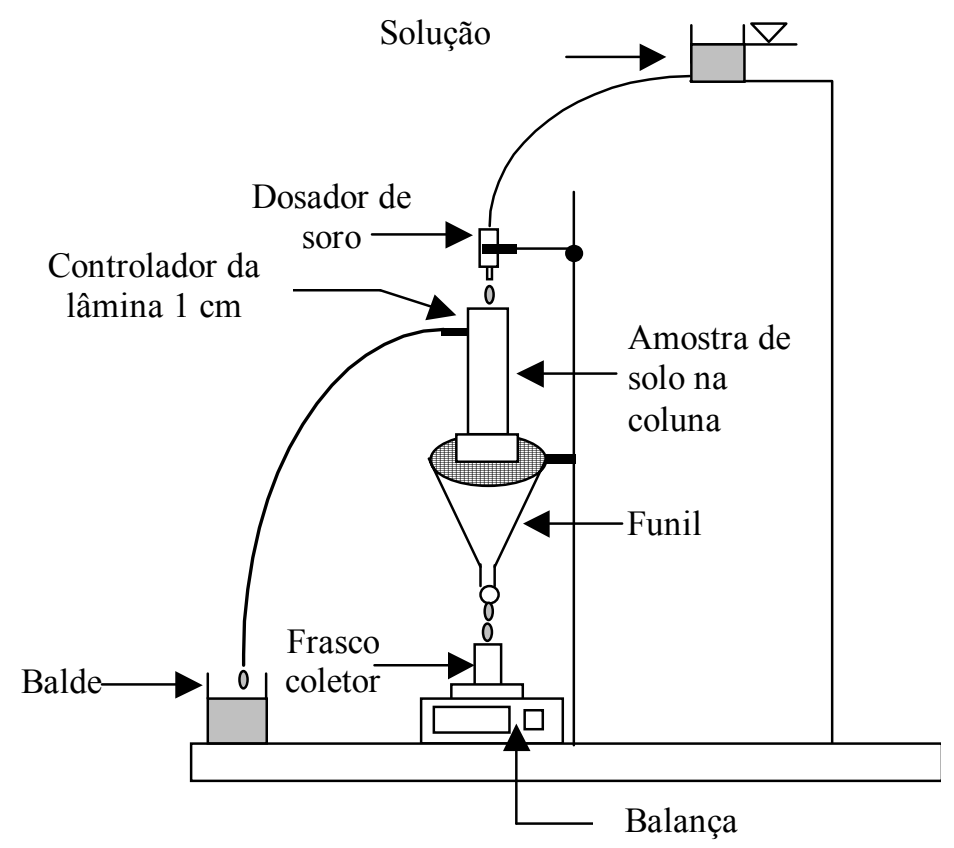

Figura 6 - Esquema para a montagem de amostras, para a elaboração das curvas da eluição (extraido de Miranda (2001))

Foi utilizado como soluto o cloreto de potássio, com uma concentração de potássio de $500 \mathrm{mgL}^{-1}$. Inicialmente preparou-se uma solução padrão de $10.000 \mathrm{mg} \mathrm{L}^{-1}$ de potássio; para isto foi colocado $19,07 \mathrm{~g}$ de $\mathrm{KCl}$ num balão de um litro e completado com água destilada até atingir esse volume. Para se obter uma solução de $500 \mathrm{mg} \mathrm{L}^{-1}$ de potássio utilizou se $100 \mathrm{ml}$ de solução padrão mais $1.900 \mathrm{ml}$ de água destilada.

$\mathrm{Na}$ aplicação de água e de solução foi utilizado um dosador de soro. A carga hidráulica empregada na extremidade superior foi de $1 \mathrm{~cm}$, sendo a mesma mantida fixa durante o todo o teste com ajuda de um ladrão. Antes de se iniciar o teste, a coluna de solo foi saturada com água destilada; este processo foi realizado lentamente deixando-se pingar água no recipiente que continha a coluna até que se alcançasse uma altura de 2/3 da coluna de solo. Logo após esta foi deixada em repouso durante 24 horas e depois desse prazo foi dado inicio ao teste, deixando-se passar água destilada pela coluna, também durante 24 horas, com o intuito de lixiviar o potássio existente na solução do solo. Finalmente foi aplicada a solução de cloreto de potássio, começando a coleta dos 
volumes de solução que atravessavam a coluna de solo, até que a concentração da solução coletada (C) se tornasse igual a concentração da solução aplicada (Co) .

Com o intuito de auxiliar na estimativa da concentração de potássio na solução (C), foi elaborada uma curva de calibração da concentração de potássio em função da condutividade elétrica (CE) da solução. O teste era finalizado quando a $\mathrm{CE}$ dos volumes coletados atingiam um valor próximo a $1,7 \mathrm{dSm}^{-1}$, o qual representava aproximadamente uma concentração de $500 \mathrm{mgL}^{-1}$ de potássio (Figura 7). Posteriormente foi determinado o teor de potássio nas amostras coletadas mediante o uso de um fotômetro de chama. Devido a limitações da escala do aparelho, muitas amostras tiveram que ser diluídas numa relação 1:5.

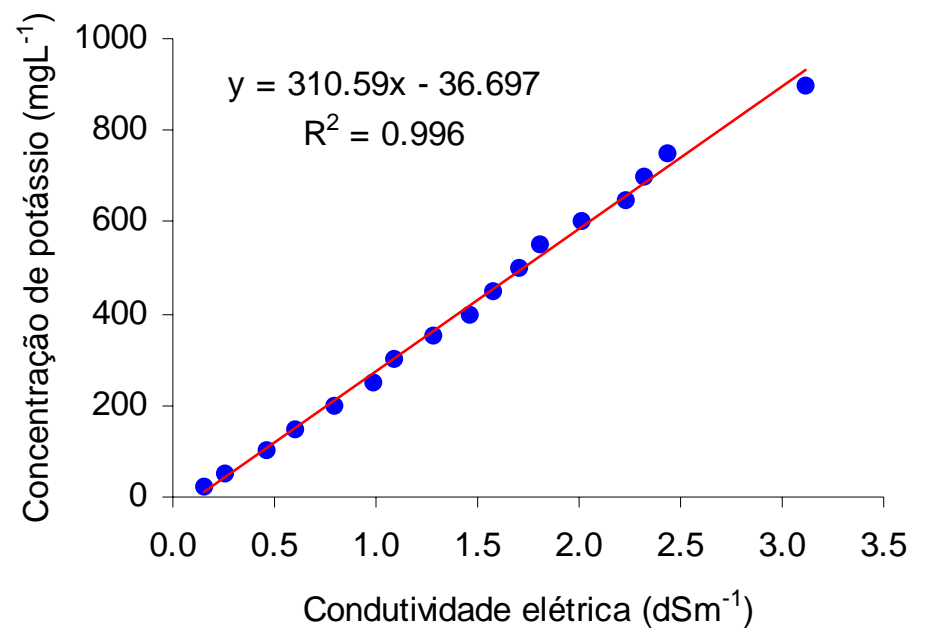

Figura 7 - Relação entre a concentração de potássio e condutividade elétrica da solução

Os volumes de solução coletados foram de $15 \mathrm{ml}$, o que representava aproximadamente 0,082 volumes de poros, conforme a equação 74. Esse volume foi controlado com uma balança de precisão de 0,01 g, assumindo-se que a solução tivesse densidade igual a um.

$\mathrm{VP}=\alpha \mathrm{Vc}$ 
em que

$\mathrm{VP}=$ volume de poros; $\mathrm{L}^{3}$;

$\alpha=$ porosidade do solo em questão, decimal; e

$\mathrm{Vc}=$ volume da coluna, $\mathrm{L}^{3}$.

Os valores obtidos de concentração de potássio, volume de poros e tempo acumulado foram empregados como dados de entrada do programa CXTFIT, desenvolvido pelo U.S. Salinity Laboratory-USDA-Riverside-CA, versão 2.1, escrito em linguagem FORTRAN. O CXTFIT determina os valores dos parâmetros de transporte de solutos no solo ou seja o coeficiente de dispersão (D), a velocidade da água nos poros $(\mathrm{V})$, a dispersividade $(\lambda)$ e o fator de retardamento $(\mathrm{Fr})$, por meio de tentativas visando maximizar o coeficiente de determinação da regressão entre a concetração relativa da solução $(\mathrm{C} / \mathrm{Co})$ e o volume de poros. Assim, foram obtidos os valores dos parâmetros de transporte que são mostrados na Tabela 3, baseados nos quais foi construída a curva de eluição (Figura 8).

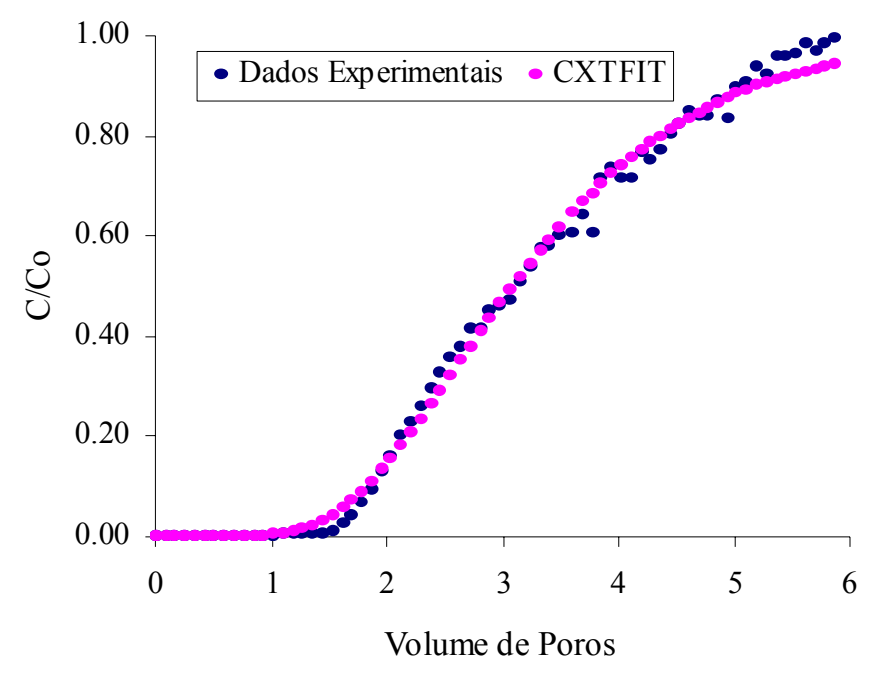

Figura 8 - Curva de eluição da solução de potássio na coluna de solo 
Tabela 3. Parâmetros de transporte do potássio no solo obtidos com o modelo CXTFIT: velocidade da água nos poros (V), coeficiente de difusão-dispersão (D), fator de retardamento (Fr), e dispersividade $(\lambda)$

\begin{tabular}{cccc}
\hline \multicolumn{4}{c}{ Parâmetros de transporte do potássio } \\
\hline $\mathrm{V}$ & $\mathrm{D}$ & $\mathrm{Fr}$ & $\lambda$ \\
$\left(\mathrm{cm} \mathrm{min}^{-1}\right)$ & $\left(\mathrm{cm}^{2} \mathrm{~min}^{-1}\right)$ & (adimensional) & $(\mathrm{cm})$ \\
1,489 & 2,705 & 4,730 & 1,816655 \\
\hline
\end{tabular}

\subsubsection{Aplicação da solução e coleta de dados}

\subsubsection{Fonte pontiforme}

Uma vez determinadas as características físico-hídricas do solo e os parâmetros do movimento do íon potássio, foi fornecido água e soluto ao solo por meio de uma solução de cloreto de potássio, com uma concentração de $500 \mathrm{mg} \mathrm{L}^{-1}$ de potássio. Com o intuito de simular um gotejador, foi utilizado um dosador de soro previamente calibrado para uma vazão de $3 \mathrm{~L} \mathrm{~h}^{-1}$. Este dosador foi localizado no centro da caixa de polietileno que continha o solo e foi acoplado a um frasco de Mariotte com capacidade de 10 litros por intermédio de um tubo capilar, mantendo-se constante a carga hidráulica dentro do frasco. O tempo de aplicação foi de duas horas, sendo portanto aplicado um volume de solução de 6 litros.

Com a finalidade de controlar a vazão e quantidade de solução aplicada, foi empregada uma balança eletrônica. O frasco de Mariotte contendo a solução foi colocado em cima da balança e foi-se registrando o peso total do frasco, conforme aplicava-se a solução.

\subsubsection{Medição da umidade do solo}

A umidade do solo após o teste foi determinada utilizando-se o método gravimétrico. Para isto foi empregado um trado do tipo caneco adaptado a um sistema de 
encamisamento do orifício de coleta com um tubete de PVC, para evitar assim a contaminação de camadas inferiores.

O diâmetro de coleta com o trado foi de $4,9 \mathrm{~cm}$, possuindo uma altura de $10 \mathrm{~cm}$, sendo o volume de solo coletado em cada amostragem igual a $190 \mathrm{~cm}^{3}$, o que equivalia a aproximadamente $260 \mathrm{~g}$ de solo seco. O tubete tinha um diâmetro interno de 4,72 cm, sendo inferior ao diâmetro da ponta do trado, o que facilitou o encamisamento gradual, conforme se aprofundava.

Os pontos de amostragem foram localizados ao longo de uma malha tomando-se como eixo central o ponto onde estava localizado o emissor; a partir desse ponto amostrou-se a cada $10 \mathrm{~cm}$ na direção horizontal $(\Delta \mathrm{r})$ e $10 \mathrm{~cm}$ na vertical $(\Delta \mathrm{z})$ ao longo de dois raios, de modo que todo anel esquematizado fosse amostrado duas vezes. $\mathrm{O}$ total de raios amostrados foram seis (duas repetições para cada tempo), dispostos de modo a formar na superfície do solo ângulos de 60 graus, ou seja o bulbo foi dividido em seis fatias de igual tamanho. Tanto na direção radial como vertical foram retiradas 5 amostras, totalizando 25 amostras por raio.

Os tempos de coleta das amostras foram antes da irrigação; 24; 48; e 72 horas após o final da irrigação.

\subsubsection{Medição da concentração de potássio}

A amostragem para a determinação da concentração de potássio na solução do solo foi realizada conjuntamente com a amostragem da umidade, sendo os locais e os tempos de amostragem os mesmos. A determinação de potássio foi feita com base na retirada do extrato de saturação do solo. Primeiro preparou-se uma pasta saturada com o solo que foi retirado e deixou-se o mesmo em repouso durante 24 horas. Posteriormente o extrato foi retirado por meio de uma bomba a vácuo para ser submetido à análise em laboratório (Figura 9). 


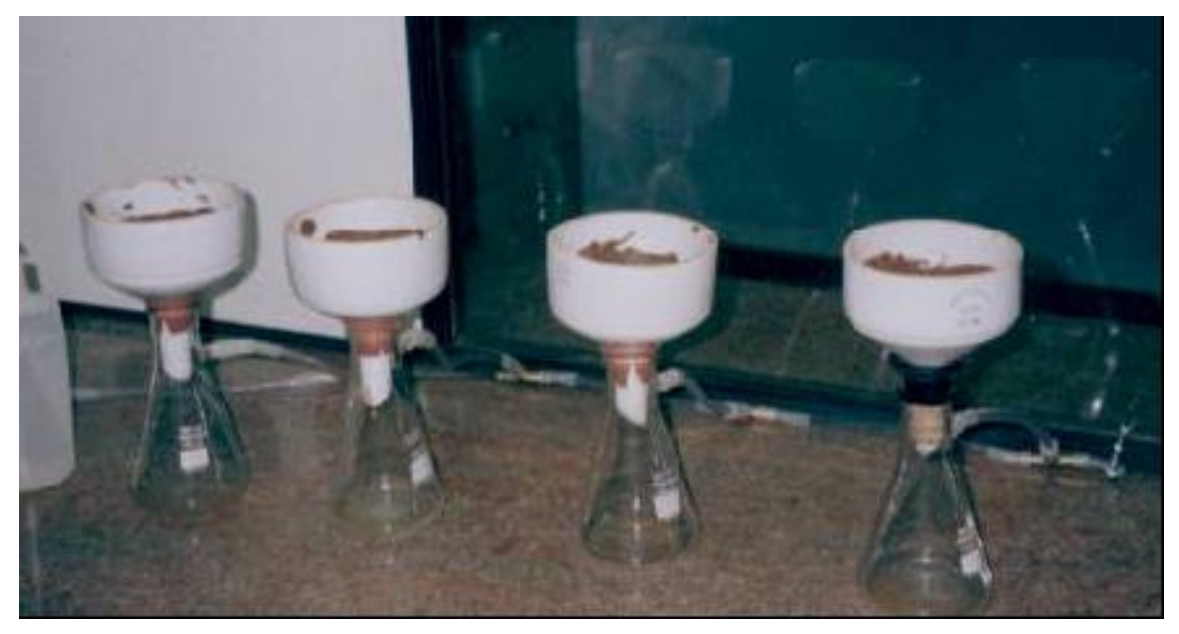

Figura 9 - Obtenção do extrato por meio de uma bomba a vácuo

O conteúdo de potássio no extrato foi determinado em um fotômetro de chamas. Quando as amostras continham altas concentrações de potássio, as mesmas eram diluidas em uma relação 1:5. Devido ao fato de ter sido adicionada água destilada para se preparar as pastas, foi necessário realizar a correção dos valores obtidos sem relação à umidade antes do preparo da pasta de extração, segundo a equação 75.

$$
\mathrm{C}_{\mathrm{kc}}=\frac{\theta_{\mathrm{e}} \mathrm{C}_{\mathrm{e}}}{\theta_{\mathrm{a}}}
$$

em que:

$\mathrm{C}_{\mathrm{kc}}=$ Concentração do potássio corrigida em função da umidade, $\mathrm{mg} \mathrm{L}^{-1}$;

$\theta \mathrm{e}=$ Umidade da pasta utilizada na extração da solução, $\mathrm{cm}^{3} \mathrm{~cm}^{-3}$;

$\mathrm{Ce}=$ Concentração do potássio no extrato, $\mathrm{mg} \mathrm{L}^{-1}$; e

$\theta \mathrm{a}=$ Umidade do solo no momento da coleta, $\mathrm{cm}^{3} \mathrm{~cm}^{-3}$.

\subsubsection{Teste do modelo}

Com os dados do solo (umidade inicial, condutividade hidráulica do solo saturado, parâmetros da curva de retenção ( $\alpha$, n, m, umidade a saturação, umidade 
residual, $\Delta \mathrm{r}$ e $\Delta \mathrm{z}$ ), do soluto (coeficiente de dispersão do soluto em agua pura, dispersividade e fator de retardamento) e da solução aplicada (vazão, concentração de potássio e tempo de aplicação), procedeu-se à simulação da movimentação simultânea de água e potássio no volume de solo considerado para os tempos de 24, 48 e 72 horas de redistribuição. Os valores empregados de $\Delta \mathrm{r}, \Delta \mathrm{z}$ e $\Delta \mathrm{t}$ para rodar o programa foram de $10 \mathrm{~cm}$ e 10 segundos, respectivamente. Posteriormente foi realizado uma comparação entre os resultados simulados e observados, visando validar o modelo sob as condições do experimento.

\subsection{Análise de sensibilidade}

Com o intuito de estudar o comportamento do modelo frente às mudanças nos parâmetros de entrada, foi realizada uma análise de sensibilidade à respeito das variações individuais da condutividade hidráulica do solo saturado, umidade inicial e saturada do solo, dispersividade, fator de retardamento, vazão do emissor e concentração do potássio. Para se medir o efeito destas variações nas simulações foi determinado o parâmetro erro padrão empregando, neste caso a seguinte relação:

$$
e=\sqrt{\frac{\sum_{i=1}^{N}(y m(i)-y s(i))^{2}}{N}}
$$

em que

$$
\begin{aligned}
\text { e } & =\text { erro padrão; } \\
\operatorname{ym}(\mathrm{i}) & =\text { valor padrão simulado pelo modelo; } \\
\mathrm{ys}(\mathrm{i}) & =\text { valor simulado pelo modelo; e } \\
\mathrm{N} & =\text { número de dados da simulação. }
\end{aligned}
$$

As variações dos parâmetros de entrada do modelo forma feitas tomando-se o resultado de 36 pontos em cada simulação e seguindo acréscimos positivos, $+10 \%$, $+20 \%,+30 \%,+40 \%,+50 \%,+50 \%,+60 \%,+70 \%,+80 \%,+90 \%$ e negativos, $-10 \%$, $20 \%,-30 \%,-40 \%,-50 \%,-60 \%,-70 \%,-80 \%,-90 \%$. 


\section{RESULTADOS E DISCUSSÃO}

Os resultados obtidos são expostos e discutidos seqüencialmente. Inicialmente é abordada a validação experimental do modelo, comparado-se os dados de umidade e de concentração de potássio no bulbo gerados pelo modelo com os observados no teste, para tempos de redistribuição de 24 horas, 48 horas e 72 horas após o final da irrigação. Na seqüência é discutido o comportamento do modelo em relação às mudanças dos parâmetros de entrada e seu efeito no conteúdo de umidade e na concentração do potássio no bulbo, ou seja, a analise de sensibilidade.

\subsection{Validação experimental do modelo}

\subsubsection{Teor de umidade e concentração de potássio no bulbo antes da irrigação}

Pela maneira como se fez o preparo do solo dentro da caixa, assumiu se que o solo era homogêneo e isotrópico. Porém, para se ter maior segurança, amostras foram coletadas radialmente a cada $10 \mathrm{~cm}$, e verticalmente também a cada $10 \mathrm{~cm}$, considerando como origem o eixo do ponto de localização do emissor.

Os resultados médios do conteúdo de umidade e de concentração de potássio no solo antes da aplicação da solução são apresentados na Tabela 4. Pode se observar que a umidade variou nas diferentes camadas entre 0,1190 a $0,1281 \mathrm{~cm}^{3} \mathrm{~cm}^{-3}$, sendo portanto quase constante ao longo do perfil do solo, o que possivelmente foi conseqüência de ter sido feita uma mistura do volume total do solo antes de se encher a caixa. Estes valores de umidade são considerados baixos, ficando perto da umidade residual do solo ( $\theta$ r), 
devido ao fato do solo ter sido seco previamente ao ar, sendo que para esta situação pode ser negligenciado o movimento de água no solo.

O conteúdo inicial de potássio na solução do solo também foi baixo, típico de latossolos de textura leve, variando entre 16,07 a $23,40 \mathrm{mg} \mathrm{L}^{-1}$. O solo durante a secagem não sofreu nemhum processo de lavagem pela chuva, pois esteve protegido dentro uma estufa plástica.

Tabela 4. Umidade inicial e concentração de potássio médias na solução do solo para várias profundidades

\begin{tabular}{ccc}
\hline $\begin{array}{c}\text { Profundidade } \\
\text { do solo }(\mathrm{cm})\end{array}$ & $\begin{array}{c}\text { Umidade } \\
\left(\mathrm{cm}^{3} \mathrm{~cm}^{-3}\right)\end{array}$ & $\begin{array}{c}\text { Potássio na solução } \\
\text { do solo }\left(\mathrm{mg} \mathrm{L}^{-1}\right)\end{array}$ \\
\hline $0-10$ & 0,1260 & 23,40 \\
$10-20$ & 0,1281 & 20,28 \\
$20-30$ & 0,1193 & 22,50 \\
$30-40$ & 0,1232 & 21,82 \\
$40-50$ & 0,1219 & 21,07 \\
$50-60$ & 0,1202 & 20,42 \\
$60-70$ & 0,1203 & 20,13 \\
$70-80$ & 0,1195 & 20,10 \\
$80-90$ & 0,1191 & 18,94 \\
$90-100$ & 0,1190 & 16,07 \\
\hline
\end{tabular}

\subsection{Umidade do solo após a irrigação}

Os dados do conteúdo de umidade do solo em base de volume ( $\theta$ ) 24 horas após o final da irrigação, gerados pelo modelo, bem como os observados, são apresentados nas Tabelas 5 e 6, respectivamente, sendo a comparação dos perfis de distribuição ilustrada por meio de isolinhas de umidade na Figura 10, respectivamente. Pode-se observar que a umidade do solo, tanto a observada quanto a simulada, variaram de cerca 
de 0,12 a $0,20 \mathrm{~cm}^{3} \mathrm{~cm}^{-3}$ aproximadamente. Dentro do bulbo, ou seja num raio de $26 \mathrm{~cm}$ e profundidade de $30 \mathrm{~cm}$ em relação ao emissor variaram na faixa de 0,17 a $0,20 \mathrm{~cm} \mathrm{~cm}^{-}$ ${ }^{3}$, decrescendo tanto no sentido radial como no sentido vertical, à medida que se afasta do emissor, adquirindo o bulbo uma forma hemisférica. Observa-se que o raio do bulbo foi levemente superior a sua profundidade. A este respeito Hachum et al. (1976) indicam que a força da gravidade tem um efeito limitado em solos argilosos e francos, onde as forças capilares dominam os efeitos sobre o fluxo de água; portanto, nestes solos os movimentos de água na direção radial e na direção vertical são aproximadamente iguais. Já em solos arenosos predomina o movimento vertical.

Fora da região do bulbo, praticamente não houve mudança na conteúdo de umidade, o que permitiu que a amostragem fosse feita somente até para um raio de 50 $\mathrm{cm}$ e até $70 \mathrm{~cm}$ de profundidade, incluindo portanto uma margem de segurança.

A umidade volumétrica no centro dos anéis concêntricos (onde estava localizado a fonte pontiforme) foi de aproximadamente $0,20 \mathrm{~cm}^{3} \mathrm{~cm}^{-3}$, em ambos casos (observada e simulada). Este valor representa um pouco menos da metade da umidade a saturação $\left(0,43 \mathrm{~cm}^{3} \mathrm{~cm}^{-3}\right)$, indicando que no intervalo de tempo que decorreu desde a finalização da irrigação até o momento da amostragem ( 24 horas) houve uma redistribuição acentuada da solução.

As umidades obtidas, tanto na simulação como no teste foram similares, encontrando-se um valor para o erro padrão igual a $0,01085 \mathrm{~cm}^{3} \mathrm{~cm}^{-3}$. No eixo central, o bulbo úmido atingiu os $35 \mathrm{~cm}$ com uma umidade de 0,166 e $0,172 \mathrm{~cm}^{3} \mathrm{~cm}^{-3}$, para o modelo e teste, respectivamente. Já para a periferia (aos $35 \mathrm{~cm}$ de raio) o bulbo atingiu os $20 \mathrm{~cm}$ de profundidade para o modelo e aproximadamente $15 \mathrm{~cm}$ de profundidade para o teste com umidades de $0,170 \mathrm{e} 0,163 \mathrm{~cm}^{3} \mathrm{~cm}^{-3}$, respectivamente. 
Tabela 5. Umidade volumétrica do solo $\left(\mathrm{cm}^{3} \mathrm{~cm}^{-3}\right)$ simulada pelo modelo após 24 horas do final da irrigação

\begin{tabular}{cccccccccc}
\hline $\begin{array}{c}\text { Profundidade } \\
(\mathrm{cm})\end{array}$ & 0 & 10 & 20 & 30 & 40 & 50 & 60 & 70 & 80 \\
\hline $0-10$ & 0,2033 & 0,2002 & 0,1899 & 0,1705 & 0,1432 & 0,1265 & 0,1260 & 0,1260 & 0,1260 \\
$10-20$ & 0,1989 & 0,1948 & 0,1812 & 0,1571 & 0,1316 & 0,1280 & 0,1281 & 0,1281 & 0,1281 \\
$20-30$ & 0,1865 & 0,1799 & 0,1599 & 0,1323 & 0,1196 & 0,1193 & 0,1193 & 0,1193 & 0,1193 \\
$30-40$ & 0,1664 & 0,1553 & 0,1333 & 0,1233 & 0,1232 & 0,1232 & 0,1232 & 0,1232 & 0,1232 \\
$40-50$ & 0,1407 & 0,1203 & 0,1220 & 0,1219 & 0,1219 & 0,1219 & 0,1219 & 0,1219 & 0,1219 \\
$50-60$ & 0,1212 & 0,1202 & 0,1202 & 0,1202 & 0,1202 & 0,1202 & 0,1202 & 0,1202 & 0,1202 \\
$60-70$ & 0,1203 & 0,1203 & 0,1203 & 0,1203 & 0,1203 & 0,1203 & 0,1203 & 0,1203 & 0,1203 \\
$70-80$ & 0,1194 & 0,1195 & 0,1195 & 0,1195 & 0,1195 & 0,1195 & 0,1195 & 0,1195 & 0,1195 \\
$80-90$ & 0,1191 & 0,1191 & 0,1191 & 0,1191 & 0,1191 & 0,1191 & 0,1191 & 0,1191 & 0,1191 \\
$90-100$ & 0,1190 & 0,1190 & 0,1190 & 0,1190 & 0,1190 & 0,1190 & 0,1190 & 0,1190 & 0,1190 \\
\hline
\end{tabular}

Tabela 6. Umidade volumétrica do solo $\left(\mathrm{cm}^{3} \mathrm{~cm}^{-3}\right)$ observada após 24 horas do final da irrigação

\begin{tabular}{cccccccccc}
\hline $\begin{array}{c}\text { Profundidade } \\
(\mathrm{cm})\end{array}$ & 0 & 10 & 20 & 30 & 40 & 50 & 60 & 70 & 80 \\
\hline $0-10$ & 0,2017 & 0,1963 & 0,1852 & 0,1631 & 0,1189 & 0,1185 & 0,1260 & 0,1260 & 0,1260 \\
$10-20$ & 0,1989 & 0,1934 & 0,1636 & 0,1264 & 0,1231 & 0,1250 & 0,1281 & 0,1281 & 0,1281 \\
$20-30$ & 0,1905 & 0,1824 & 0,1422 & 0,1199 & 0,1162 & 0,1193 & 0,1193 & 0,1193 & 0,1193 \\
$30-40$ & 0,1723 & 0,1308 & 0,1215 & 0,1103 & 0,1158 & 0,1232 & 0,1232 & 0,1232 & 0,1232 \\
$40-50$ & 0,1208 & 0,1125 & 0,1201 & 0,1286 & 0,1219 & 0,1219 & 0,1219 & 0,1219 & 0,1219 \\
$50-60$ & 0,1119 & 0,1200 & 0,1114 & 0,1215 & 0,1202 & 0,1202 & 0,1202 & 0,1202 & 0,1202 \\
$60-70$ & 0,1085 & 0,1261 & 0,1203 & 0,1203 & 0,1203 & 0,1203 & 0,1203 & 0,1203 & 0,1203 \\
$70-80$ & 0,1236 & 0,1197 & 0,1195 & 0,1195 & 0,1195 & 0,1195 & 0,1195 & 0,1195 & 0,1195 \\
$80-90$ & 0,1173 & 0,1251 & 0,1191 & 0,1191 & 0,1191 & 0,1191 & 0,1191 & 0,1191 & 0,1191 \\
$90-100$ & 0,1269 & 0,1101 & 0,1190 & 0,1190 & 0,1190 & 0,1190 & 0,1190 & 0,1190 & 0,1190 \\
\hline
\end{tabular}




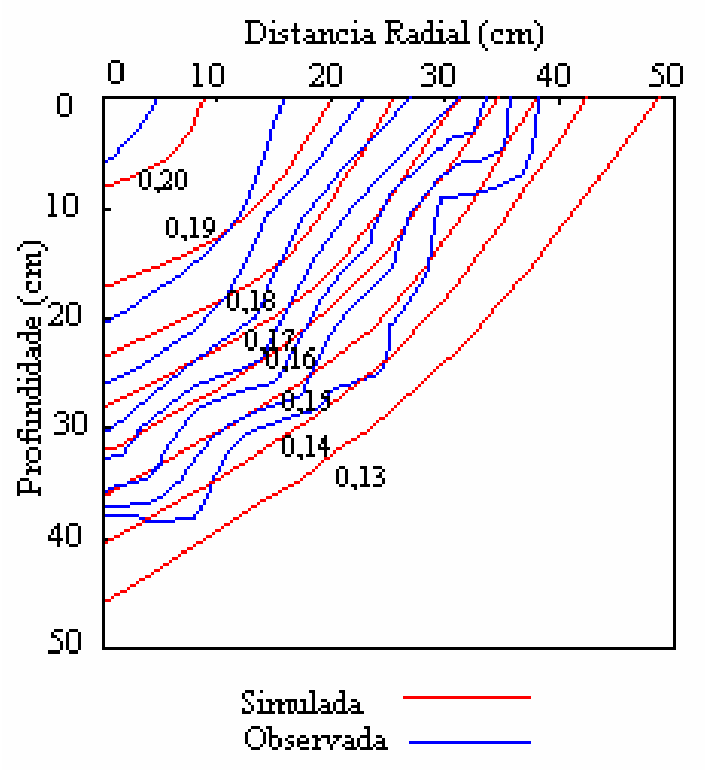

Figura 10 - Umidade volumétrica do solo $\left(\mathrm{cm}^{3} \mathrm{~cm}^{-3}\right)$ simulada pelo modelo e observada após 24 horas do final da irrigação

Para um tempo de redistribuição de 48 horas após a irrigação, a amostragem do solo em todo o eixo central do bulbo (distancia radial igual a zero) não foi feita devido ao fato de que nesse ponto já tinha sido realizada a coleta para um tempo de 24 horas, realizando-se portanto a amostragem a partir de uma distancia radial de $10 \mathrm{~cm}$.

A relação entre os dados gerados pelo modelo e os obtidos no teste para este tempo de estudo, estão detalhados nas Tabelas 7 e 8, e Figura 11. Observa-se que as dimensões do bulbo ficaram praticamente constantes quando comparadas com o tempo de 24 horas de redistribuição, mas houve uma diminuição da umidade, principalmente nas células próximas ao ponto do emissor. Na superficie do solo, numa distância radial de $10 \mathrm{~cm}$, a umidade volumétrica do solo variou em torno a $0,18 \mathrm{~cm}^{3} \mathrm{~cm}^{-3}$ para as duas situações (simulada e observada), sofrendo um decréscimo de umidade de aproximadamente 7,5\% quando comparado com o tempo de 24 horas. Mas o decréscimo das células superiores acarretou um acréscimo da umidade das células adjacentes laterais e inferiores, produto da redistribuição da água no solo, mesmo sendo a taxas muito baixas. 
Tabela 7. Umidade volumétrica do solo $\left(\mathrm{cm}^{3} \mathrm{~cm}^{-3}\right)$ simulada pelo modelo após 48 horas do final da irrigação

Profundidade

Distancia radial $(\mathrm{cm})$

\begin{tabular}{cccccccccc}
$(\mathrm{cm})$ & 0 & 10 & 20 & 30 & 40 & 50 & 60 & 70 & 80 \\
\hline $0-10$ & 0,1876 & 0,1855 & 0,1787 & 0,1659 & 0,1467 & 0,1281 & 0,1260 & 0,1260 & 0,1260 \\
$10-20$ & 0,1847 & 0,1819 & 0,1734 & 0,1573 & 0,1361 & 0,1280 & 0,1281 & 0,1281 & 0,1281 \\
$20-30$ & 0,1760 & 0,1722 & 0,1597 & 0,1395 & 0,1211 & 0,1195 & 0,1193 & 0,1193 & 0,1193 \\
$30-40$ & 0,1617 & 0,1552 & 0,1395 & 0,1243 & 0,1232 & 0,1232 & 0,1232 & 0,1232 & 0,1232 \\
$40-50$ & 0,1424 & 0,1332 & 0,1229 & 0,1219 & 0,1219 & 0,1219 & 0,1219 & 0,1219 & 0,1219 \\
$50-60$ & 0,1232 & 0,1203 & 0,1202 & 0,1202 & 0,1202 & 0,1202 & 0,1202 & 0,1202 & 0,1202 \\
$60-70$ & 0,1203 & 0,1203 & 0,1203 & 0,1203 & 0,1203 & 0,1203 & 0,1203 & 0,1203 & 0,1203 \\
$70-80$ & 0,1195 & 0,1195 & 0,1195 & 0,1195 & 0,1195 & 0,1195 & 0,1195 & 0,1195 & 0,1195 \\
$80-90$ & 0,1191 & 0,1191 & 0,1191 & 0,1191 & 0,1191 & 0,1191 & 0,1191 & 0,1191 & 0,1191 \\
$90-100$ & 0,1190 & 0,1190 & 0,1190 & 0,1190 & 0,1190 & 0,1190 & 0,1190 & 0,1190 & 0,1190 \\
\hline
\end{tabular}

Tabela 8. Umidade volumétrica do solo $\left(\mathrm{cm}^{3} \mathrm{~cm}^{-3}\right)$ observada após 48 horas do final da irrigação

\begin{tabular}{|c|c|c|c|c|c|c|c|c|c|}
\hline \multirow{2}{*}{$\begin{array}{l}\text { Profundidade } \\
\qquad(\mathrm{cm})\end{array}$} & \multicolumn{9}{|c|}{ Distancia radial $(\mathrm{cm})$} \\
\hline & 0 & 10 & 20 & 30 & 40 & 50 & 60 & 70 & 80 \\
\hline $0-10$ & & 0,1886 & 0,1714 & 0,1612 & 0,1503 & 0,1024 & 0,1260 & 0,1260 & 0,1260 \\
\hline $10-20$ & & 0,1780 & 0,1656 & 0,1485 & 0,1056 & 0,1125 & 0,1281 & 0,1281 & 0,1281 \\
\hline $20-30$ & & 0,1631 & 0,1494 & 0,1024 & 0,1234 & 0,1033 & 0,1193 & 0,1193 & 0,1193 \\
\hline $30-40$ & & 0,1424 & 0,1144 & 0,1128 & 0,1087 & 0,1230 & 0,1232 & 0,1232 & 0,1232 \\
\hline $40-50$ & & 0,1322 & 0,1003 & 0,1063 & 0,1124 & 0,1012 & 0,1219 & 0,1219 & 0,1219 \\
\hline $50-60$ & & 0,1025 & 0,1258 & 0,1258 & 0,1178 & 0,1124 & 0,1202 & 0,1202 & 0,1202 \\
\hline $60-70$ & & 0,1104 & 0,1125 & 0,1119 & 0,1215 & 0,1199 & 0,1203 & 0,1203 & 0,1203 \\
\hline $70-80$ & & 0,1197 & 0,1195 & 0,1195 & 0,1195 & 0,1195 & 0,1195 & 0,1195 & 0,1195 \\
\hline $80-90$ & & 0,1251 & 0,1191 & 0,1191 & 0,1191 & 0,1191 & 0,1191 & 0,1191 & 0,1191 \\
\hline $90-100$ & & 0,1101 & 0,1190 & 0,1190 & 0,1190 & 0,1190 & 0,1190 & 0,1190 & 0,1190 \\
\hline
\end{tabular}


Os valores de umidade simulados foram levemente superiores aos observados, mas a tendência dos dados nas diferentes células foi a mesma, determinando-se um valor para o erro padrão igual a $0,01504 \mathrm{~cm}^{3} \mathrm{~cm}^{-3}$.

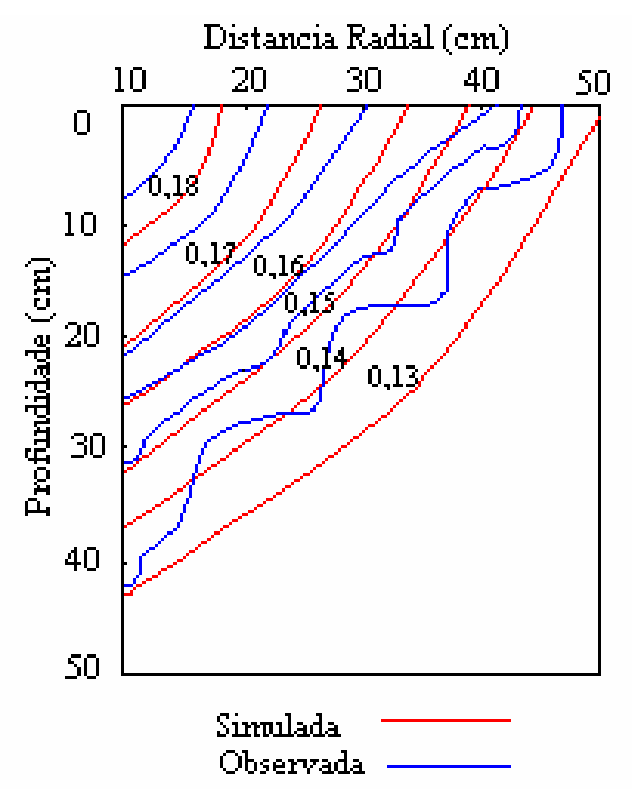

Figura 11 - Umidade volumétrica do solo $\left(\mathrm{cm}^{3} \mathrm{~cm}^{-3}\right)$ simulada pelo modelo e observada após 48 horas do final da irrigação

Decorrido o tempo de 72 horas após a irrigação, a amostragem do solo foi feita da mesma maneira do que para 48 horas. Os dados simulados e observados estão indicados nas Tabelas 9 e 10, e na Figura 12. Nas duas condições (dados simulados e observados) as células próximas à fonte pontiforme continuaram perdendo água para as células adjacentes, mas com pequena intensidade, ficando com uma umidade em torno a $0,178 \mathrm{~cm}^{3} \mathrm{~cm}^{-3}$, o que representa um decréscimo do $5 \%$ em relação ao tempo de 48 horas; mas mesmo assim, isto não contribuiu significativamente para alterações nas dimensões do bulbo. Ambas as umidades (simulada e observada) tiveram um comportamento aproximado no que se refere à distribuição de umidade, obtendo-se uma valor para o erro padrão igual a $0,00833 \mathrm{~cm}^{3} \mathrm{~cm}^{-3}$. 
Tabela 9 . Umidade volumétrica do solo $\left(\mathrm{cm}^{3} \mathrm{~cm}^{-3}\right)$ simulada pelo modelo após 72 horas do final da irrigação

\begin{tabular}{cccccccccc}
\hline $\begin{array}{c}\text { Profundidade } \\
(\mathrm{cm})\end{array}$ & 0 & 10 & 20 & 30 & 40 & 50 & 60 & 70 & 80 \\
\hline $0-10$ & 0,1799 & 0,1782 & 0,1728 & 0,1629 & 0,1474 & 0,1298 & 0,1261 & 0,1260 & 0,1260 \\
$10-20$ & 0,1775 & 0,1755 & 0,1688 & 0,1564 & 0,1387 & 0,1282 & 0,1278 & 0,1281 & 0,1281 \\
$20-30$ & 0,1707 & 0,1677 & 0,1584 & 0,1420 & 0,1234 & 0,1197 & 0,1196 & 0,1193 & 0,1193 \\
$30-40$ & 0,1589 & 0,1543 & 0,1419 & 0,1262 & 0,1232 & 0,1232 & 0,1232 & 0,1232 & 0,1232 \\
$40-50$ & 0,1427 & 0,1358 & 0,1245 & 0,1219 & 0,1219 & 0,1219 & 0,1219 & 0,1219 & 0,1219 \\
$50-60$ & 0,1248 & 0,1211 & 0,1203 & 0,1202 & 0,1202 & 0,1202 & 0,1202 & 0,1202 & 0,1202 \\
$60-70$ & 0,1203 & 0,1203 & 0,1203 & 0,1203 & 0,1203 & 0,1203 & 0,1203 & 0,1203 & 0,1203 \\
$70-80$ & 0,1195 & 0,1195 & 0,1195 & 0,1195 & 0,1195 & 0,1195 & 0,1195 & 0,1195 & 0,1195 \\
$80-90$ & 0,1191 & 0,1191 & 0,1191 & 0,1191 & 0,1191 & 0,1191 & 0,1191 & 0,1191 & 0,1191 \\
$90-100$ & 0,1190 & 0,1190 & 0,1190 & 0,1190 & 0,1190 & 0,1190 & 0,1190 & 0,1190 & 0,1190 \\
\hline
\end{tabular}

Tabela 10. Umidade volumétrica do solo $\left(\mathrm{cm}^{3} \mathrm{~cm}^{-3}\right)$ observada após 72 horas do final da irrigação

\begin{tabular}{|c|c|c|c|c|c|c|c|c|c|}
\hline Profundidade & & & & Dista & ncia radia & $(\mathrm{cm})$ & & & \\
\hline$(\mathrm{cm})$ & 0 & 10 & 20 & 30 & 40 & 50 & 60 & 70 & 80 \\
\hline $0-10$ & & 0,1792 & 0,1783 & 0,1601 & 0,1393 & 0,1283 & 0,1260 & 0,1260 & 0,1260 \\
\hline $10-20$ & & 0,1730 & 0,1629 & 0,1498 & 0,1205 & 0,1129 & 0,1281 & 0,1281 & 0,1281 \\
\hline $20-30$ & & 0,1642 & 0,1491 & 0,1297 & 0,1123 & 0,1154 & 0,1193 & 0,1193 & 0,1193 \\
\hline $30-40$ & & 0,1497 & 0,1236 & 0,1139 & 0,1252 & 0,1198 & 0,1232 & 0,1232 & 0,1232 \\
\hline $40-50$ & & 0,1242 & 0,1153 & 0,1206 & 0,1212 & 0,1233 & 0,1219 & 0,1219 & 0,1219 \\
\hline $50-60$ & & 0,1268 & 0,1291 & 0,1125 & 0,1193 & 0,1168 & 0,1202 & 0,1202 & 0,1202 \\
\hline $60-70$ & & 0,1157 & 0,1147 & 0,1150 & 0,1138 & 0,1214 & 0,1203 & 0,1203 & 0,1203 \\
\hline $70-80$ & & 0,1197 & 0,1195 & 0,1195 & 0,1195 & 0,1195 & 0,1195 & 0,1195 & 0,1195 \\
\hline $80-90$ & & 0,1251 & 0,1191 & 0,1191 & 0,1191 & 0,1191 & 0,1191 & 0,1191 & 0,1191 \\
\hline $90-100$ & & 0,1138 & 0,1190 & 0,1190 & 0,1190 & 0,1190 & 0,1190 & 0,1190 & 0,1190 \\
\hline
\end{tabular}




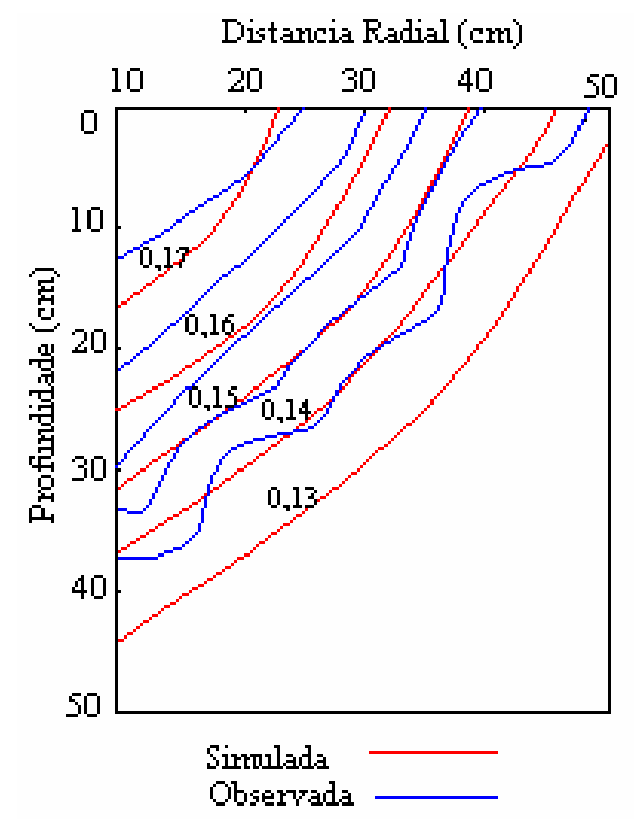

Figura 12 - Umidade volumétrica do solo $\left(\mathrm{cm}^{3} \mathrm{~cm}^{-3}\right)$ simulada pelo modelo e observada após 72 horas do final da irrigação

Neste tipo de solo, pode-se dizer que após 24 horas a redistribuição da água dentro do bulbo molhado praticamente termina, sendo as maiores mudanças observadas nas células próximas ao emissor, ou seja, o fluxo de água que ocorreu após este tempo foi pequeno, de forma que as dimensões do bulbo passaram a permanecer praticamente inalteradas

Em geral, os valores obtidos experimentalmente apresentaram-se semelhantes aos simulados pelo modelo. As pequenas diferenças possivelmente devem ser conseqüência de limitações do modelo e da precisão das medidas experimentais. É importante ressaltar-se que as hipóteses feitas no desenvolvimento do modelo foram que o solo é homogêneo, que não existe evaporação, que o conteúdo inicial de água no solo é uniforme, que não existe ocorrência de histerese, e que a água aplicada pelo emissor distribui-se uniformemente em todas as direções. Além disto, no modelo, assumiu-se valores médios aritméticos das propriedades físico hídricas do solo entre duas células adjacentes, como é o caso da condutividade hidráulica, sendo que na realidade a 
mudança de um ponto ao outro é gradual. Já Nogueira et al. (2000) empregaram a média harmônica de três camadas na determinação da condutividade hidráulica. Em relação ao solo homogêneo e isotrópico, possivelmente houve uma variação das propriedades físico-hídricas no solo, pois, o enchimento da caixa com o solo foi feito em camadas de $10 \mathrm{~cm}$, fato este que provavelmente acarreta uma variação da densidade global do solo. Com respeito à evaporação, durante o teste observou-se uma ligeira condensação de água na parte inferior do plástico que cobria a caixa. Com relação à histerese, segundo Levin et al. (1979), durante a redistribuição, devido aos baixos teores de umidade do solo na periferia do bulbo, a histerese tem uma influência pronunciada, o que pode ter ocorrido no teste .

Outro fato importante é que durante o teste foi observado a formação de uma fina crosta embaixo do emissor, possivelmente pela dispersão de partículas durante a aplicação da solução, o que provavelmente acarretou uma redução da porosidade e da condutividade hidráulica nesta região, fato que também foi observado por Lafolie et al. (1989a).

Também não se deve descartar uma possível contaminação das camadas do solo quando se fez a amostragem com o trado, pois embora tenha-se feito o encamisamento do furo quando da coleta das amostras, pode ter havido o contato de pequenas quantidades de solo.

\subsection{Concentração do potássio no solo após a irrigação}

O potássio, por ser um cátion, é adsorvido pelas partículas de argila; este fato pode ser observado na Tabela 3, que revela a obtenção de um valor para o fator de retardamento (Fr) igual a 4,73 (semelhante ao encontrado por Miranda (2001) para o mesmo tipo de solo) o que indica que uma parte do potássio aplicado com a solução é retido pelo solo.

Segundo os resultados obtidos da concentração de potássio na solução do solo nas diferentes células, após 24 horas do final da irrigação, tanto para os simulados pelo modelo (Tabela 11), quanto aos observados no teste (Tabela 12), os quais estão também 
Tabela 11. Concentração de potássio na solução do solo $\left(\mathrm{mg} \mathrm{L}^{-1}\right)$ simulada pelo modelo, 24 horas após a irrigação

\begin{tabular}{|c|c|c|c|c|c|c|c|c|c|}
\hline \multirow{2}{*}{$\begin{array}{l}\text { Profundidade } \\
(\mathrm{cm})\end{array}$} & \multicolumn{9}{|c|}{ Distancia radial $(\mathrm{cm})$} \\
\hline & 0 & 10 & 20 & 30 & 40 & 50 & 70 & 80 & \\
\hline $0-10$ & 817,458 & 235,706 & 42,811 & 19,635 & 21,060 & 23,330 & 23,400 & 23,400 & 23,400 \\
\hline $10-20$ & 398,168 & 62,900 & 20,329 & 19,122 & 22,093 & 22,596 & 20,280 & 20,280 & 20,280 \\
\hline $20-30$ & 87,038 & 20,866 & 17,784 & 20,660 & 22,459 & 22,481 & 22,500 & 22,500 & 22,500 \\
\hline $30-40$ & 22,003 & 18,123 & 20,476 & 21,809 & 21,822 & 21,822 & 21,820 & 21,820 & 21,820 \\
\hline $40-50$ & 18,832 & 20,216 & 21,059 & 21,069 & 21,069 & 21,069 & 21,070 & 21,070 & 21,070 \\
\hline $50-60$ & 20,289 & 20,417 & 20,419 & 20,420 & 20,420 & 20,420 & 20,420 & 20,420 & 20,420 \\
\hline $60-70$ & 20,130 & 20,130 & 20,130 & 20,130 & 20,130 & 20,130 & 20,130 & 20,130 & 20,130 \\
\hline $70-80$ & 20,100 & 20,100 & 20,100 & 20,100 & 20,100 & 20,100 & 20,100 & 20,100 & 20,100 \\
\hline $80-90$ & 18,940 & 18,940 & 18,940 & 18,940 & 18,940 & 18,940 & 18,940 & 18,940 & 18,940 \\
\hline $90-100$ & 16,070 & 16,070 & 16,070 & 16,070 & 16,070 & 16,070 & 16,070 & 16,070 & 16,070 \\
\hline
\end{tabular}

Tabela 12. Concentração de potássio na solução do solo $\left(\mathrm{mg} \mathrm{L}^{-1}\right)$ observada após 24 horas da irrigação

\begin{tabular}{ccccccccccc}
\hline $\begin{array}{c}\text { Profundidade } \\
(\mathrm{cm})\end{array}$ & 0 & 10 & 20 & 30 & 40 & 50 & 60 & 70 & 80 & \\
& & & & & & & & \\
\hline $0-10$ & 787,215 & 194,230 & 44,503 & 31,258 & 21,543 & 17,289 & 18,497 & 23,400 & 23,400 \\
$10-20$ & 312,681 & 98,059 & 20,313 & 21,803 & 20,249 & 20,280 & 20,280 & 20,280 & 20,280 \\
$20-30$ & 98,861 & 54,287 & 18,259 & 18,258 & 22,500 & 22,500 & 22,500 & 22,500 & 22,500 \\
$30-40$ & 65,007 & 21,369 & 16,293 & 21,820 & 21,820 & 21,820 & 21,820 & 21,820 & 21,820 \\
$40-50$ & 24,915 & 13,860 & 14,368 & 21,070 & 21,070 & 21,070 & 21,070 & 21,070 & 21,070 \\
$50-60$ & 19,315 & 16,972 & 15,683 & 20,420 & 20,420 & 20,420 & 20,420 & 20,420 & 20,420 \\
$60-70$ & 18,735 & 16,759 & 16,893 & 20,130 & 20,130 & 20,130 & 20,130 & 20,130 & 20,130 \\
$70-80$ & 15,724 & 20,100 & 20,100 & 20,100 & 20,100 & 20,100 & 20,100 & 20,100 & 20,100 \\
$80-90$ & 16,252 & 18,940 & 18,940 & 18,940 & 18,940 & 18,940 & 18,940 & 18,940 & 18,940 \\
$90-100$ & 18,247 & 16,070 & 16,070 & 16,070 & 16,070 & 16,070 & 16,070 & 16,070 & 16,070 \\
\hline
\end{tabular}


representados na Figura 13, pode-se verificar que este cátion foi retido nas camadas superficiais. Tanto para os dados simulados quanto para os observados observa-se que as maiores concentrações ficaram entorno do emissor, em um raio de até $10 \mathrm{~cm}$ e profundidade de $20 \mathrm{~cm}$, onde as concentrações de potássio variaram de 62 até $817 \mathrm{mg} \mathrm{L}^{-}$ 1 .

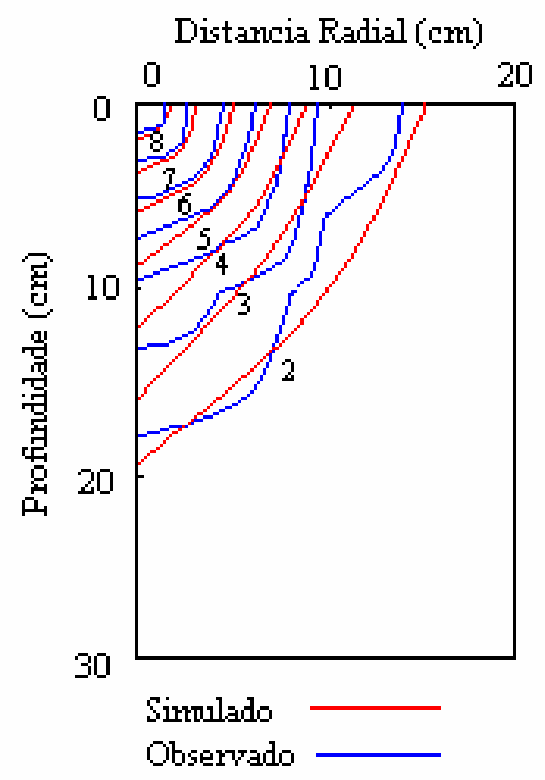

Figura 13 - Concentração de potássio na solução do solo (mg L $\left.\mathrm{L}^{-1} \mathrm{x} 100\right)$ simulada e observada após 24 horas da irrigação

O volume de solo contendo potássio em quantidades consideráveis ("bulbo de potássio") foi menor que o bulbo úmido, ou seja, o deslocamento deste cátion não acompanhou totalmente o deslocamento da água (fluxo em massa ou fluxo convectivo). Isto pode ser explicado pelo fato do potássio da solução do solo interagir com o complexo de troca de cátions do solo (expressado pelo fator de retardamento), sendo portanto este elemento retido no solo na região mais próxima ao ponto de aplicação, de forma que a solução que se deslocou para as regiões mais externas do bulbo possivelmente possuia uma concentração de potássio menor.

Os valores de concentração de potássio simulados pelo modelo apresentaram-se semelhantes aos observados no teste (com um valor para o erro padrão igual a 30,07 mg 
$\mathrm{L}^{-1}$ ), seguindo o mesmo padrão de distribuição. Entretanto, em geral, os valores obtidos experimentalmente mostraram-se ligeiramente inferiores aos gerados pelo modelo.

Nas Tabelas 13 e 14 são apresentados os resultados gerados pelo modelo e os observados no teste, respectivamente para um tempo de redistribuição de 48 horas após a irrigação; na Figura 14 é esquematizada um perfil comparativo. Como já foi explicado, para tempos de redistribuição de 48 e 72 horas após a irrigação, a amostragem do solo em todo o eixo central do bulbo não foi feita devido ao fato de que nesse ponto já tinha sido realizada a coleta para um tempo de 24 horas.

Pode-se observar que o conteúdo de potássio nas células do bulbo permaneceu de maneira quase inalterada, embora a concentração deste elemento em geral tenha se elevado, como resultado da diminuição do teor de água nas células. O potássio presente na solução do solo nos anéis localizados entre 10 a $20 \mathrm{~cm}$ do eixo apresentaram concentrações que variaram entre 46 a $250 \mathrm{mg} \mathrm{L}^{-1}$, para ambos casos, ou seja, as concentrações medidas e simuladas apresentaram tendência e distribuição semelhantes, com um erro padrão igual a $12,67 \mathrm{mg} \mathrm{L}^{-1}$ (neste caso menor que para 24 horas); a diferença entre os valores simulados e observados esteve na faixa de $10 \%$.

O conteúdo de potássio nas células no solo 72 horas após a irrigação permaneceu praticamente inalterado com relação ao mostrado para 48 horas, sendo que a concentração deste elemento na superfície do solo num raio entre 10 a $20 \mathrm{~cm}$ do emissor, variou entre 48 a $258 \mathrm{mg} \mathrm{L}^{-1}$, com diferenças entre os dados simulados e observados em torno de $12 \%$ (Tabelas 15 e 16; Figura 15), com um valor para o erro padrão igual a $11,30 \mathrm{mg} \mathrm{L}^{-1}$, ligeiramente inferior ao valor obtido para 48 horas. 
Tabela 13. Concentração de potássio na solução do solo $\left(\mathrm{mg} \mathrm{L}^{-1}\right)$ simulada pelo modelo, 48 horas após a irrigação

\begin{tabular}{cccccccccc}
\hline $\begin{array}{c}\text { Profundidade } \\
(\mathrm{cm})\end{array}$ & 0 & 10 & 20 & 30 & 40 & 50 & 60 & 70 & 80 \\
\hline $0-10$ & 868,970 & 250,612 & 46,212 & 20,331 & 20,648 & 23,089 & 23,400 & 23,400 & 23,400 \\
$10-20$ & 424,341 & 68,268 & 21,563 & 19,129 & 21,485 & 22,595 & 20,280 & 20,280 & 20,280 \\
$20-30$ & 95,120 & 22,322 & 17,875 & 19,793 & 22,233 & 22,464 & 22,500 & 22,500 & 22,500 \\
$30-40$ & 23,458 & 18,191 & 19,694 & 21,612 & 21,824 & 21,824 & 21,820 & 21,820 & 21,820 \\
$40-50$ & 18,693 & 19,610 & 20,943 & 21,069 & 21,069 & 21,069 & 21,070 & 21,070 & 21,070 \\
$50-60$ & 20,025 & 20,384 & 20,419 & 20,420 & 20,420 & 20,420 & 20,420 & 20,420 & 20,420 \\
$60-70$ & 20,129 & 20,130 & 20,130 & 20,130 & 20,130 & 20,130 & 20,130 & 20,130 & 20,130 \\
$70-80$ & 20,100 & 20,100 & 20,100 & 20,100 & 20,100 & 20,100 & 20,100 & 20,100 & 20,100 \\
$80-90$ & 18,940 & 18,940 & 18,940 & 18,940 & 18,940 & 18,940 & 18,940 & 18,940 & 18,940 \\
$90-100$ & 16,070 & 16,070 & 16,070 & 16,070 & 16,070 & 16,070 & 16,070 & 16,070 & 16,070 \\
\hline
\end{tabular}

Tabela 14. Concentração de potássio na solução do solo $\left(\mathrm{mg} \mathrm{L}^{-1}\right)$ observada após 48 horas da irrigação

\begin{tabular}{|c|c|c|c|c|c|c|c|c|c|}
\hline \multirow{2}{*}{$\begin{array}{l}\text { Profundidade } \\
\qquad(\mathrm{cm})\end{array}$} & \multicolumn{9}{|c|}{ Distância radial $(\mathrm{cm})$} \\
\hline & 0 & 10 & 20 & 30 & 40 & 50 & 60 & 70 & 80 \\
\hline $0-10$ & & 222,714 & 71,903 & 20,392 & 19,348 & 16,486 & 23,400 & 23,400 & 23,400 \\
\hline $10-20$ & & 87,238 & 18,249 & 16,245 & 18,362 & 20,280 & 20,280 & 20,280 & 20,280 \\
\hline $20-30$ & & 31,624 & 16,345 & 21,648 & 22,500 & 22,500 & 22,500 & 22,500 & 22,500 \\
\hline $30-40$ & & 20,718 & 22,819 & 21,820 & 21,820 & 21,820 & 21,820 & 21,820 & 21,820 \\
\hline $40-50$ & & 14,397 & 17,294 & 21,070 & 21,070 & 21,070 & 21,070 & 21,070 & 21,070 \\
\hline $50-60$ & & 15,326 & 16,947 & 20,420 & 20,420 & 20,420 & 20,420 & 20,420 & 20,420 \\
\hline $60-70$ & & 18,537 & 15,872 & 20,130 & 20,130 & 20,130 & 20,130 & 20,130 & 20,130 \\
\hline $70-80$ & & 20,100 & 20,100 & 20,100 & 20,100 & 20,100 & 20,100 & 20,100 & 20,100 \\
\hline $80-90$ & & 18,940 & 18,940 & 18,940 & 18,940 & 18,940 & 18,940 & 18,940 & 18,940 \\
\hline $90-100$ & & 16,070 & 16,070 & 16,070 & 16,070 & 16,070 & 16,070 & 16,070 & 16,070 \\
\hline
\end{tabular}




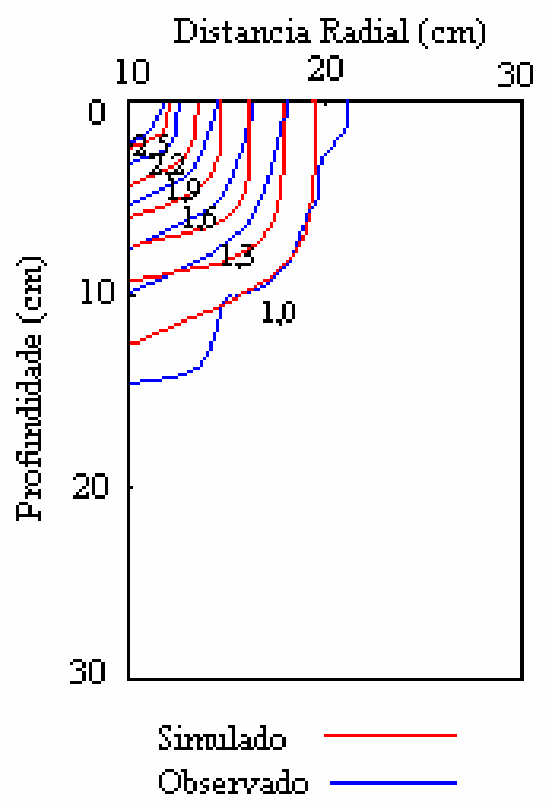

Figura 14 - Concentração de potássio na solução do solo (mg L $\left.\mathrm{L}^{-1} \mathrm{x} 100\right)$ simulada e observada, após 48 horas da irrigação

Tabela 15. Concentração de potássio na solução do solo $\left(\mathrm{mg} \mathrm{L}^{-1}\right)$ simulada pelo modelo, 72 horas após a irrigação

\begin{tabular}{cccccccccc}
\hline $\begin{array}{c}\text { Profundidade } \\
(\mathrm{cm})\end{array}$ & 0 & 10 & 20 & 30 & 40 & 50 & 60 & 70 & 80 \\
\hline $0-10$ & 897,218 & 258,848 & 48,140 & 20,788 & 20,574 & 22,840 & 23,400 & 23,400 & 23,400 \\
$10-20$ & 438,832 & 71,285 & 22,303 & 19,242 & 21,156 & 22,567 & 20,280 & 20,280 & 20,280 \\
$20-30$ & 99,738 & 23,186 & 18,037 & 19,504 & 21,892 & 22,445 & 22,500 & 22,500 & 22,500 \\
$30-40$ & 24,360 & 18,315 & 19,419 & 21,398 & 21,823 & 21,866 & 21,820 & 21,820 & 21,820 \\
$40-50$ & 18,699 & 19,307 & 20,731 & 21,067 & 21,069 & 21,070 & 21,070 & 21,070 & 21,070 \\
$50-60$ & 19,809 & 20,305 & 20,417 & 20,420 & 20,420 & 20,420 & 20,420 & 20,420 & 20,420 \\
$60-70$ & 20,128 & 20,130 & 20,130 & 20,130 & 20,130 & 20,130 & 20,130 & 20,130 & 20,130 \\
$70-80$ & 20,100 & 20,100 & 20,100 & 20,100 & 20,100 & 20,100 & 20,100 & 20,100 & 20,100 \\
$80-90$ & 18,940 & 18,940 & 18,940 & 18,940 & 18,940 & 18,940 & 18,940 & 18,940 & 18,940 \\
$90-100$ & 16,070 & 16,070 & 16,070 & 16,070 & 16,070 & 16,070 & 16,070 & 16,070 & 16,070 \\
\hline
\end{tabular}


Tabela 16. Concentração de potássio na solução do solo $\left(\mathrm{mg} \mathrm{L}^{-1}\right)$ observada após 72 horas da irrigação

\begin{tabular}{|c|c|c|c|c|c|c|c|c|c|}
\hline \multirow{2}{*}{$\begin{array}{l}\text { Profundidade } \\
\text { (cm) }\end{array}$} & \multicolumn{9}{|c|}{ Distancia radial $(\mathrm{cm})$} \\
\hline & 0 & 10 & 20 & 30 & 40 & 50 & 60 & 70 & 80 \\
\hline $0-10$ & & 225,681 & 62,395 & 20,392 & 16,729 & 20,147 & 23,400 & 23,400 & 23,400 \\
\hline $10-20$ & & 85,924 & 24,276 & 18,467 & 18,342 & 20,280 & 20,280 & 20,280 & 20,280 \\
\hline $20-30$ & & 25,146 & 18,538 & 21,648 & 22,500 & 22,500 & 22,500 & 22,500 & 22,500 \\
\hline $30-40$ & & 18,593 & 19,627 & 21,820 & 21,820 & 21,820 & 21,820 & 21,820 & 21,820 \\
\hline $40-50$ & & 20,683 & 18,305 & 21,070 & 21,070 & 21,070 & 21,070 & 21,070 & 21,070 \\
\hline $50-60$ & & 19,872 & 17,142 & 20,420 & 20,420 & 20,420 & 20,420 & 20,420 & 20,420 \\
\hline $60-70$ & & 21,691 & 19,482 & 20,130 & 20,130 & 20,130 & 20,130 & 20,130 & 20,130 \\
\hline $70-80$ & & 20,100 & 20,100 & 20,100 & 20,100 & 20,100 & 20,100 & 20,100 & 20,100 \\
\hline $80-90$ & & 18,940 & 18,940 & 18,940 & 18,940 & 18,940 & 18,940 & 18,940 & 18,940 \\
\hline $90-100$ & & 16,070 & 16,070 & 16,070 & 16,070 & 16,070 & 16,070 & 16,070 & 16,070 \\
\hline
\end{tabular}

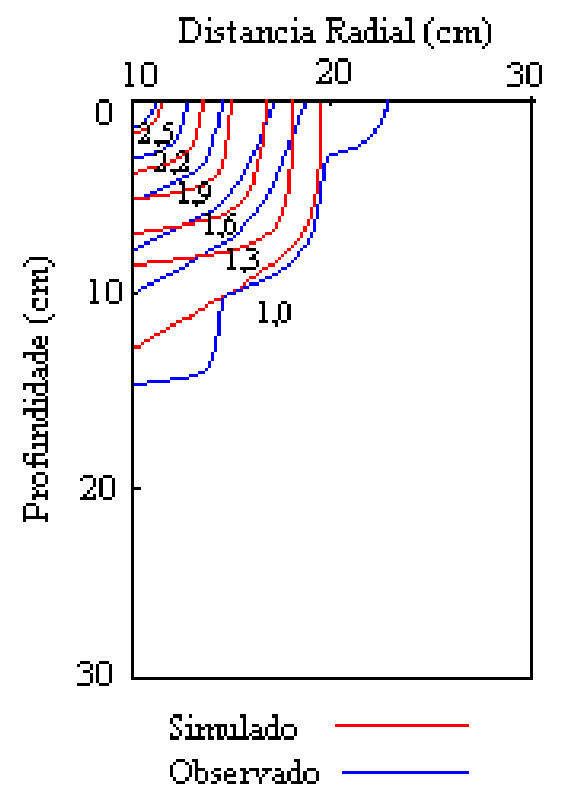

Figura 15 - Concentração de potássio na solução do solo (mg $\left.\mathrm{L}^{-1} \mathrm{x} 100\right)$ simulada e observada após 72 horas da irrigação 
Em termos gerais, nos três tempos de redistribuição considerados, a concentração de potássio na solução do solo simulada pelo modelo foi similar à observada nas condições de experimentação, sendo que o deslocamento deste elemento acompanhou parcialmente o deslocamento de água, concentrando-se fundamentalmente nas células mais internas do bulbo. Como já foi explicado no caso da umidade, as diferenças encontradas entre as concentrações de potássio simuladas e observadas possivelmente foram devidas principalmente a limitações do modelo, pois no seu desenvolvimento não foram considerados os processos de histerese, considerando-se apenas sua movimentação e o processo de adsorção. Também influenciaram a variação das propriedades físico-hídricas do solo da caixa, os erros na amostragem e os erros na determinação da concetração do potássio na solução no laboratorio.

Observou-se também, para os três tempos de redistribuição, que os valores de concentração de potássio obtidos experimentalmente foram ligeiramente inferiores aos gerados pelo modelo, o que pode ter ocorrido devido às variações da densidade global no preenchimento da caixa, à interação do potássio da solução do solo com os outros cátions presentes no complexo de troca do solo, como o $\mathrm{Ca}, \mathrm{Na}, \mathrm{Mg}$ e $\mathrm{Al}$ (Apêndice 1). Além disso existe o fato de que a determinação do fator de retardamento foi feita em um solo lavado com água destilada sob condições de saturação, praticamente livre de cátions em solução, o que possivelmente não representa exatamente o retardamento do potássio que ocorre sob condições reais, quando as células do bulbo estão sob diferentes níveis de umidade (condição de não saturação) e quando há outros cátions na solução do solo.

Por outro lado, a concentração de potássio observada nos três tempos de estudo apresentou taxas muito baixas de redistribuição e concentrou-se na superfície do solo nas proximidades da fonte puntiforme, o que demonstra que além de ser retido nas camadas mais internas ao interagir com a matriz do solo, o potássio é transportado principalmente pelo fluxo convectivo junto com a água (denominado também fluxo de massa) em forma proporcional a sua vazão e concentração.

Portanto, pode-se dizer que o padrão geral de distribuição do potássio no solo considerado pelo modelo, é dependente da concentração inicial da solução do solo, da 
concentração na água de irrigação, da vazão do emissor e características físico-químicas do solo.

\subsection{Análise de sensibilidade do modelo}

A análise de sensibilidade foi feita com o intuito de verificar o comportamento do modelo em relação às mudanças dos parâmetros de entrada e seu efeito nas concentrações de umidade e potássio no bulbo. Os parâmetros de entrada tais como: vazão do gotejador, condutividade hidráulica do solo saturado, umidade de saturação e umidade inicial do solo, dispersividade e fator de retradamento do solo, sofreram variações de $-90 \%$ a $+90 \%$ e os efeitos foram analisados, calculando-se o erro padrão quando comparados com os dados originais.

\subsubsection{Análise de sensibilidade em relação à distribuição da umidade no bulbo}

Conforme se observa na Figura 16, o conteúdo de umidade do bulbo é muito sensível à variações da umidade de saturação do solo, porém, quando esse parâmetro começa a decrescer (como conseqüência de uma redução da porosidade), as células próximas ao emisor ficam saturadas, e começa a se formar uma lâmina de água na superfície do solo, aspecto este que deixa de ser considerado pelo modelo.

Em relação à condutividade hidráulica do solo saturado, verifica-se que esta tem um efeito relevante sobre a umidade do bulbo, principalmente quando variada negativamente; já para incrementos positivos a curva do erro padrão teve uma menor declividade, sendo o modelo portanto menos sensível a incrementos da condutividade hidráulica do que à reduções neste parâmetro (Figura 16). 


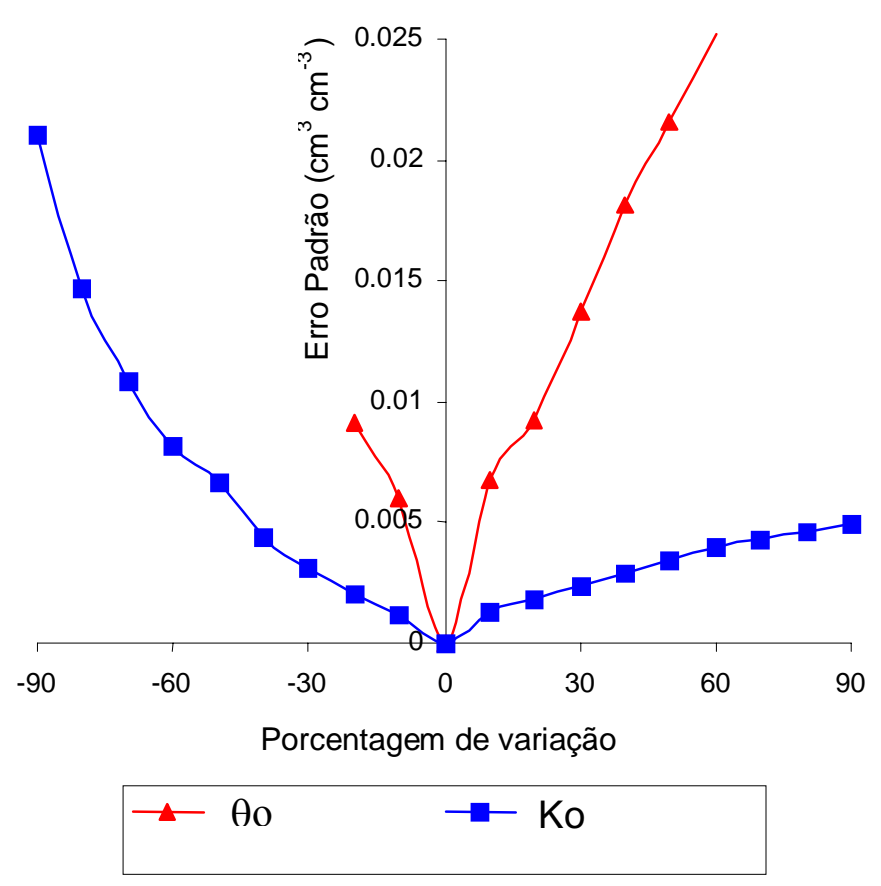

Figura 16 - Representação da analise de sensibilidade do modelo em relação ao perfil de umidade do solo no bulbo, aplicando de $-90 \%$ a $+90 \%$ de variação na umidade volumétrica de saturação $(\theta 0)$ e condutividade hidráulica do solo saturado (Ko)

No caso da umidade inicial do solo (Figura 17), houve limitações na realização da análise de sensibilidade, pois veirficou-se que o modelo é muito sensível, tanto a variações positivas quanto a variações negativas deste parâmetro. No primeiro caso o solo fica rapidamente saturado e logo encharcado na superfície, e no segundo, a umidade do solo pode ficar menor que a umidade residual, aspecto que não pode ser contabilizado pelo modelo por não ter significado físico .

A mudança na vazão (em taxas iguais ou menores que a capacidade de infiltração do solo) acarretou maior erro padrão quando foi decrescida, enquanto que quando foi acrescida, os erros padrões foram bem menores, ou seja, o modelo foi mais sensível a reduções da vazão da fonte pontiforme do que a incrementos (Figura 17). 


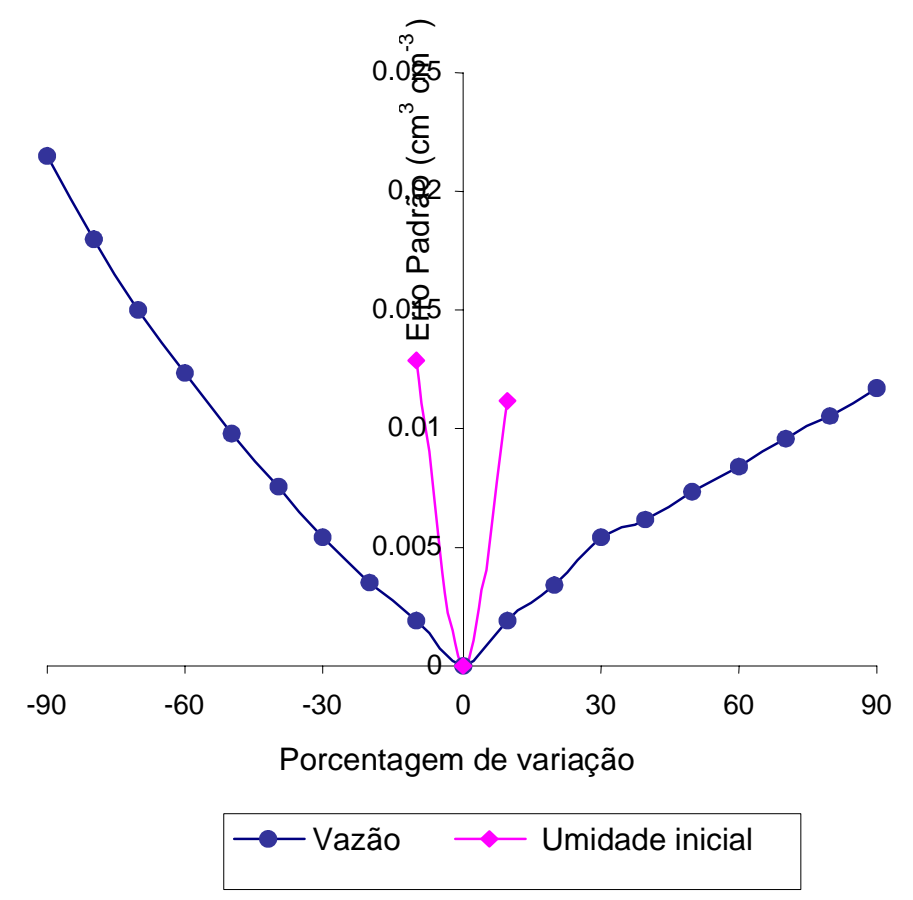

Figura 17 - Representação da analise de sensibilidade do modelo em relação ao perfil de umidade do solo no bulbo, aplicando de $-90 \% \mathrm{a}+90 \%$ de variação na vazão do gotejador e na umidade volumétrica inicial do solo

\subsubsection{Análise de sensibilidade em relação à distribuição da concentração do potássio no bulbo}

Como pode ser observado na Figura 18, é pequena a sensibilidade do modelo a incrementos da umidade de saturação do solo, $\theta$ o, relacionado com a distribuição do potássio. Já para diminuições de $\theta$ o o comportamento é similar, mas até um certo limite, pois o solo começa a se encharcar acarretando as impossibilidades já discutidas. A sensibilidade do modelo a respeito deste parâmetro foi menor que para o caso da distribuição da umidade no bulbo, pois o potássio não segue exatamente a mesma dinâmica da água no solo.

No que se refere à condutividade hidráulica do solo saturado, o modelo é sensível a decréscimos deste parâmetro, principalmente para valores muito baixos. Para 
variações positivas, o modelo é pouco sensível, sendo quase que praticamente insensível para valores elevados de Ko (Figura 18).

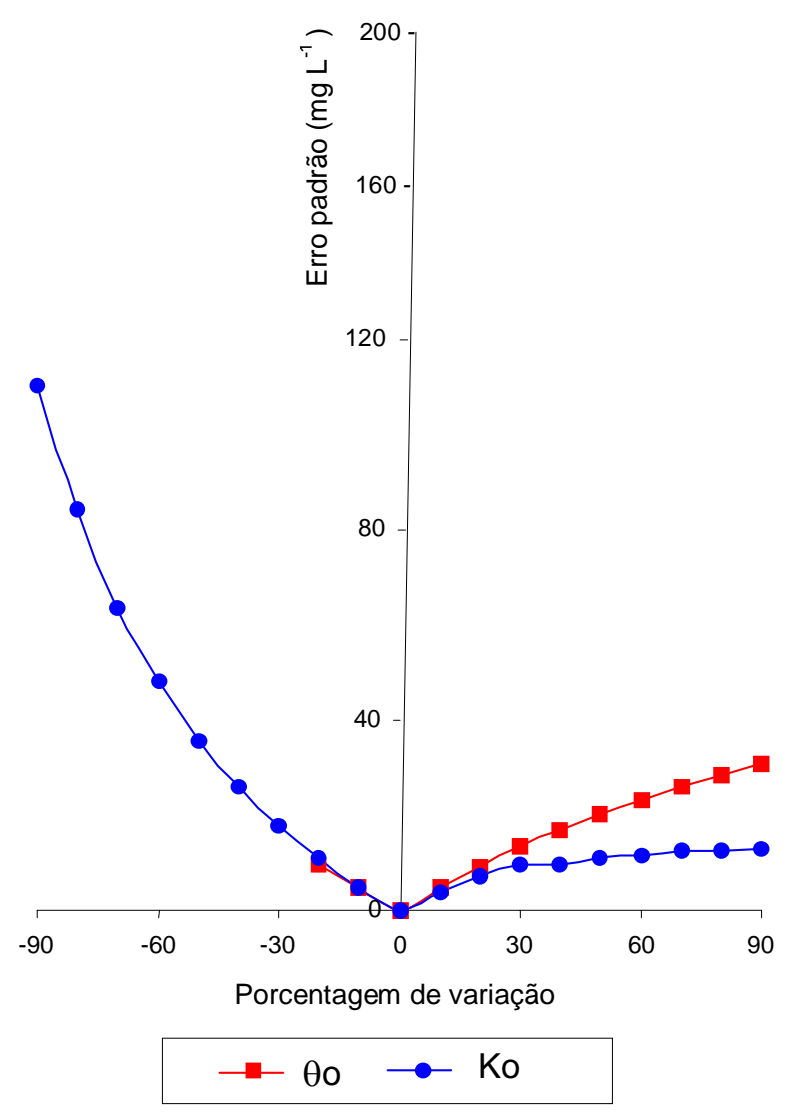

Figura 18 - Representação da analise de sensibilidade do modelo em relação à concentração do potássio no bulbo, aplicando de $-90 \%$ a $+90 \%$ de variação na umidade volumétrica de saturação $(\theta o)$ e na condutividade hidráulica do solo saturado (Ko)

A sensibilidade do modelo a respeito da umidade inicial do solo teve o mesmo comportamento observado na análise anterior, ou seja, o modelo foi muito sensível na faixa de -10 a $+10 \%$; no intervalo restante ocorreu impossibilidades de cálculo, pois ou o solo ficava encharcado na superfície ou a umidade do solo ficava menor que a umidade residual (Figura 19). 
Observou-se que a vazão é um parâmetro que influencia muito na distribuição do potássio no solo, principalmente para variações negativas, quando o modelo demonstrou ser muito sensível, pois como este cátion se desloca fundamentalmente por fluxo de massa, baixas vazões afetam sensivelmente sua movimentação, diminuindo seu transporte. Já para incrementos deste parâmetro a sensibilidade foi moderada (Figura 19).

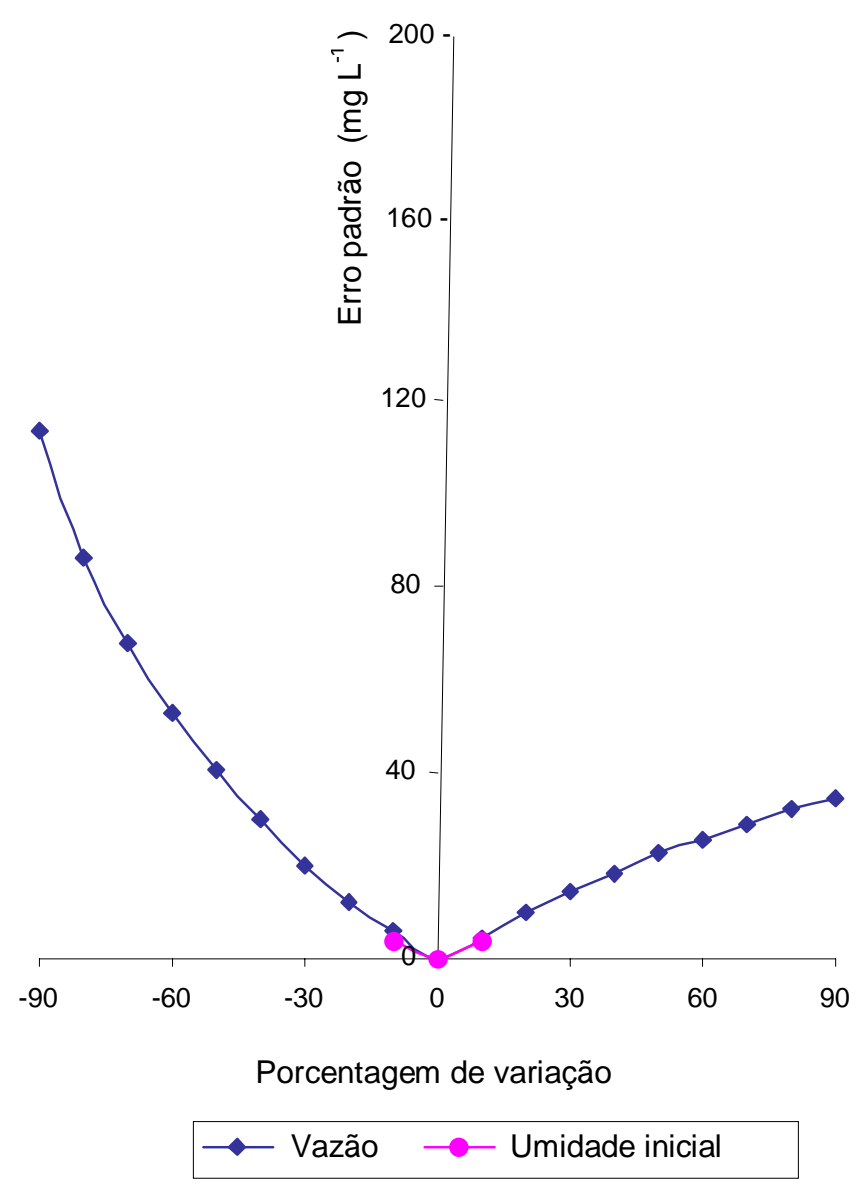

Figura 19 - Representação da analise de sensibilidade do modelo em relação à concentração do potássio no bulbo, aplicando de $-90 \%$ a $+90 \%$ de variação na vazão do gotejador e na umidade volumétrica inicial do solo

Com relação às características que relacionam soluto e solo, a dispersividade foi o fator que menor sensibilidade provocou no modelo, possivelmente pelo fato de que a contribuição do fluxo por dispersão hidrodinâmica ao deslocamento no potássio no solo 
é baixa. Já no caso do fator de retardamento, os maiores valores do erro padrão foram obtidos quando foi realizado um decréscimo nos valores deste parâmetro (com um valor máximo para uma redução de 90\%), possivelmente devido ao fato de que conforme este parâmetro diminui o transporte do potássio tem a tendência de ser maior. Para variações positivas do fator de retardamento o modelo foi apenas moderadamente sensível (Figura 20).

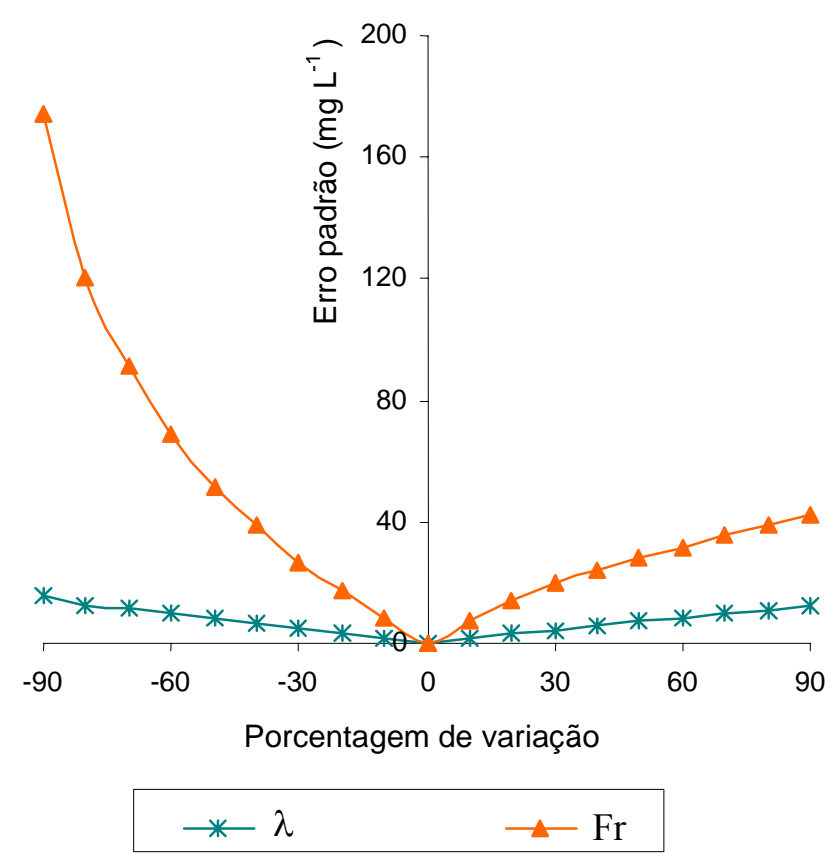

Figura 20 - Representação da analise de sensibilidade do modelo em relação à concentração de potássio no bulbo, aplicando de $-90 \%$ a $+90 \%$ de variação na dispersividade $(\lambda)$ e no fator de retardamento do solo $(\mathrm{Fr})$

Dos parâmetros analisados na distribuição de umidade dentro do bulbo, os que tiveram maior erro padrão (conseqüentemente revelaram maior sensibilidade do modelo), foram, em ordem decrescente de importância, a umidade inicial e a umidade de saturação do solo, a vazão do emissor e a condutividade hidráulica do solo saturado, principalmente para variações negativas deste dois últimos. 
$\mathrm{Na}$ distribuição do potássio, o modelo é mais sensível, em ordem decrescente de prioridade, à diminuições do valor do fator de retardamento, da vazão do gotejador e da condutividade hidráulica do solo saturado. 


\section{CONCLUSÕES}

Os resultados alcançados pelo modelo por meio das simulações da distribuição da água e do potássio no solo sob irrigação por gotejamento, bem como os resultados experimentais permitiram obter-se as seguintes conclusões :

- O movimento e a distribuição de água e de potássio aplicados via irrigação por gotejamento podem ser modelados matematicamente a partir da solução das equações de fluxo transiente mediante o uso do método dos volumes de controle.

- Houve um bom ajuste nos valores da distribuição conjunta de água e de potássio no bulbo quando comparados os dados simulados pelo modelo com os dados obtidos experimentalmente, obtendo-se valores médios para o erro padrão iguais a 0,01141 $\mathrm{cm}^{3} \mathrm{~cm}^{-3}$ e $18,013 \mathrm{mg} \mathrm{L}^{-1}$ para a umidade e a concentração de potássio, respectivamente.

- A distribuição do potássio ficou limitada às camadas mais internas do bulbo, sendo o deslocamento deste cátion retardado ao interagir com a matriz do solo.

- O modelo, no que diz respeito à distribuição da água no solo, mostrou-se bastante sensível a variações da umidade de saturação e da umidade inicial do solo, e moderadamente sensível a decréscimos da vazão do emissor e da condutividade hidráulica do solo saturado. 
- A distribuição do potássio é afetada fundamentalmente pelas propriedades hidráulicas e físico-químicas do solo e pela taxa de aplicação de água no solo, sendo o modelo bastante sensível a variações negativas da condutividade hidráulica do solo saturado, do fator de retardamento do solo e da vazão do gotejador.

- O modelo, se mostrou pouco sensível às variações da dispersividade do solo, o que demonstra que, nas condições testadas, o potássio desloca-se principalmente pelo fluxo convectivo. 


\section{REFERÊNCIAS BIBLIOGRÁFICAS}

ALVAREZ, J.; HERGUEDAS, A; ATIENZA, J. Modelización numerica y estimación de parámetros para la descripción del transporte de solutos en columnas de suelo en laboratorio. Madrid: INIA, 1995. 69p.

ANGELAKIS, A; ROLSTON, D. E.; KADIR, T.; SCOTT, V. Soil water distribution under trickle source. Journal of Irrigation and Drainage Engineering, v.119, n.3, p.484-500, 1993.

ARMSTRONG, C.; FLETCHER; WILSON, T. Computer model for moisture distribution in stratified soils under trickle source. Transactions of the ASAE, n.26, p. 1704-1709, 1983.

ASSOULINE, S. The effects of microdrip and conventional drip irrigation on water distribution and uptake. Soil Science Society American Journal, v.4, n. 66, p.1630-1636, 2002.

BAR-YOSEF, B. Advances in fertirrigation. Advances in Agronomy, v.65, p.1-77, 2000.

BEN-ASHER, J.; LOMEN, D. O; WARRICK, A W. Linear and nonlinear models of infiltration from a point source. Soil Science Society American Journal, v.1, n.42, p.3-6, 1978. 
BIGGAR, J. M.; NIELSEN, D. R. Miscible displacement and leaching phenomenon. Agronomy Monograph, v.11, p.254-274, 1967.

BIGGAR, J. W.; NIELSEN, D. R. Spatial variability of the leaching characteristics of a field soil. Water Resources Research, v.1, n.12, p.78-84, 1976.

BOTREL, T. A Simulação da distribuição espacial da água em solo irrigado com gotejador. Piracicaba, 1988. 61p. Tese (Doutorado) - Escola Superior de Agricultura "Luiz de Queiroz", Universidade de São Paulo.

BRANDT, A; BRESLER, E.; DINAR, N.; BEM-ASHAR, J.; HELLER, J.; GOLDBERG, D. Infiltration from trickle source: I Mathematical models. Soil Science Society American Proceedings, v.35, n.5, p. 675-682, 1971.

BRESLER, E. Two-dimensional transport of solutes during nonsteady infiltration from a trickle source. Soil Science Society American Journal, v.4, n.39, p.604-613, 1975

BRESLER, E. Trickle-Drip Irrigation: Principles and Aplication to Management. Advances in Agronomy, v.29, p.343-393, 1977.

BRESLER, E; HELLER, J.; DINER, N; BEM-ASHER, J. BRANDT, A; GOLDBERG, D. Infiltration from trickle source: II. Experimental data and theorical predictions. Soil Science Society American Proceedings, v.5, n.35, p. 683-689, 1971.

CLEARY, R. W. Qualidade da água subterránea. In: BRANCO, S. M. Hidrologia Ambiental. São Paulo: Universidade de São Paulo, 1991, p.211-296.

CLOTHIER, B. E. Solute travel times during trickle irrigation. Water Resources Research, v.20, n. 12, p. 1848-1852, 1984. 
CLOTHIER, B. E.; SAUER, T. J. Nitrogen transport during drip fertirrigation with urea. Soil Science Society American Journal, v.4, n.52, p.345-349, 1988.

CLOTHIER, B. E.; SCOTTER, D.; HARPER, E. Three-dimensional infiltration and trickle irrigation. Transactions of the ASAE, n. 83, p. 497-501, 1985.

COSTA, S. N. Desenvolvimento de um modelo computacional para simular o transporte de água e solutos no solo sob condições de escoamento não-permanente na vertical. Viçosa, 1998. 145 p. Tese (Doutorado) - Universidade Federal de Viçosa.

CRUZ, R. L. Modelização do balanço hídrico de uma cultura irrigada por um sistema de irrigação localizada. Botucatu, 2000. 80 p. Tese (Livre Docente) - Faculdade de Ciências Agronômicas, Universidade Estadual Paulista “Júlio de Mesquita Filho".

FRIZZONE, J. A.; BOTREL, T. A. Aplicação de fertilizantes via agua de irrigação. In: VITTI, G. C; BOARETTO, A. E. Fertilizantes fluidos, Piracicaba: POTAFOS, 1994. p. 227-260.

HACHUM, A. Y.; ALFARO, J. F.; WILLARDSON, L. S. Water movement in soil from trickle source. Journal of Irrigation and Drainage Engineering, v.102, n.2, p.179$192,1976$.

HERNANDEZ, F. B.T. Potencialidade da fertirrigação. In: VITTI, G. C; BOARETTO, A. E. Fertilizantes fluidos, Piracicaba: POTAFOS, 1994. p.215-225.

HOCHMUTH, G. Fertilzer management for drip-irrigated vegetables in Florida. HortTechnology, n.2, p.27-31, 1992. I. A. Irrigation association. Chemigation. I. A. 1997.212 p. 
JURY, W. A. Field scale water and solute transport thhrough unsatured soils. In: SAHINBERG, I.; Shalhevet. Soil salinity under irrigation: Process and mangement, Amsterdam: Spring-Verlag, 1984. p.115-125.

JURY, W. A.; FLÜHLER. Transport of chemical through soil: Mechanism, models, and field applications. Advances in Agronomoy, v. 47, p.141-201, 1992.

JURY, W. A.; ELABD, H.; RESTETO, M. Field study of napropamide movement through unsatured soil. Water Resources Research, v.5, n.22, p.749-755, 1986.

KENG, J. C. W.; SCOTT, T. W.; LUGO-LOPEZ, M. A fertilizer management with drip irrigation in a oxixol. Agronomy Journal, v.6, n.71, p.971-980, 1979.

KHAN, A.; YITAYEW, M.; WARRICK. Field evaluation of water an solute distribution from point source. Journal of Irrigation and Drainage Engineering, v.122, n.4, p. 221- 227, 1996.

KERKIDES, P.; ELMALOGLOV, S.; GRIGORAKIS, G. Linearized and non linearized infiltration solutions for strip source. Acta Horticulturae, v.2, n.449, p.729-737, 1997.

KOSKINEN, W. C.; HARPER, S. S. The retention process: Mechanism. In: CHENG, H. H.; BAILEY, G. W.; GREEN, R. E., et al.. Pesticides in the Soil Environment: process, impacts, and modeling. Madison: Soil Science Society American, 1990. p.51-78.

LAFOLIE, F.; GUENNELON, R.; VAN GENUCHTEN, M. Th. Analysis of water flow under trickle irrigation: I Theory and numerical solution. Soil Science Society American Journal, n. 53, p. 1310-1318, 1989 a. 
LAFOLIE, F.; GUENNELON, R.; VAN GENUCHTEN, M. Th. Analysis of water flow under trickle irrigation: II Experimental evaluation. Soil Science Society American Journal, n. 53, p.1318-1323, 1989 b.

LEVIN, I.; VAN ROOYEN, P. C.; VAN ROOYEN, F. C. The effect of discharge rate and intermitent water application by point-source irrigation on the soil moisture distribution pattern. Soil Science Society American Journal, n. 43, p. 8-16, 1979.

LIBARDI, P. L. Dinâmica da água no solo. 2 ed. Piracicaba: O autor, 2000. 509 p.

LUBANA, P. S.; NARDA, N. K. Modeling soil water dynamics under trickle emittersa Review. Journal Agricultural Engineering Research, v.3, n.78, p. 217-232, 2001 .

MATOS, A. T.; COSTA, L. M.; FONTES, M. P.; MARTINEZ, M. A. Retardation factors and the dispersion-diffusion coeficients of $\mathrm{Zn}, \mathrm{Cd}, \mathrm{Cu}$ and $\mathrm{Pb}$ in soils from Viiçosa-MG, Brazil. Transactions of the ASAE, v. 42, n.4, p.903-910, 1999.

MIRANDA, J. H. Modelo para simulação da dinâmica de nitrato em colunas verticais de solo não saturado. Piracicaba, 2001. 79 p. Tese (Doutorado) - Escola Superior de Agricultura "Luiz de Queiroz”, Universidade de São Paulo.

MMOLAWA, K.; OR, D. Root zone solute dynamics under drip irrigation: A review Plant and Soil, n.222, p.163-190, 2000'.

MMOLAWA, K.; OR, D. Water na solute dynamics under a drip irrigated crop: experiments and analytical model. Transactions of the ASAE, v. 43, n.6, p.1597$1608,2000 b$. 
MUALEM, Y. A. A new model for predicting the hidraulic conductivity of unsaturated porous media. Water Resources Research, v. 12, n.3, p.513-522, 1976.

NIELSEN, D. R.; BIGGAR, J. W. Miscible displacement: III. Theorical considerations. Soil Science Society of American Proceedings, v. 26, n. 2, p.216-221, 1962.

NIGHTINGAlE, H. I.; DAVIES, K. R.; PHENE, C. J.. Trickle irrigation of cotton: efect on soil chemical properties. Agricultural Water Management, n.11, p.159$168,1986$.

NOGUEIRA, C. P.; COELHO, E. F.; LEÃO M. C. S. Caracteristicas e dimensões do volume de um solo molhado sob gotejamento superficial e subsuperficial. Revista Brasileira de Engenharia Agrícola e Ambiental, v. 4, n. 3, p.315-320, 2000.

OLIVEIRA, L. F. C. Modelo para transporte de solutos no solo e no escoamento superficial. Viçosa, 1999. 171 p. $\quad$ Tese (Doutorado) - Universidade Fderal de Viçosa.

OLIVEIRA, L. F. C. de; CARVALHO, D. F. de. Modelo computacional para simular o transporte de solutos no solo. Engenharia Rural, v. 1, n.8, p.1-126, 1997.

OR, D. Drip irrigation in heterogeneos soils: steady-state field experiments for stochastic model evaluation. Soil Science Society American Journal, n. 60, p.1339-1349, 1996.

PARKER, J. C.; VAN GENUCHTEN, M. Th. Determining transport parameters from laboratory and Field tracer experiments. Madison: Virginia Agricultural Experiment, 1984. 96p. (Bulletin, 83/84). 
PARLANGE, J. Y. Two and three-dimensional steady infiltration. Soil Science, n. 113, p.101, 1972.

PREVEDELlO, C. L. Física de Solos com Problemas Resolvidos. Curitiba: Saeafs, 1996. 446p.

ROLSTON, D. E.; MILLER, R. J.; SCHULBACH. Management principles: fertilization. In: NAKAYAMA, F. S.; BUCKS, D. Trickle irrigation for crop production design operation and management. Amsterdam: Elsevier, 1986. 317$344 \mathrm{p}$.

SMith, M. C.; BOtTCHER, A. B.; CAMPBELl, K. L.; THOMAS, D. L. Measurements of pesticide transport to shallow groundwater. Transactions of the ASAE, v.28, n.5, p.1450-1457, 1985.

SPARKS, D. L.; HUANG, P. M. Physical chemistry of soil potassium. In: MUNSON, R. Potassium in agriculture. Atlanta: American Society of Agronomy; Phosphate Potash \& Phosphate Institute, 1985. p. 201-276.

STANKOVICH, J. M.; LOCKINGTON, D. A. Brooks-Corey and van Genuchten soilwater models. Journal of Irrigation and Drainage Engineering, v.4, n.110, p. 31$341,1995$.

TAGHAVI, S. A; MARIÑO, M. A. ; ROLSTON, D. E.; Infiltration from trickle irrigation source. Journal of Irrigation and Drainage Engineering, v.110, n.4, p.331-341, 1984.

TAVORA, J. E. M. De. Reservas minerais de potássio e suas exploações. In: INSTITUTO DE POTASSA \& FOSFATO. Potássio na agricultura Brasileira. Brasília: Instituto Internacional da Potassa. 1982. p.37-50. 
TILlMAN, R. W.; SCOTTER, D. R.; ClOthiER, B. E.; WHITE, R. E. Solute movement during intermittent water flow in a field soil an some implications for irrigation and fertilizer application. Agricultural Water Mangement, n.20, p.119$133,1991$.

TORIDE, N.; LEIJ, F. VAN GENUCHTEN, M. TH. The CXTFIT code for estimating parameters from laboratory or field tracer experiments, verion 2.1. Califórnia: Research Report U. S.; Salinity Laboratory Agricultural Research Service; U. S. Departament of Agriculture, 1999. 85p.

TUNG CHU, S. Capillary tube infiltration model. Journal of Irrigation and Drainage Engineering, v.123, n.5, p.514-521, 1993.

URIU, K.; R. M. CARLSON; HENDERSON, D. Application of potasium fertilizer to prunes trhough a drip irrigation systems. In: INTERNATIONAL AGRICULTURAL PLASTICS CONGRESS, 7., Proceedings. San Diego: California University, 1997. p.221-214.

VAN DER PLOEG, R. R.; BENECKE, P. Unsteady unsatured, n-dimensional moisture flow in soil: a computer simulation program. Soil Science Society of America Proceedings, v.38, p. 881-885, 1974.

VAN GENUCHTEN, M. TH. A closed form equation for predicting the hydraulic conductivity of unsatured Soils. Soil Science Society American Journal, v. 44, p. $892-898,1980$. 
VAN GENUCHTEN, M. TH.; WIERENGA, P. J. Solute dispersion coefficients and retardation factors. In: KLUTE, A. Methods of Soil Analysis. I-Physical and Mineralogical Methods. Madison: Soil Science Society of America, 1986. p.10251054.

WAGENET, R. J. Water and solute flux. In: KLUTE, A. Methods of Soil Analysis. IPhysical and Mineralogical Methods. Madison: Soil Science Society of America, 1986. p.1055-1088.

WAGENET, R. J.; RAO, P. S. C. Modeling pesticide fate in soils. In: CHENG. H. H. Pesticides in the soil enviroment: process, impacts and modeling. Madison: Soil Science Society of America, 1990. p.351-400.

WANG D.; YATES R.; SIMUNEK, J.; VAN GENUCHTEN, M. T. Solute transport in simulated conductivity fields under diferents irrigations. Journal of Irrigation and Drainage Engineering, v.123, n.5, p.336-343, 1997.

WARRICK, A. W. Time-dependent linearized infiltration: I Point source. Soil Science Society American Journal, v. 3, n.38, p.383-386. 1974.

WARRICK, A. W. Design principles soil water distribuition. In: NAKAYAMA, F. S.; BUCK, D. A. Trickle Irrigation for crop productions. Amsterdam: John Wiley, 1986. p. 93-116. 


\section{APÊNDICES}


APÊNDICE 1 - Análise físico-química do solo

UNIVERSIDADE DE SÃO PAULO

ESCOLA SUPERIOR DE AGRICULTURA "LUIZ DE QUEIROZ"

DEPARTAMENTO DE SOLOS E NUTRIÇÃO DE PLANTAS

Análise física do solo

\begin{tabular}{lcc}
\hline No Lab & Identificação & $\begin{array}{c}\text { Condutividade Eléctrica } \\
\text { mmhos/cm }\end{array}$ \\
\hline 22786 & AM-Peneira & 0,054 \\
\hline
\end{tabular}

Análise física do solo

\begin{tabular}{llc}
\hline No Lab & Identificação & $\begin{array}{c}\text { D.R } \\
\mathrm{g} / \mathrm{cm}^{3}\end{array}$ \\
\hline 22786 & AM-Peneira & 0,054 \\
\hline
\end{tabular}

Análise granulométrica

\begin{tabular}{|c|c|c|c|c|c|c|c|c|c|c|c|}
\hline \multicolumn{3}{|c|}{ No Amostra } & \multicolumn{4}{|c|}{ Areia (\%) } & \multirow{2}{*}{$\begin{array}{r}\text { Silte } \\
(\%)\end{array}$} & \multicolumn{2}{|c|}{ Argila (\%) } & \multirow{2}{*}{$\begin{array}{c}\text { Floculação } \\
(\%)\end{array}$} & \multirow{2}{*}{$\begin{array}{l}\text { Clase } \\
\text { Textura }\end{array}$} \\
\hline Lab. & Identif. & MG & G & M & $\mathrm{F}$ & Tot & & Tot & Agua & & \\
\hline 22786 & AM-Peneira & $*$ & $*$ & $*$ & * & 67 & 6 & 27 & * & * & md-arg \\
\hline
\end{tabular}

Análise Química

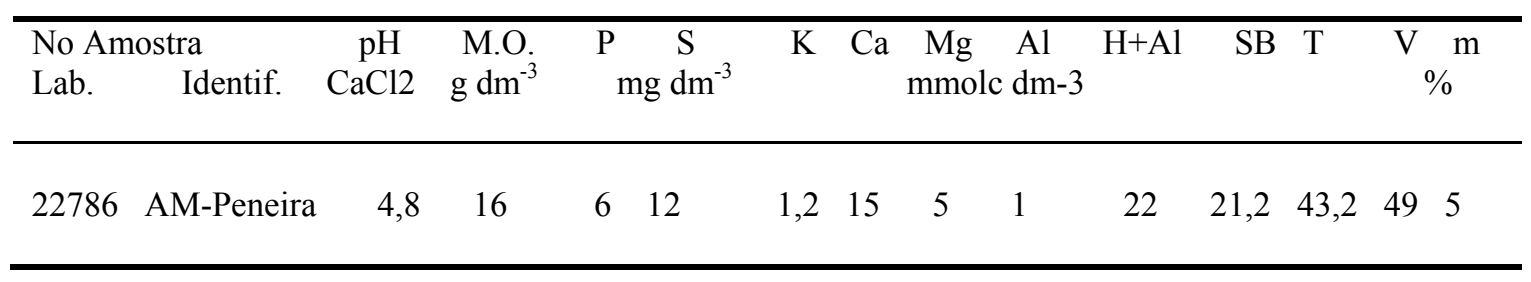


APÊNDICE 2 - Curva de Retenção de água e conductividade hidráulica do solo

\section{UNIVERSIDADE DE SÃO PAULO \\ ESCOLA SUPERIOR DE AGRICULTURA “LUIZ DE QUEIROZ” \\ DEPARTAMENTO DE ENGENHARIA RURAL LABORATORIO DE FÍSICA DE SOLOS}

$\begin{array}{lllllllllll}\text { AMOSTRA } & \text { Satur } & 10 \text { cm.c.a } & 20 \text { cm.c.a } & 50 \text { cm.c.a } & 100 \text { cm.c.a } 300 \text { cm.c.a } 500 \text { cm.c.a } 1000 \text { cm.c.a } & 5000 \text { cm.c.a } & 15000 \text { cm.c.a } \\ \text { R1 } & 140,59 & 138,27 & 136,63 & 129,51 & 125,75 & 124,2 & 122,43 & 121,26 & 119,95 & 119,23 \\ \text { R2 } & 142,44 & 140,8 & 139,83 & 133,49 & 128,38 & 126,22 & 124,64 & 123,28 & 122,09 & 121,65 \\ \text { R3 } & 143,1 & 141,56 & 140,7 & 134,53 & 129,39 & 127,41 & 126,28 & 124,86 & 123,3 & 122,49\end{array}$

Umidade com base em peso

$$
(\mathrm{g} / \mathrm{H} 2 \mathrm{O} / \mathrm{g} / \mathrm{Solo})
$$

$\begin{array}{lllllllllll}\text { AMOSTRA } & \text { Satur } & 20 \text { cm.c.a } & 30 \text { cm.c.a } & \text { 40cm.c.a } & 100 \text { cm.c.a300 cm.c.a } 500 \text { cm.c.a } 1000 \text { cm.c.a } & 5000 \text { cm.c.a } & 15000 \text { cm.c.a } \\ \text { R1 } & 0,374 & 0,343 & 0,321 & 0,225 & 0,175 & 0,154 & 0,131 & 0,115 & 0,097 & 0,088 \\ \text { R2 } & 0,351 & 0,330 & 0,318 & 0,236 & 0,169 & 0,141 & 0,121 & 0,103 & 0,088 & 0,082 \\ \text { R3 } & 0,343 & 0,324 & 0,313 & 0,234 & 0,168 & 0,143 & 0,129 & 0,110 & 0,090 & 0,080\end{array}$

Umidade com base em volume

$(\mathrm{cm} 3 \mathrm{H} 2 \mathrm{O} / \mathrm{cm} 3 \mathrm{Solo})$

$\begin{array}{lllllllllll}\text { AMOSTRA } & \text { Saturado } & 20 \text { cm.c.a } & 30 \mathrm{~cm} . c . a & 40 \mathrm{~cm} . c . a & 100 \mathrm{~cm} . c . & 300 \mathrm{~cm} . c . a 500 \text { cm.c.a } 1000 \mathrm{~cm} . c . a & 5000 \text { cm.c.a } 15000 \text { cm.c.a } \\ \text { R1 } & 0,499 & 0,457 & 0,428 & 0,301 & 0,233 & 0,206 & 0,174 & 0,153 & 0,130 & 0,117 \\ \text { R2 } & 0,482 & 0,453 & 0,436 & 0,323 & 0,232 & 0,194 & 0,166 & 0,142 & 0,121 & 0,113 \\ \text { R3 } & 0,482 & 0,454 & 0,439 & 0,328 & 0,236 & 0,201 & 0,181 & 0,155 & 0,127 & 0,113\end{array}$

Condutividade Hidráulica Saturada do Solo

Amostra K0 (cm/h) Classificação

R1 7,826 Moderadamente rápida

R2 $10,221 \quad$ Moderadamente rápida

R3 8,718 Moderadamente rápida

$\operatorname{dens}(\mathrm{g} / \mathrm{cm} 3)$

1,33

1,37

1,40 
APÊNDICE 3 - Fotografías ilustrativas de trabalho

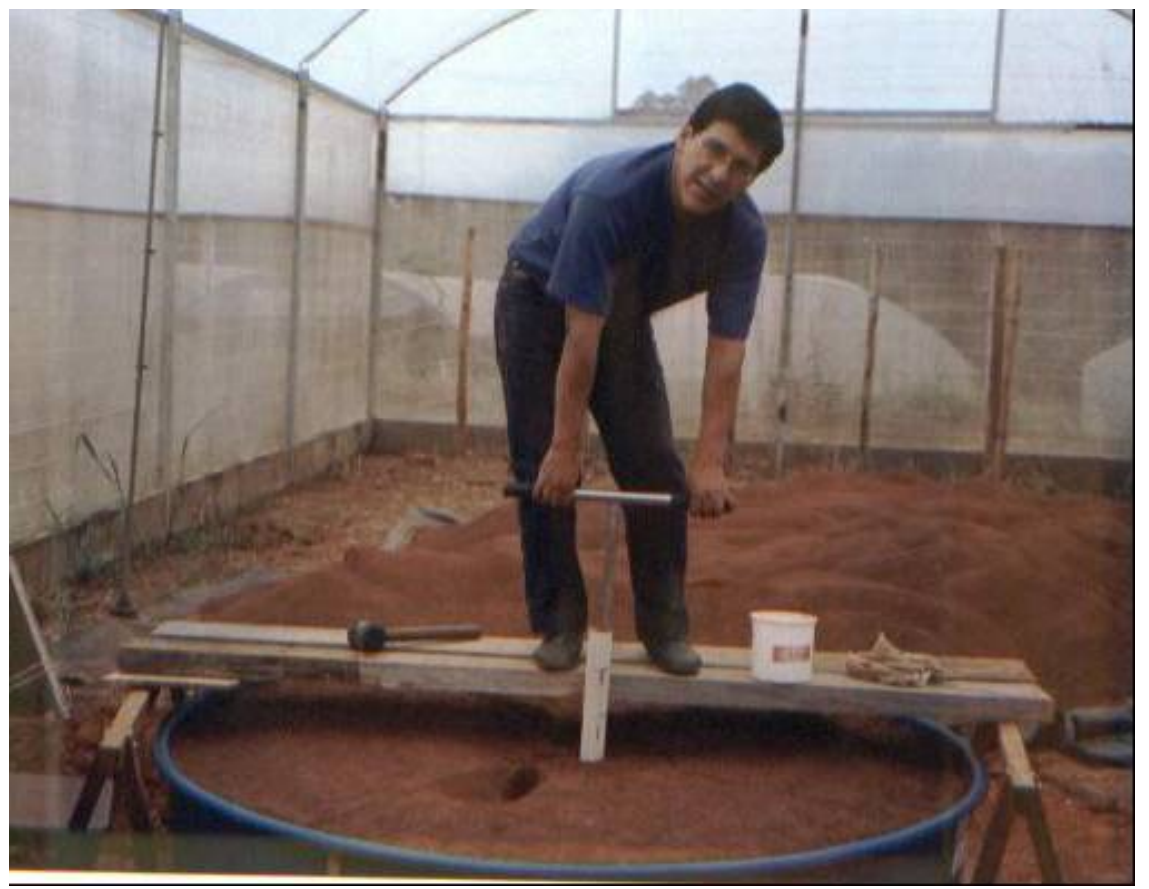

Figura A - Trado e sistema de encamisamento para a coleta de amostras de solo

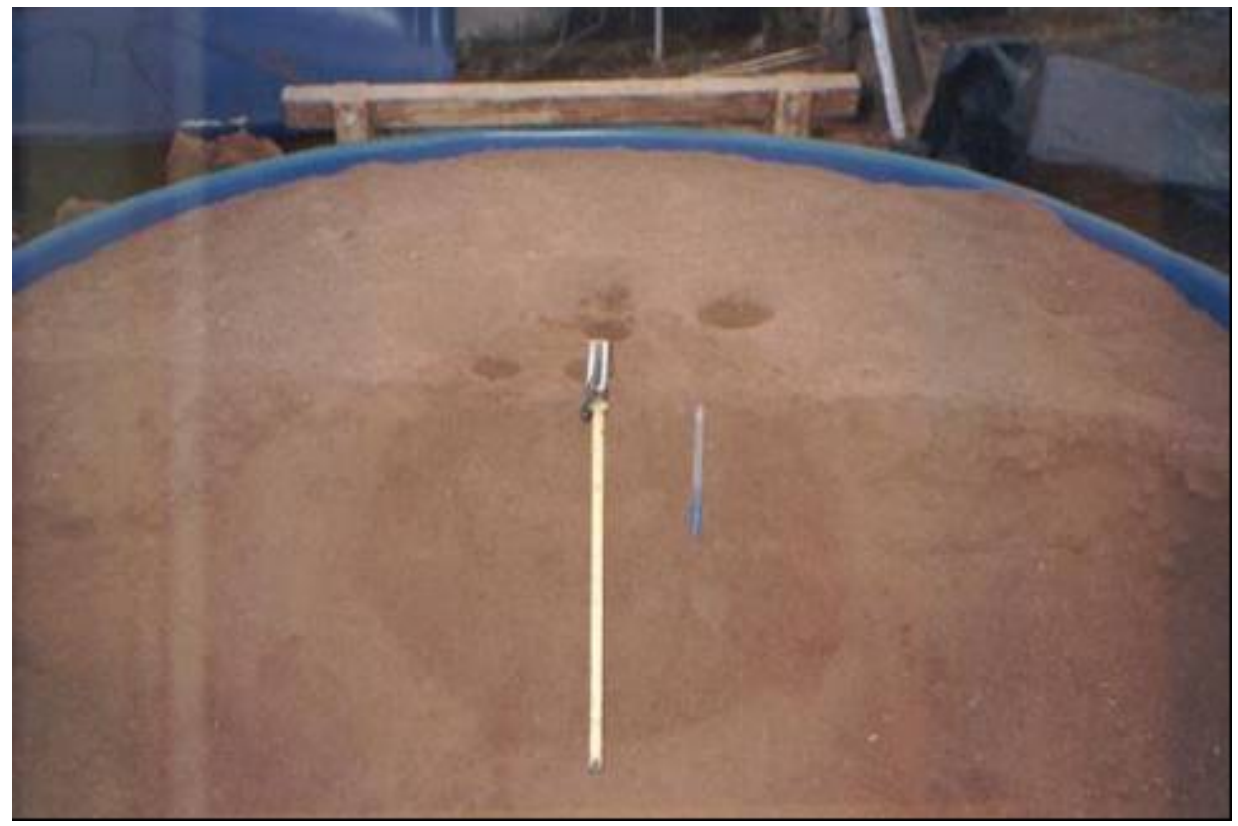

Figura B - Dimensão vertical do bulbo após 72 horas da irrigação 


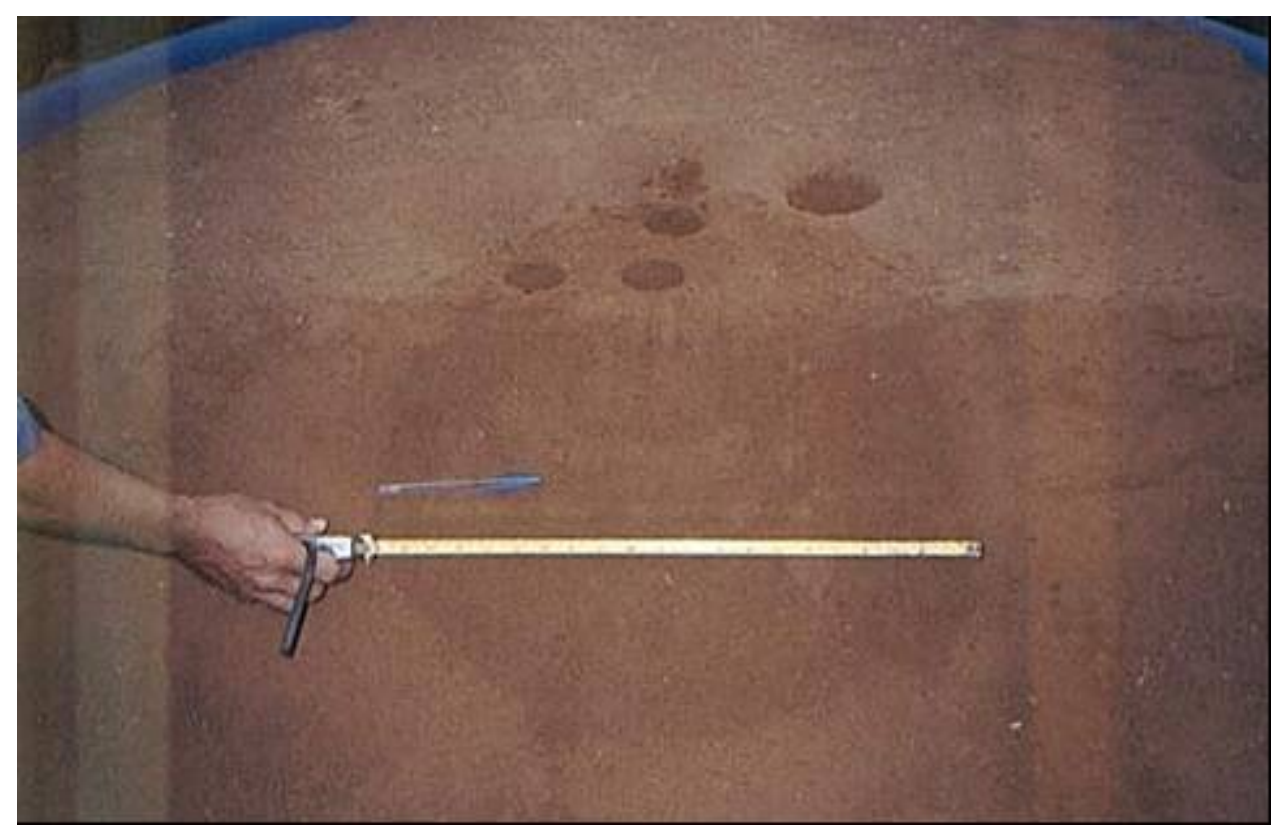

Figura C - Dimensão horizontal do bulbo após 72 horas da irrigação

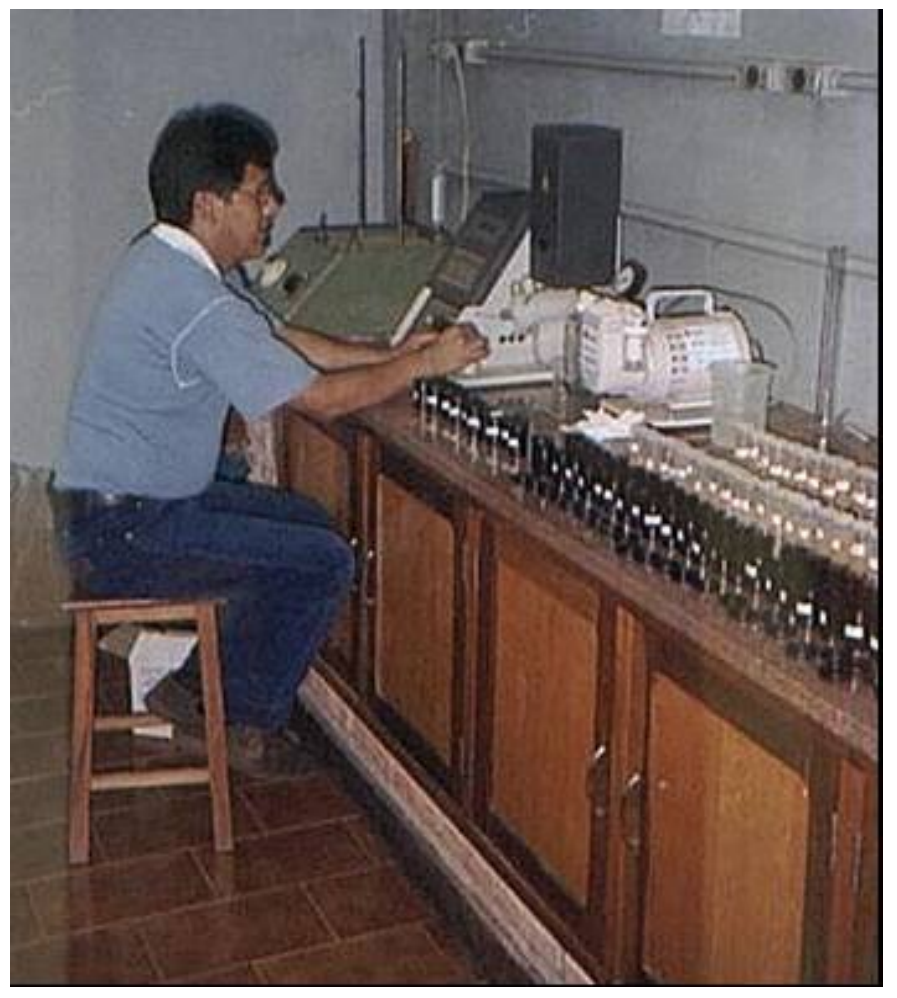

Figura D - Análise do conteúdo de potássio no extrato de saturação do solo com o fotômetro de chama 